Portland State University

PDXScholar

Dissertations and Theses

Dissertations and Theses

10-25-1995

\title{
Communicative Action as Feminist Epistemology
}

Todd Nathaniel Gilman

Portland State University

Follow this and additional works at: https://pdxscholar.library.pdx.edu/open_access_etds

Part of the Political Science Commons

Let us know how access to this document benefits you.

Recommended Citation

Gilman, Todd Nathaniel, "Communicative Action as Feminist Epistemology" (1995). Dissertations and Theses. Paper 4906.

https://doi.org/10.15760/etd.6782

This Thesis is brought to you for free and open access. It has been accepted for inclusion in Dissertations and Theses by an authorized administrator of PDXScholar. Please contact us if we can make this document more accessible: pdxscholar@pdx.edu. 


\section{THESIS APPROVAL}

The abstract and thesis of

Todd Nathaniel Gilman for the

Master of Arts degree in Political science

were presented October 25, 1995 and accepted by the thesis

committee and the department.

COMMITTEE APPROVALS:

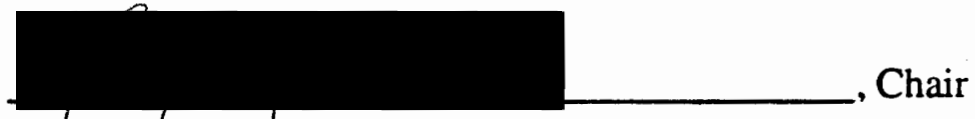

Craig Is. Carr

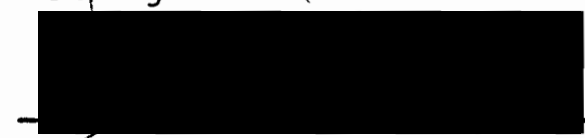

Gary L. Scott



Kathryn Farr

Representative of the Office of Graduate Studies

DEPARTMENT APPROVAL:



ACCEPTED FOR PORTLAND STATE UNIVERSITY BY THE LIBR ARY

by

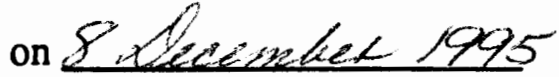




\begin{abstract}
An abstract of the thesis of Todd Nathaniel Gilman for the Master of Arts in Political Science presented October 1995.
\end{abstract}

Title: Communicative Action as Feminist Epistemology

This thesis proposes that feminist social and political theory adopt the epistemology inherent in Jurgen Habermas's communicative ethics in order to more coherently work toward the goal of freeing individuals from social oppression. This thesis first examines the fundamental differences that exist between the particular claims for knowledge made by the three major schools of feminist theory; the empirical feminists, the standpoint feminists, and those allied with postmodernism. After illuminating the specifics of these feminist claims, the conception of knowledge central to Habermas's thought is explored and shown to be split into three distinct realms; the objective, the social, and the subjective.

It is shown that the three realms of Habermas's knowledge account for the underlying claims of the differing groups of feminist theory, and provide a basis for reconciling the differences between them. Habermas's objective realm of knowledge corresponds to the concerns of empirically oriented feminists. A need for an accurate description of the events and conditions of the actual world is shared by both, as is a trust in the human potential for grasping these objects and events accurately. Standpoint feminism's concern for interpersonal relations, accounting for the context of an individual's or group's existence, is reflected in the type of knowledge that Habermas 
considers social in nature. Habermas's conception of our capacity for social knowledge, which guides our actions with other human beings, is shown to be dependent upon both social existence and communication. Finally, Habermas acknowledges the human potential for critical knowledge to explain the individual's ability to differentiate herself from the group, a task which a postmodern feminism demands to avoid essentializing any aspect of women.

If feminist theory is able to move beyond the entrenched differences that it now finds itself locked within, perhaps then it will be able to continue with the project shared with Habermas, that of providing a meaningful emancipation for human beings. 
COMMUNICATIVE ACTION AS FEMINIST EPISTEMOLOGY

by

TODD NATHANIEL GILMAN

A thesis submitted in partial fulfillment of the requirements for the degree of

\author{
MASTER OF ARTS \\ in \\ POLITICAL SCIENCE
}

Portland State University

1995 


\section{THESIS CONTENTS}

CHAPTER I: INTRODUCTION .................................................................

CHAPTER II: FEMINIST WAYS OF KNOWING..................................... 12

Feminist Empiricism...................................................................... 14

Away from "Bad Science"

The "Subject" of Knowledge

The Objective Nature of Knowledge

Politics of Empiricism

The Feminist Standpoint.

Away from Objectivity

Embedded Subjects of Knowledge

A New Type of Knowledge

Justification of Knowledge Claims

Defending a Feminist Standpoint

Postmodernism

Standpoint as Incoherent and Insufficient

A Postmodern Self

Anti-Universalist Nature of Knowledge

Justification of Knowledge

In Support of a Feminist Postmodernism

Enlightenment Revisited

Community of Subjects

Reconsidering Objectivity

Return to Justificatory Strategies

Forward with the Feminist Project. 
CHAPTER III: COMMUNICATIVE SOCIAL SCIENCE .56

Shift to a Philosophy of Language

Expanding Rationality

Leaving Descartes

The Lifeworld .68

Habermas's Use of Action Theory

Autonomy Through Socialization

Communicative Action

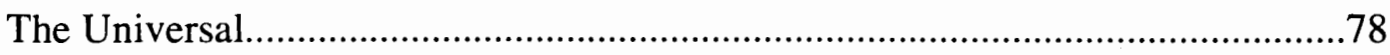

Meaning, Truth, and Rationality Through Consensus

The Principle of Universalization

Discourse Ethics

Scientific, Practical, and Critical............................................................93

\section{CHAPTER IV:}

TOWARD A COMMUNICATIVELY STRUCTURED FEMINISM.............96



"Realist" Knowledge

Role for Objectivity

Social Knowledge 109

Contextuality

Consensus Theory of Meaning and Truth

Solidarity

Critical Knowledge

Gender Bias

Considering Communicative Rationality

Non-Foundational

CHAPTER V: CONCLUSION:

COMMUNICATIVE ACTION AS FEMINIST EPISTEMOLOGY 


\section{CHAPTER I}

\section{INTRODUCTION}

Feminist political and social theory today faces a dilemma, a dilemma which stems from the foundations of its allegiance with a philosophical investigation into the ability of the feminist political movement to deal with some of the most basic terms of its own debate. Notions such as "justice," "woman," and "rationality" are hotly contested as being either essential or antithetical to a project aimed toward the emancipation of women. These disputed concepts revolve around what feminist scholars claim to know, and what they claim can be known, about the nature of women specifically, and humanity in general. What some scholars claim to know, others argue to be unknowable, and the features of a theory that these scholars regard unknowable, still others find essential to any feminist project. To resolve this discord, in a manner agreeable to feminism as both a political and philosophical movement intent on human emancipation, requires an explanation of a unified feminist "way of knowing," a feminist epistemology.

Feminists, however, are not the only theorists involved in a questioning and reconstruction of human understanding in a manner consistent with an emancipating project. One of the most complete, recent investigations into these themes has been that of Jürgen Habermas. He also has begun with a question concerning what is possible for human beings to know about the world, about a life in social interaction, and how it would be to best guide our actions in this world. He has developed a strong understanding of human social life based on a notion of communicative action, and 
from this foundation he has moved to investigate what is possible and proper in social ordering, outlined through a theory of discourse ethics. This inquiry has led Habermas to new insights in the idea of knowledge and how it relates to moral and ethical questions.

In this thesis, questions raised by the search for an acceptable feminist epistemology will be compared to some of the central insights of Habermas's theory of discourse ethics. Both share some criticisms of traditional Enlightenment epistemology while at the same time depending deeply upon it for foundations. While both seek to move away from many of the Enlightenment's tenets, both remain firmly and purposefully tied to its central theme of working toward human emancipation, i.e., setting individuals free from the tyranny of oppression. What both sets of theories reject as the flotsam and jetsam of post-Enlightenment social science, combined with what both tie firmly to the deck of their theory, suggests many interesting similarities. A comparison of what remains on board and what is tossed to sea by both schools of thought may provide insight for feminist theory in its attempt to become a coherent political and philosophical movement.

This thesis seeks to explore fully the possibility of feminist political and philosophical thought making a shift toward Habermas's philosophy of language. In order for feminist theory as a whole to become more communicatively oriented, Habermas's ethics will be required to demonstrate concern for the claims for knowledge particular to each feminist school of thought. Habermas's treatment of empirical concerns, his ability to account for our existence as embedded creatures, and yet our ability to be individuals, will all be important considerations for comparison. Whether or not Habermas's work in this area can be translated into real world improvements in the lives of individuals remains to be seen. Certainly feminism, with its foundations in social activism rather than academic philosophy, holds some advantage in this area, and 
with some insight and conjecture, we may be able to see how a cooperative allegiance between these two schools, rather than an uninformed misunderstanding, may help both achieve their goal of a humanity free from domination.

\section{FEMINIST EPISTEMOLOGIES}

The recognition that epistemological assumptions have political consequences has kept a concern for a theory of knowledge a central theme in feminist writings. ${ }^{1} \mathrm{~A}$ theoretical self-understanding of the intellectual presuppositions of feminist inquiry remains fundamental to understanding what various writers have referred to as "women's ways of knowing" or "women's experience." These terms have represented a feminist investigation into the realm of knowledge as well as a reluctance to adopt uncritically the traditional terms of epistemological inquiry. ${ }^{2}$ But inquiry into epistemology is also important for another philosophical turn which many feminists have taken. Many now write that the terms and goals of the feminist project must be more inclusive than is permitted by a singular investigation of issues of gender. If feminist theory is to aim towards an emancipation of women, it must aim equally at the ending of all varieties of oplression, as there are many 'types' of women oppressed by many types of power. Any theory to liberate white, middle-class women must also liberate working class women, women of color, and women oppressed due to their status as citizens of third-world nations. ${ }^{3}$ These developments have begun to change the focus of feminist theory.

\footnotetext{
${ }^{1}$ Kathleen Lennon and Margret Whitford, eds., Knowing the Difference: Feminist Perspectives in Epistemology (New York: Routledge, 1994), 1.

2Linda Alcoff and Elizabeth Potter, "Introduction: When Feminisms Intersect Epistemology," chap in Feminist Epistemologies (New York: Routledge, 1993), 1-2.

${ }^{3}$ Linda Nicholson, ed., Feminism/Postmodernism (New York: Routledge, 1990), 1-4.
} 
Some of the earliest work in feminist theory was critical of the results of empirical science as it had been traditionally practiced. Initial feminist insights saw that traditional science had simply been done poorly, focused exclusively on the experience of men in society and neglected the actual lives and existence of women. The idea followed that an enlightened scientist, one aware of the traditional bias against women, would be able to produce less biased, and more "scientific" results. These results would be inclusive of the lives of both men and women, and a more accurate representation of all individuals. This version of feminism pursues the goals of empirical science with a more enlightened mission. Feminist empiricism has been praised as being a more inclusive use of the traditions of scientific method. ${ }^{4}$

For many feminists, however, this method was inadequate for discovering and exposing the androcentrism of traditional science. The plight of women could only be fully understood through a scientific methodology specifically aware of the lives of women, investigated from the perspective of women. This led feminists to build a science from the standpoint of women, a standpoint fully aware of their underprivileged position in society, and aware of the role that women have played in society. ${ }^{5}$ This science is aware of women's experience with care and connectedness, with home labor, and importantly, her experience as an outsider. ${ }^{6}$ This standpoint would incorporate emotion and feeling, and would be directly opposed to the objectivity and disinterestedness of empiricism, even feminist empiricism. These feminists are

\footnotetext{
${ }^{4}$ For further explanation see: Allison Jaggar, Feminist Politics and Human Nature (Sussex: Rowman and Allanheld, 1983), 355-358.

${ }^{5}$ See for example: Jaggar, Feminist Politics; and Sandra Harding, Whose Science? Whose Knowledge? Thinking From Women's Lives (Ithica: Cornell University Press, 1991).

${ }^{6}$ For further examples which emphasize women's experiences see Nancy Chodorow, The Reproduction of Mothering (Berkeley: University of California Press, 1978); and Nancy Hartsock, Money, Sex, and Power: Toward a Feminist Historical Materialism (New York: Longman, 1986).
} 
very firm in their criticism of traditional Cartesian dualism, the philosophical separation of mind and body, and any acceptable theory of interaction for them will need to account for our existence as physical as well as thinking creatures. Further, in addition to embodiedness, feminist analysis in many disciplines has emphasized the significance of the context of investigation. ${ }^{7}$ This has led many feminist writers to question the feasibility of any universal knowledge that might be independent of physical existence and location. With recognition of embodiment comes a recognition of difference between groups of humans, and any universal connection between them will need to be carefully defended. With human physical existence there will need to be a clearer understanding of what it is that makes us human, and why there is any conception of a "correct" order to interaction or morality.

But this science too is insufficient and inappropriate for the demands of another group of feminist scholars. First, standpoint science continues to rely upon many of the assumptions of misogynist science. Second, a reliance upon a 'feminist standpoint' seems to identify a way of being that is uniquely and cross culturally female. This essentialism becomes problematic as the point of view of women of color, lesbians, or women of the third world are incorporated into "feminism." To reject this assigned way of being, some feminists have turned towards an allegiance with postmodernism in order to account for each individual as different, unique, and not dependent on any particular understanding of being female. Postmodern feminism is opposed to the objectivity of positivism or the possibility of objective knowledge at all. ${ }^{8}$ A postmodern epistemology is devised such that no individual is predetermined to a way of being and

\footnotetext{
${ }^{7}$ Alcoff and Potter, "When Feminisms Intersect Epistemology," 1.

${ }^{8}$ See Jane Flax, "Postmodernism and Gender Relations in Feminist Theory," in Feminism/Postmodernism, ed. Linda Nicholson (New York: Routledge, 1990), 39-62.
} 
each individual is allowed to exist in their own particular context, embedded, but not pre-determined. ${ }^{9}$

This more recent turn of feminism, however, has also left many wanting, as writers have begun to question what an alliance with postmodernism brings to their struggle. What is left of 'feminism' if there is no functioning category of "woman"? What is left of the world of connection that women turned to in the standpoint theories if each is radically unconnected and differentiated? ${ }^{10}$ These questions have led feminist writers to back away from the claims of postmodernism to seek another, more coherent understanding of human life. This new understanding will be required to remain true to the underlying goal of feminist theory, that of emancipation for women, but it will also need to be aware of the critiques of each of the above attempts towards a feminist epistemology. To date, there is only an understanding of the inadequacies of previous attempts at feminist epistemology. Feminist writers have only pointed towards the direction this next theory might take and there has been no fully successful attempt at this latest development in feminist theory.

\section{JÜRGEN HABERMAS}

The third chapter of this thesis seeks to explore a possible source of enlightenment for this next stage in the development of feminist epistemology. Here we travel to the European continent, the Frankfurt School and Jürgen Habermas's development of a

\footnotetext{
${ }^{9}$ See Donna Haraway, "A Manifesto for Cyborgs: Science, Technology, and Socialist Feminism in the 1980s, " in Feminism/Postmodernism, ed. Linda Nicholson (New York: Routledge, 1990), 190-234.

${ }^{10}$ See Christine Di Stefano, "Dilemmas of Difference: Feminism, Modernity, and Postmodernism," in Feminism/Postmodernism, ed. Linda Nicholson (New York: Routledge, 1990), 63-82.
} 
theory of communicative action and discourse ethics. The epistemology involved in his work has not yet been fully explored by feminist writers, and may provide valuable insight into human interaction for feminist epistemology.

Habermas has been credited by many writers as having been influential in shifting a great deal of philosophical debate from a philosophy of consciousness to a philosophy of language. This has grown out of Habermas's need to explain the insufficiency of traditional empirical-analytic science's ability to explain fundamental human phenomena. With this shift, Habermas has worked to expand the notion of rationality from a strictly strategic understanding to a more complex and inclusive notion capable of explaining human abilities to achieve mutual understanding. While the empiricalanalytic sciences provide important information for much of our existence, they must be supplemented by other types of science, based on other types of knowledge.

Habermas's thinking is founded upon a conception of human social life as "communicative action" which forms the bases of all human interaction and our social existence. ${ }^{11}$ The development of human social life has been intertwined with our ability to symbolically mediate our interactions, and cannot be adequately understood without an understanding of how language is a part of our interaction. Each human community depends fundamentally on a background knowledge of these symbolic interactions which coordinate all other interactions. This background knowledge, shared by all members of a community is referred to as their lifeworld. Human beings are seen as dependent on this lifeworld and on our linguistic abilities, for both our knowledge and our identities.

${ }^{11}$ See Jürgen Habermas, The Theory of Communicative Action, volume 1, Reason and the Rationalization of Society, trans. by Thomas McCarthy (Boston: Beacon Press, 1984; original German edition published by Suhrkamp Verlag, 1981); and Jurgen Habermas, The Theory of Communicative Action, volume 2, Lifeworld and System: A Critique of Functionalist Reason, trans. by Thomas McCarthy (Boston: Beacon Press, 1987; original German edition published by Suhrkamp Verlag, 1981). 
Habermas has also begun to devise a detailed understanding of what universally connects human beings. ${ }^{12}$ As all human beings depend on their lifeworld in order to successfully communicate with other individuals, there must be a method of mediation that enables the repair of interruptions, or misunderstandings about the lifeworld. This process of reaching agreement about what counts as valid for a background assumption is universally used in human communities. Without such a process, human interaction would occur upon a broken and incoherent set of assumptions which would make mutual understanding between individuals impossible. Habermas's claims for this process are not based on any mystical understanding about the nature of reaching consensus, but are instead carefully based on what would be empirically necessary for communication to occur at all.

From this understanding of a universal connection between social actors, Habermas shows how ethical norms are worked out in communities, and how they come to be accepted as valid by all members of that community. This will also explain how some of these norms come to be challenged by other members of that community, and are seen as valid or invalid when challenged before the more universally accepted criteria for validity. This is an important development which feminists will need to pay particular attention to, as it demonstrates how new and radically different ways of knowing might come to be more accepted, as feminist theory aims to accomplish.

${ }^{12}$ See Jürgen Habermas, Moral Consciousness and Communicative Action, trans. by Christian Lenhart and Shierry Weber Nicholson (Cambridge, MA: MIT Press, 1993; original German edition published by Suhrkamp Verlag, 1983); and Jürgen Habermas, Justification and Application: Remarks on Discourse Ethics, trans. by Ciaran P. Cronin (Cambridge, MA: MIT Press, 1993; original German edition published by Suhrkamp Verlag 1990 and 1991). 


\section{SYNTHESIS}

The fourth chapter of this thesis will explore the ability of Habermas's epistemology to satisfy the criteria demanded by a feminist political theory. While a limited number of feminist writers have explored a few, specific aspects of Habermas's theory, ${ }^{13}$ there has been neither a full feminist examination of communicative action's epistemic foundations, nor of Habermas's latest writings on the universal aspects of discourse ethics. One intent of this investigation will be to show that transitions made by feminist theory from empiricism, through standpoint theory and postmodernism, has led feminist theory back to the project of the Enlightenment and its original intentions. Following this return, it still remains unclear how feminist political and philosophical thought can reconcile the deep divisions within its own work. This paper's use of Habermasian thought will demonstrate how many of the same concerns faced by feminists have been fairly treated and successfully integrated into a single theory in Habermas's theory of communicative action. It will be shown how many of the concerns incorporated by Habermas could be acceptable to the many camps within feminist theory.

First, it will be shown that Habermas and the feminists have similar ideas on the nature of knowledge. Again, both reject most concepts of a single "gods-eye" approach to what can be known by agents. Discourse ethics removes reliance upon a single, 'proper' way of life that all communities must adhere to. Habermas also uses an

\footnotetext{
${ }^{13}$ For examples of these partial feminist critiques of Habermas see: Nancy Fraser, "What's Critical About Critical Theory? The Case of Habermas and Gender," chap. in Unruly Practices: Power, Discourse, and Gender in Contemporary Social Theory (Minneapolis, University of Minnesota Press, 1989), 113-143; or Marie Flemming, "Women's Place in Communicative Reason," in Women and Reason, eds. Elizabeth Harvey and Kathleen Okruhlik (Ann Arbor: University of Michigan Press, 1992), 254-262.
} 
understanding of validity claims to knowledge rather than relying upon a notion of the truth of a knowledge claim. Further, as many feminists have rejected the claim to objectivity that has founded much of Western science, Habermas's reliance on reasons will again be attractive. For Habermas, the validity of a claim to knowledge is not based on the vantage point from which the knowledge is derived, but rather because reasons acceptable to all can be offered to support the claim. Finally, as many feminists have critiqued the flaws of an instrumental rationality, the notion of rationality will be explored and shown compatible.

Similarities shared by Habermas and feminists concerning epistemic agency will also be explored. As called for by many feminist epistemologies, Habermas builds communicative action in specific opposition to Cartesian notions that truth or meaning can be discovered through a solitary endeavor. There is no separation of knower and knowing in communicative action. Further, there is a specific emphasis on human interconnectedness for both individual identity and a sense of community. This is compatible with feminist concern for caring and mutual awareness that has been absent in most western philosophy. The linguistic grounding of these aspects of human existence also removes any dependence on special, exclusive criteria for rationality or 'humanness.' Certain uses of these criteria have long been used to exclude women and other "irrationals" from philosophical importance. In communicative action, however, any actor capable of speech is a focus of consideration.

Criteria concerning the justification of knowledge are also of fundamental concern to both Habermas and feminist theory. While Habermas has been selective in incorporating any assumptions of the Enlightenment into his works, he believes that important aspects of the Enlightenment must be retained if the project of human emancipation from oppression is to be realized. Although much of feminist theory is directly hostile to the Enlightenment, some feminists too have recently realized that to 
reject all standards of judgment leaves no criteria left to consider the justness of human relations. If feminists seek the emancipation of women, they too must retain some idea of what it will mean to be free of domination. The justification of knowledge, where Habermas and some feminists have begun to engage directly the postmodernist challenge to any universal concepts, will be the final key to showing how feminist theory can move together with Habermas toward a human existence free from oppression. 


\section{CHAPTER II}

\section{FEMINIST WAYS OF KNOWING}

For the past three decades, feminist theory has been engaged in a critique of the products, methods, and assumptions of the scientific inquiry into human social and political interaction. This continuing feminist investigation has led to questioning the foundations of knowledge itself, challenging our ability to know answers to some of the most basic problems of human social life. In order to know about how we should interact, we must be clear about what we can know about ourselves and about each other. For feminists, responding to this challenge means a careful consideration of the social role and identity of women as individuals in communal life. This clarification concerns epistemological assumptions, and how they relate to moral and ethical questions of human interaction.

Feminist philosophers have argued for and against of a number of differing approaches to create this feminist knowledge. Some remain tied to the traditions of empiricism, to notions of objectivity, and the idea that a knowledge unmediated by circumstance and appearing to be universal, is achievable, desirable, and that its further acquisition will lead to human emancipation. Others write that knowledge can never be more than particular, and that any "universal" knowledge only serves male dominance, not the liberation of women. Another battle revolves around the correct understanding of what it means to be a woman, and whether or not one's sex deeply unites a group of individuals, or whether gender is only one of many peripheral aspects of one's being. 
Finally, there is a debate over the criteria for validating claims to any of this knowledge, what these criteria would be, or whether there is any true "validity" at all.

Whether or not a resolution of these debates is possible is not yet known, but a number of feminists continue working to develop a theory of feminist knowledge which may transcend these differences and be acceptable to all of these groups. A brief exploration of what these attempts have entailed, and the debates surrounding their separate projects will prove useful in understanding the wide range of demands that feminist theory makes upon an epistemology. These include some very powerful critiques of traditional Western epistemology, and some very enlightening claims for consideration in the future development of any acceptable theory of human knowledge.

In addition to gaining insight into the strengths and weakness of current feminist thought, this chapter will point out steps which feminist theory will need to take as it seeks to resolve its internal disagreements. The overview to follow will examine major developments in contemporary feminist theory: empiricism, standpoint theory, and postmodernism, while attempting to avoid becoming bogged down in the myriad of specific positions within each of them. The chapter will show that none of these options remain uncontested, as none presents an epistemology wholly compatible with a coherent feminist theory. Examination of the parallels between these theories, along with the rifts between them, will point this inquiry towards the direction feminist epistemology must take to become a coherent political and philosophical movement. This task should further assist us in seeing the ways feminist theory remains engaged in the debate over how an epistemology can be devised to strengthen and support the aims of a social, political, and philosophical movement seeking the emancipation of human beings. 


\section{FEMINIST EMPIRICISM}

The first appearance of a feminist science oriented to the demands of women began in fields oriented toward empirical science, and remains tied to these epistemological claims within their philosophical investigation. Even before feminism began its critique of the foundations of knowledge, feminists were actively employing the empirical sciences to ask questions about the adequacy of theories concerning women in biology, anthropology, and sociology. Whether or not these sciences were fairly portraying the lives and experiences of women, in their claims to study 'all mankind,' was seriously questioned. Feminist critiques argued that most social science had been built upon models developed within a world dominated by males, and the results of those studies had thus been "limited by the particular interests, perspectives and experiences" of males. ${ }^{1}$ A science limited in such a fashion, excluding from consideration one-half of its supposed population and focusing on the interests of the other half, is not faithful to the ideals of scientific inquiry. These feminists argue that social biases, androcentrism, and a subsequent misapplication of scientific method, have been the root cause of poor science in the past. Poorly conducted science has resulted in the formation of false beliefs, guiding attention towards improper scientific questions, which when answered, provide scientific knowledge tainted by the original biases. These feminists argue for changes to be made in scientific communities to end these biases and expand scientific knowledge to its fullest potential.

This group of feminists, who have worked to end the androcentric bias in science, while leaving scientific method as it is, have been labeled "feminist empiricists" by

\footnotetext{
${ }^{1}$ Marcia Millman and Rosabeth Moss Kantor, Another Voice: Feminist Perspectives on Social Life and Social Science (Garden City: Anchor Books, 1975), viii.
} 
Sandra Harding, or "liberal feminists" by Allison Jaggar. ${ }^{2}$ Such a feminist science works to correct the tradition which often excludes women as being irrational, not 'fully human,' or dependent upon men for support. These feminists intend to include women in the scientific process, as both the subjects and objects of inquiry, to understand women's experiences as fully and legitimately human lives. Helen Longina described feminist empiricism as centrally concerned with designing research for women rather than merely about women, requiring a special consideration of the specific contexts of women's lives. She further questions what actual benefit there might be from 'discovering' any new epistemology. To what degree is it true that "if we could just get the epistemology right, we would get the science right" ${ }^{3}$ It does not seem that we can simply dismiss all of the accumulated knowledge that has been produced in the last few hundred years by traditional science.

\section{Away From "Bad Science"}

Empirical feminists are particularly interested in critiquing the poor execution of otherwise good science. They are concerned that the methods of traditional science have been applied in a restricted fashion, and that removing these limitations and expanding the realm of scientific inquiry would vastly expand the usefulness and acceptability of knowledge to humanity. Feminist empiricists accept the philosophical bases of scientific inquiry, and seek to finally fulfill its primary goal, arriving at a true knowledge of the world. This will be achieved by rejecting the biased assumptions with which the

\footnotetext{
${ }^{2}$ See Allison Jaggar, Feminist Politics. 355-358; and Sandra Harding, "Rethinking Standpoint Epistemology: What Is 'Strong Objectivity,"' in Feminist Epistemologies, eds. Linda Alcoff and Elizabeth Potter (New York: Routledge, 1993), 49-82.

${ }^{3}$ Helen E. Longino, "Subjects, Power, and Knowledge: Description and Prescription in Feminist Philosophies of Science," in Feminist Epistemologies, eds. Linda Alcoff and Elizabeth Potter (New York: Routledge, 1993), 101.
} 
method had previously been applied. To these feminists, the use of "bad science," science which has been guided by a sexist bias, has been responsible for many of the poor, and incomplete results of past science.

This misapplication of scientific method can be seen in the role of women portrayed in traditional models of social life used in the social sciences. These models represent as typical and significant social interaction, realms where only males commonly exist as actors, areas such as work or politics, and away from locations of women's activity, the home, the grocery, or the laundry. ${ }^{4}$ The importance of the "mundane," private aspects of social life become more important in feminist science, acknowledging that these are aspects of both men's and women's lives. ${ }^{5}$ They argue for a shift in our perception of social relations; for example, changing the focus of the study of vast social organizations from management to the majority of these groups composed of secretaries and office workers, ${ }^{6}$ or rethinking the reverence to the male "genius artists" of the seventeenth and eighteenth centuries who depended upon the social structure's support of change and development, a social structure made up significantly of women. ${ }^{7}$ In other cases the results of this science were actually seen as hostile towards women, where androcentric science had proved capable of producing "valid" scientific research able to legitimize rape, or proving the genetic superiority of males at

\footnotetext{
${ }^{4}$ Lyn H. Lofland, "The "Thereness" of Women: A Selective Review of Urban Sociology," in Another Voice: Feminist Perspectives on Social Life and Social Science, eds. Marcia Millman and Rosabeth Moss Kantor (Garden City: Anchor Books, 1975), 144-170.

${ }^{5}$ Millman and Kantor, Another Voice, xii-xiii.

${ }^{6}$ Rosabeth Moss Kantor, "Women and the Structure of Organizations: Explorations in Theory and Behavior," in Another Voice: Feminist Perspectives on Social Life and Social Science, eds. Marcia Millman and Rosabeth Moss Kantor (Garden City: Anchor Books, 1975), 34-74.

${ }^{7}$ Gaye Tuchman, "Women and the Creation of Culture," in Another Voice: Feminist Perspectives on Social Life and Social Science, eds. Marcia Millman and Rosabeth Moss Kantor (Garden City: Anchor Books, 1975), 171-202.
} 
mathematics. ${ }^{8}$ Feminist empiricists hope to alter the science which has produced and reproduced forces that keep women subjugated by and subordinate to men.

An important improvement for science would be the development of alternative models to relieve the "systematic blindness" of science to social reality. A refocusing of scientific models would not exclude men, but rather include the study of women, thus creating a more complete understanding of human life, involving both men and women. Research ought to be done with the elimination of androcentric biases, producing more objective, non-political, and "scientific" results. A process of systematic observation, with the observer guided by strict adherence to neutral procedures, will lead to the eradication of sexism necessary for truly scientific results. These observers will most certainly no longer be exclusively male if this bias is to be avoided, and the addition of female scientists will be a first step towards seeing that science is not simply 'male-centered. ${ }^{9}$ Thus, by following the prescriptions of what has long been understood as the scientific method, a better, more encompassing science will be established. Feminists in this tradition intend no special privileges for women, seeking only that equal opportunity be given to all individuals to be both subject and object of scientific inquiry. There should be no discrimination in science because of sex. ${ }^{10}$ Further, by not departing radically from "science as usual," feminist empiricism is argued to be more readily accepted by established science.

\footnotetext{
${ }^{8}$ Karen Messing, "The Scientific Mystique: Can a White Lab Coat Guarantee Purity in the Search for Knowledge about the Nature of Women?" in Women's Nature: Rationalizations of Inequality, eds. Marian Lowe and Ruth Hubbard (New York: Pergamon Press, 1983), 75-85.

${ }^{9}$ Messing, "The Scientific Mystique," 84-85.

10 Jaggar, Feminist Politics, 357.
} 


\section{The "Subject" of Knowledge}

Important characteristics of the empirical feminist's epistemology can be illustrated through the agent of knowledge empiricism presupposes. Positivist science relies upon the Cartesian notion of a separation between mind and body. The body is seen to remain tied to subjective impulses which should not be allowed to influence the pure, objective processes of the mind in searching for scientific knowledge. As each mind is capable of pure thought, rejecting the influences of physical existence is the only way of achieving universal, scientific knowledge. Only knowledge produced free from the influences of physical existence or characteristics of the body is sought, thus feminist empiricists do not seek to identify the differences that men or women might claim as knowledge, as these differences are rejected as biased. Disembodiment allows subjects to be unitary, homogeneous and identical in their completeness. These individuals produce knowledge which is consistent and coherent. Knowledge is not produced by a community or by social groups, where there may be differences within or between groups. A heterogeneous subject, or multiple subjects, might produce knowledge that is inconsistent or incoherent. ${ }^{11}$

Another distinctive trait of empiricism concerns not the disembodiment of the scientist, but assumptions about scientific interactions, where objects of research are studied by scientific subjects. ${ }^{12}$ This subject is a central figure in empirical, positivist research, neither historically attached to her surroundings, nor linked to the object studied. Neither the subject's existence nor the investigation itself has a significant effect upon the objects being studied. Feminist empiricism retains these scientific separations,

\footnotetext{
${ }^{11}$ Harding, "Rethinking Standpoint Epistemology," 63.

12 Ibid., 63-64.
} 
between a subject's mind and body, as well as between scientific subjects and objects to be studied.

\section{The Objective Nature of Knowledge}

Feminists within this tradition accept assumptions concerning the existence of a world independent of human attempts to understand it, and that true human knowledge of this world's existence is possible. There is no challenge to norms of empirical research, such as detached observation or of fallibility, only to the incompleteness of the empirical research that has gone before. Scientific results are properly based upon the experience of individuals, and information gained through sensory experiences. Empirical feminism is not less objective than previous science, but rather emphasizes the desirability of objective knowledge, and more rigorously pursues its achievement. These feminists argue that they hold the point of view of the truly rational, unattached observer and are thus able to provide the most unbiased and objective understanding of human actions possible. ${ }^{13}$

With all knowledge based in experience, there is a traditional scientific intent to separate the normative and empirical aspects of knowledge. The normative, evaluative, and judgmental aspects of knowledge are all excluded from empirical science. The empirical is objective, observable, and thus, universal, not relying upon any particular characteristic of the subject to be accepted. Any consideration of the observer's values, interests, and emotions is rejected since these would bias the scientific results. The result of this unbiased method is objective knowledge, the goal of positive scientific method. Philosophy of science is relied upon to construct rules which provide a guide to drawing inferences from these experiences. ${ }^{14}$ With strict adherence to scientific

\footnotetext{
13 Jaggar, Feminist Politics, 357-8.

${ }^{14}$ Ibid., 355-57.
} 
method any other observer, male or female, will be able to agree with the scientific account of what has been described.

\section{Politics of Empiricism}

The political result of a feminism guided by the goal of applying the traditional assumptions and methods of scientific inquiry, is an alliance with the traditional Western movement to emancipate individuals, the Enlightenment. These feminists are comfortable working within the claims, assumptions, and goals of the liberal tradition, and argue for an application of liberal principles with a more strict adherence to their nature. "Liberal feminism" remains founded upon a notion of human nature being individualistic, with no necessary connection between these separate actors. ${ }^{15}$ It accounts for actors, working from calculated, rational choices, as atomistic and isolated individuals who have no interconnections with other actors that significantly relate to their being.

Liberal feminists seek no special privileges for women, and only defend a claim to equal rights and equal opportunity for all. There is commonly an argument for "sexual equality" and the creation of gender neutral policies of social organization. Therefore liberal feminists feel the benefits of their theory will be apparent and appealing to all. If men rationally apply the criteria for objectivity to the traditional emphasis on male interests, they too will see the soundness and justness of a liberalism enlightened by the feminist movement. The advantages of this political theory are apparent from the position of a rational detached observer, the observer central to the claims of this understanding of science.

15 Ibid., 357-358. 


\section{THE FEMINIST STANDPOINT}

For many feminists, however, this reliance on the traditional methodology and goals of empirical science does not arrive at the core difficulty in emancipating women from a male-dominated world. It is argued that power relations are structured by those able to decide what knowledge is and how it functions, and that continued reliance upon knowledge legitimated by a tradition of men does not allow women to achieve the power that they need in order to free themselves of male dominance. Power is seen as fundamentally connected to knowledge, and in order to posses their own power, women must to be able to use a knowledge created from the experience women have had in their lives. An alternative science can be created, based upon this knowledge and power, and opposed to science built upon a male understanding of knowledge and a male possession of power. By working within a knowledge built upon a woman's perception of the world, this science hopes to more clearly discern the oppression of male dominance, to more fully understand the significance of women in social life, and empower women with the ability to free themselves from male oppression.

The creation of a feminist standpoint science, based upon a feminist knowledge and understanding of the world, has been explored by many influential authors in the feminist camp. ${ }^{16}$ This turn of emphasis in feminist epistemology is placed by some in the late 1970s, when a deeper "hermeneutics of suspicion" emerged in feminist theory. ${ }^{17}$ Concern grew that one's perspective on reality, and one's style of thinking, as well as the questions asked in investigation, may be influenced by a gender bias. These

\footnotetext{
${ }^{16}$ See Allison Jaggar, Feminist Politics; Sandra Harding, Whose Science?; or Nancy Hartsock, Money, Sex, and Power, as only a few of the possible examples.

${ }^{17}$ Susan Bordo, "Feminism, Postmodernism, and Gender-Skepticism," in Feminism/Postmodernism, ed. Linda Nicholson (New York: Routledge, 1990), 143.
} 
theorists hold that all knowledge claims are made from some particular location, some particular point of view, and based upon some foundational beliefs. Any claim to be free of this embeddedness in location, the often claimed "God's-eye-view" from positive science, is untenable. Standpoint theorists claim that traditional science has been done from the unquestioned and uncriticized standpoint of men, supporting and continuing the domination of women in society. Thus, if a foundational standpoint is unavoidable for any science, a more appropriate and less oppressive science would be achieved by replacing the male oriented foundation with a female standpoint, a feminist view of science.

Sandra Harding compares the feminist rejection of traditional science to the rejection of what Thomas Kuhn referred to as a "normal" or "mature" science. 18 In a mature science the conceptual and methodological assumptions are shared and accepted by most inquirers in a field. As Kuhn argues, there is no reason to believe that a consensus among scientists guarantees an ultimate, or "more correct" knowledge of the actual nature of the world. The creation of a feminist standpoint is then a move towards a "successor science."19 Women need their own understanding of social life, an understanding which is aware that daily activity contains an interpretation of the world and an understanding of how power relationships are at work in a society. ${ }^{20}$ Standpoint theorists claim neither traditional nor postmodern theories of knowledge provide

18 Sandra Harding, "The Instability of the Analytical Categories of Feminist Theory," in Feminist Theory in Practice and Process, eds. Micheline R. Malson, Jean F. O'Barr, Sarah Westphal-Whil, and Mary Wyer (Chicago: University of Chicago Press, 1986), 18. See also Thomas S. Kuhn, The Structure of Scientific Revolutions (Chicago: University of Chicago Press, 1970).

${ }^{19}$ Mary Hawkesworth, "Knowers, Knowing, Known: Feminist Theory and Claims of Truth," in Feminist Theory in Practice and Process, eds. Micheline R. Malson, Jean F. O'Barr, Sarah Westphal-Whil, and Mary Wyer (Chicago: University of Chicago Press, 1986), 330.

${ }^{20}$ Nancy Hartsock, "Foucault on Power: A Theory for Women?" in Feminism/Postmodernism, ed. Linda Nicholson (New York: Routledge, 1990), 168-172. 
women with the power to end their historic subjugation to men, and that only a new, specifically feminist science can provide the ability to clear away the illusions of the old science.

Two of the earliest influential writings concerning a female point of view were those of Nancy Chodorow and Carol Gilligan. ${ }^{21}$ Chodorow's work investigated the psychological development of women as opposed to the development of men, creating a theory that essentially described the ways of women's knowing, based on an interpretation of women's social experiences. Building upon this argument, Gilligan's research concerning a "different voice" pointed out the traditional androcentrism of psychology, specifically the model of moral development created by Lawrence Kohlberg. Gilligan argued that his theory was necessarily incomplete by focusing its model specifically upon the experience of men and boys. Her book explored the terms of women's moral discourse in order to investigate its own standards of development. In this way she created a feminine "counter-model" to moral development specific to women, differing from that of men. ${ }^{22}$

\section{Away from Objectivity}

A feminist standpoint acknowledges the benefits and accomplishments of feminist science pursued within the confines of an empiricist paradigm, but criticizes the feminist reaction to the traditions of "bad science" as not strong enough. Relying upon the norms and methods of "science as usual" is too weak to systematically identify the

${ }^{21}$ Nancy Chodorow, The Reproduction of Mothering; and Carol Gilligan, In a Different Voice: Psychological Theory and Women's Development (Cambridge: Harvard University Press, 1982).

${ }^{22}$ For a discussion of how Gilligan's final conclusion remains an essential description of women's moral development, even though it relies upon some empirical methodologies, see Nancy Fraser and Linda Nicholson, "Social Criticism Without Philosophy: An Encounter Between Feminism and Postmodernism," in Feminism/Postmodernism, ed. Linda Nicholson (New York: Routledge, 1990), 32-33. 
biases upon which such a science is structured. The notion of objectivity has not been endowed with enough power to detect the sexist and androcentric assumptions that are the dominant beliefs of the modern period. ${ }^{23}$ The very idea of objectivity in knowledge is rejected, as a feminist standpoint finds all knowledge embedded and contextual, and therefore saturated in the value that positivism claims to be free of.

Standpoint feminism also rejects the traditional foundations for science because of the knowledge claims rejected or excluded by empirical science. Within scientific communities a group of qualified observers develop whose claims to knowledge are accepted, while claims from those who do not meet this community's criteria for acceptance are rejected. ${ }^{24}$ Further, the knowledge claims which these communities consider valid are extremely limited. Only knowledge claims unattached to particular circumstances are accepted as knowledge, and those claims tied to emotions or supported by a particular interpretation of history or cultural position were rejected. The scientific community has been so oriented to focus on value-free claims, that it has also tended to exclude claims from those individuals who are seen to typify those values. These rejected individuals, who embody the characteristics of emotion, culture, or history, have commonly been women and those from colonized groups ${ }^{25}$.

Standpoint theory seeks to embrace those rejected by empiricism, women or the colonized, who embody gender, emotion, or history. This rejection of traditional rationality has led some to label the movement of feminist standpoint science as "anti-

${ }^{23}$ Harding, "Rethinking Standpoint Epistemology," 51-52.

${ }^{24}$ Ibid. 70.

${ }^{25}$ Alison Jaggar, "Love and Knowledge: Emotion in Feminist Epistemology," in Women and Reason, eds. Elizabeth Harvey and Kathleen Okruhlik (Ann Arbor: University of Michigan Press, 1992), 115-142. 
rationalism."26 Standpoint theory openly confronts the historical use of the term "rational" as a means of denigrating women as the "irrational." In response to this history, standpoint theory seeks to valorize this excluded and denigrated 'other,' and to build a science upon her "irrational" characteristics. This leads to a science which includes concepts of emotion, nature, body, and intuition. The standpoint project would hope to build a social order that accommodates women in all of their female differences, rather than sanitize individuals into imperfect and ununique copies of the "everyman."

\section{Embedded Subjects of Knowledge}

In addition to claiming the contextuality of knowledge, feminist standpoint theory demands consideration for the embodiment of the subject of knowledge. Jaggar writes that the conception of human nature is essential to feminism, and begins with a rejection of classical Cartesian dualism, the separation of the mind and body. Reliance on a dualism, separation of mind and body, leads science toward "political skepticism and solipsism."27 This stems from the liberal assumption that individuals are solitary and have needs and interests that are separate and in competition with other individuals. This, however, is an unrealistic picture of humans, even if one assumes only healthy adults, as the necessity of reproductive biology alone points to the impossibility of selfsufficiency. Ignoring biological existence deprives liberals from the most basic way of identifying human needs.

Abstract individualism assumes that essential human characteristics are derived prior to any social context. Jaggar feels, however, that meaning is given to inner experience and behavior only by the emotions, beliefs, and attitudes given to us by our social

${ }^{26}$ Christine Di Stefano, "Dilemmas of Difference: Feminism, Modernity, and Postmodernism," in Feminism/Postmodernism, ed. Linda Nicholson (New York: Routledge, 1990), 67.

${ }^{27}$ Jaggar, Feminist Politics, 40. 
context. Contemporary research also has shown that many cognitive and emotional differences stem from sexual differences. If these points are even partially true, then the idea of a "presocial human being with out any determinate kind of nature is conceptually incoherent." 28 Central to the liberal idea of rationality is autonomy or self-definition. If, however, the central needs, desires, and beliefs of the individual are based on those of society, then the ultimate authority of the individual comes into question. In addition, liberal rationality is connected with the need for the individual to maximize their selfinterest. Jaggar feels that while this egoism may be an accurate model for males, this has not historically been the role of women.

Another consequence of the embodiment of subjects is the rejection of the positivist conception of an unattached observer recording the actions of a distinct object of study. As was stated above, there is to be no ideal vantage point from which to observe, no God's-eye or universal position. With the rejection of any unembedded position, the distinction between subject and object begins to atrophy. The subjects are as "real and visible" as any object. Further, there becomes no object that is not touched by the existence of the subject. All observers must interpret whatever it is that they perceive, whether a social or a physical phenomenon, the line separating the two is gone. ${ }^{29}$ This conception of the scientific observer will allow investigation to account for the attachments that individuals, observer and observed, have in the world. It will also allow a greater role for gender, attachment, and emotion in scientific inquiry, factors that are an inescapable component of human social life.

A key part of human interaction stems from our emotional interaction, another aspect of human life which has not been adequately considered by traditional science.

\footnotetext{
${ }^{28}$ Ibid., 42.

${ }^{29}$ Harding, "Rethinking Standpoint Epistemology," 63-64.
} 
Jaggar writes that traditional epistemology treats emotion with suspicion and hostility. ${ }^{30}$ In the positivist tradition, emotions only play a role as the stimulus that begins a scientific investigation, prodding the scientist to begin an investigation. In the testing and judgment of these hypotheses, however, the focus upon "replicability" works to cancel out all emotional influences. While this distinction between discovery and verification may filter out the values of individual researchers, it does not remove the values of the social context of the investigation. ${ }^{31}$ Emotions and values are a part of the scientific enterprise, at all levels. Feminist standpoint theory argues that for science to be accurate requires that it be able to acknowledge the continuous interaction between "how we understand the world and who we are as people." 32 To allow the full development of knowledge will then require a better understanding of the important role that emotions play in its acquisition.

Another development in the nature of the subjects of knowledge concerns their identity. In empirical science there was always an emphasis on the individual discoverer of knowledge, of the individual who was able to observe and to understand. In a standpoint theory, however, individuals no longer produce knowledge, which is instead seen as the creation of communities. Standpoint theory holds that any "discovery" of knowledge only becomes valid after it has been accepted by the community. ${ }^{33}$ Further, the agents of knowledge in a feminist standpoint claim to be "heterogeneous and multiple," representing the feminist claim that there is no ideal type of agent, no singular way of being that is able to discover and posses legitimate

\footnotetext{
${ }^{30}$ Allison Jaggar, "Love and Knowledge," 115-142.

${ }^{31}$ Ibid., 126-127.

${ }^{32}$ Ibid., 135.

${ }^{33}$ Harding, "Rethinking Standpoint Epistemology," 65.
} 
knowledge. The knowledge claims of these heterogeneous communities of knowledge are intended to be compatible with the claims of other marginalized groups, who have also been excluded from making knowledge claims.

\section{A New Type of Knowledge}

A central claim made from the feminist standpoint concerns the value-content of knowledge, where all knowledge is held to be contextual. All claims to knowledge are embedded in a history and social existence, and to consider knowledge separate from these influences is to follow a false ideal. The isolated, detached, ideal-observer which is found in so many empirical epistemologies, has no place in a standpoint theory. Again, if there is no ideal location or perspective from which to observe, and any vantage point is value laden, feminist standpoint theory argues that the best vantage point to choose for scientific inquiry is that of women. Feminism needs to consider the "historical, political, and theoretical process" that has created women as the subjects as well as the objects of knowledge. ${ }^{34}$ By historically situating a subject, she is less likely to mistake herself for the "universal man." Women, who hold a subordinate status in society, do not have an interest in distorting their perception of reality in order to justify the injustice of their dominant position, in the way that men do in a male dominated world. Women, without a need to alter their perception of reality, are therefore more likely to develop a "clearer and more trustworthy understanding of the world."35

Standpoint theorists also point to other ways in which our basic perceptions of the world imply notions of Cartesian thought. The comprehensivness of dualism is even apparent in the rules of logic. As standpoint theorists point out, even the principles of

\footnotetext{
${ }^{34}$ Hartsock, "Foucault on Power," 170-71.

35 Jaggar, Feminist Politics, 384.
} 
logic divide the world into "A and not-A." The principle of identity (if anything is $\mathrm{A}$ it is A) and the principle of contradiction (nothing can be both A and not-A), both work to exclude the "middle," that which is neither A nor not-A. These principles, however, are not representative of the empirical world, where objects are constantly in the process of transition, growing or decaying, and are very rarely at condition $\mathrm{A}$, or its opposite. ${ }^{36}$ This in turn has provided those in possession of the power to define knowledge a way to define what is $\mathrm{A}$ and what is not-A, rational or irrational, human or non-human. Nancy Hartsock asks, in whose interest is it to maintain these dichotomies ? Only those who have placed themselves outside of time and space, outside of change. ${ }^{37}$ Those who have defined themselves as $\mathrm{A}$, as rational, as truly human beings.

\section{Justification of Knowledge Claims}

The creation of a particular standpoint in which knowledge is legitimated is not a radically new idea in the history of philosophy. Most feminist standpoint theorists base their ideas of a privileged female perception of reality in Hegel's consideration of what can be known about a relationship between a master and slave from the master's point of view. 38 Hegel argues it is in the master's interest to create a false interpretation of the world in order to legitimize her continued dominance over another human being. It is, on the other hand, the slave who does not benefit from a social advantage and possesses an unclouded position from which to view the relationship. Marx and Engel's developed this insight into the "standpoint of the proletariat," and it is within this tradition that feminist standpoint theorists developed what they consider the only true

\footnotetext{
${ }^{36}$ Nancy Jay, "Gender and Dichotomy," Feminist Studies 7 (1981): 38-56; in Hartsock, "Foucault on Power," 162-163.

${ }^{37}$ Hartsock, "Foucault on Power," 163.

${ }^{38}$ Harding, "Rethinking Standpoint Epistemology," 53-54; Jaggar, Feminist Politics. 377-383.
} 
vantage point from which to observe the human condition. This vantage point is not that of the dominant male position in society, but the standpoint of the subjugated woman. ${ }^{39}$

Standpoint theory does not claim a unique position from which to find truth, only that this position does not depend on a distorted view of the world. This position, free from illusion, is available to any group which has historically been subjugated or repressed. 40 Although the possibility of an "unmediated" truth is rejected by standpoint theorists, the notion of truth is not altogether abandoned. 41 Standpoint theorists argue that while dominant social positions result in distorted views of society, those in other positions in society are able to see through the ideological camouflage and correctly perceive the world.

Sandra Harding has written an influential account of how the notion of "objectivity" also remains available to a standpoint theory. ${ }^{42}$ For Harding, a feminist standpoint produces a more adequate, and more unbiased scientific viewpoint which she calls, "strong objectivity." Strong objectivity requires that the subject of knowledge be located in the same epistemological context as the objects of knowledge. Further, all of the objectivity-maximizing procedures which are focused upon the object of observation must also be focused upon the observers, the scientists and the society which produced them. ${ }^{43}$ For Harding, and many standpoint theorists, a "maximally critical study of scientists" and their communities can only be done by those who have been

${ }^{39}$ Harding, "Rethinking Standpoint Epistemology," 54.

40 Harding, "Rethinking Standpoint Epistemology," 66-67; and Harding, "The Instability of the Analytical Categories of Feminist Theory," 29-30

${ }^{41}$ Hawkesworth, "Knowers, Knowing, Known," 330.

42 Harding, "Rethinking Standpoint Epistemology,"; and Harding, "The Instability of the Analytical Categories of Feminist Theory."

43 Harding, "Rethinking Standpoint Epistemology," 69. 
marginalized by such communities. The result of such a critical reflection of objectivity seeking method requires that scientists and their communities exist in "democraticallyadvancing projects for scientific and epistemological reasons as well as moral and political ones." 44

\section{Defending a Feminist Standpoint}

Standpoint theorists have considered the postmodern critics of epistemology, who warn that any epistemology eventually leads to exploitation and placing limitations on thought by legitimizing the beliefs of the powerful. Standpoint feminists, however, feel that feminism cannot stand with these arguments, and in fact must build on an epistemology as a defense against both traditional empiricism and relativism. Traditional objectivism tends towards an incoherent, value-free disinterestedness and a defense of the status quo. Relativism provides us no foundations to accept feminist interpretations of sexual, familial, or work relations. ${ }^{45}$ Support for the creation of a feminist standpoint epistemology emerges in light of the importance for feminism as a political movement to have an epistemology of its own. Only from the standpoint of women, long oppressed and excluded in this society, is the project of the emancipation of women likely to succeed. Standpoint theory unites women, as women, on the basis of their shared experiences in social life, forming a bond between them in their fight against male domination.

\footnotetext{
${ }^{44}$ Ibid., 69.
}

${ }^{45}$ Sandra Harding, "Feminism, Science, and the Anti-Enlightenment Critiques," in Feminism/Postmodernism, ed. Nicholson (New York: Routledge, 1990), 87-88. 


\section{POSTMODERNISM}

Not all feminists, however, are convinced by nor co-opted into the position of the standpoint epistemologists. Some writers in feminist theory have begun to criticize what they refer to as earlier "oversimplifications of history," and to move away from the use of gender as an analytical category. They argue that to write of any "male" or "female" reality or perspective is to assign a way of being to individuals and to "homogenize diversity and obscure particularity." 46 To create essential descriptions of the way women are to act and be opposes the battle which the feminists movement has long fought for, the ability to be different than the way they are described by the status quo.

For these authors, feminist theory properly belongs in the realm of postmodern thought. Feminist critiques of the self, knowledge, and truth are too far divorced from these concepts of the enlightenment to be compatible with any theory that relies upon these traditionally oppressive ideas. The future of feminism "cannot lie in reviving or appropriating Enlightenment concepts of the person or knowledge."47 Both feminism and postmodernism attempt to develop new criticisms of social relations not dependent on traditional philosophical foundations. ${ }^{48}$

\footnotetext{
${ }^{46}$ Bordo, "Gender Skepticism," 143.

${ }^{47}$ Jane Flax, "Postmodernism and Gender Relations in Feminist Theory," 42.

${ }^{48}$ Fraser and Nicholson, "Social Criticism without Philosophy," 19.
} 


\section{Standpoint as Incoherent and Insufficient}

The turn to a postmodern feminism begins with an examination of the many problematic presuppositions of the feminist standpoint claim that a feminist understanding of the world can be "truer" than previous, male, standpoints. Postmodernists question why anyone should accept the idea that one group, dominant or oppressed, has a privileged access to the truth. For postmodernism, there is no position that is closer to the truth than any other, and every "standpoint" is equally far from universal truth. Standpoint theory assumes that this oppressed class, unlike the dominating men, can be free of the determination assigned to them by their participation in the social system. The notion of a standpoint assumes that the oppressed are not only undamaged by their oppression, it assumes that this position of submission has given them a privileged, i.e. more than different, ability to perceive reality. 49

Standpoint theory also rests on some essential description of what is female, although no understanding of this deep identity has been shown to be universally coherent. There are two traditional approaches to science that have assigned an essential way of being to women. First, is a biological determinism, which relies upon claims of a woman's role in reproduction and for a nurturing nature "inherent" in women. Another has been a cross-cultural examination of male and female spheres of activity, the public and private realms, as an explanation of why women are generally bound to the home in social relations. Neither of these, however, is sufficient for understanding the diversity of forms which gender or sexism can take existing across cultures and times. Both of these themes were flawed in their attempt to find a single "grand feature" of human existence that would explain all the features of sexism. As

\footnotetext{
${ }^{49}$ Ibid., 56.
} 
postmodernism denies the existence of these 'large descriptions' of social life, this has strengthened the call for a postmodern turn in feminism that more adequately explains the diversity of social existence.

While it may be true that there is a seemingly universal feature of human societies called "gender," the actual manifestations of this idea are widely diverse and it is simply not always the case that "difference" equates with "unequal" across social contexts. 50 Standpoint theory depends upon a system of gendered social relations in which there is a category of beings who are fundamentally alike by virtue of their sex, and that an opposing group is also somehow fundamentally alike in a way different from the first. Postmodernism rejects the existence of these alleged bonds between individuals, either across vast cultural differences or within a neighborhood. To postmodernists it is incoherent to claim, on the one hand, there is a fundamental difference in selfconsciousness between men and women, while on the other hand, claiming that this self-understanding is basically similar among women and among men, across cultures, classes, and races. Any similarity claimed to be cross-cultural becomes difficult to guarantee when given any actual context or example. These essentialist claims serve as a strong method for developing a bond among women, but they seem deficient in their representations of differences that exist between women. These differences have become an increasing concern with the emergence of feminist voices from communities of differing class and ethnic backgrounds. These differences must be accounted for in any acceptable feminist epistemology.

${ }^{50}$ Di Stefano, "Dilemmas of Difference," 64. 


\section{A Postmodern Self}

Postmodern feminism rejects the essentialist project of assigning a gender identity and is critical of any epistemology which assigns a deep sense of self. Postmodernists reject psychoanalytic claims that an identity is formed in early childhood and remains constant thereafter. To suggest that self-identities are permanently formed in childhood suggests that a simple solution to these problems lies in the way we raise our children. Many feel that feminist critiques of social life are more powerful than implied by the claim that "allowing boys to play with dolls would be sufficient to bring about equality between the sexes." 51 Essentialists also tend to claim that their deep self-understanding influences and directs every action that subjects and objects engage in. Arguing that these identities determine all of one's future actions seems to presuppose an understanding of a public-private life difference that men and women will lead. Such a distinction should only be claimed valid for specific, modern, and Western societies, as there is little cross-cultural evidence for this similarity. Such claims play a powerful role in the writings of Chodorow and Gilligan. Gilligan wrote of "a" voice determining how women would react in given situations, not that there were a plurality of voices offering a number of possible resolutions to the moral dilemmas. ${ }^{52}$

Feminism allied with the methods of postmodernism seeks to avoid any essential identification of the subject. It must replace unitary notions of "woman" with a more plural notion of social identity. A notion aware not only of variables of gender, but also of class, race, age, and ethnicity. Jane Flax argues simply against the existence of a stable or coherent self and that no human faculty is capable of any form or reason

\footnotetext{
${ }^{51}$ Fraser and Nicholson, "Social Criticism without Philosophy," 30.

52 Ibid., 32.
} 
which allows insight into one's own processes of thought or into "laws of nature." 53 Donna Haraway's influential, enthusiastic support of a postmodern rejection of firm boundaries for feminism argues for "pleasure in the confusion of boundaries and responsibilities in their construction." 54 She favors a feminism as a "continuous cultural reinvention, postmodernist critique, and historical materialism." 55 Haraway feels that the struggles which have presented themselves to feminists have become too diverse for any single theory to account for. Claims made by a particular theory about the characteristics of the category "woman" can be shown to exclude many non-white women, while a category of "black" can essentialize black women and rule out white women. There was no singular "she" among women, and only a sea of differences that leaves us unable to identify similarities or invite allegiance:

"There is nothing about being "female" that naturally binds women. There is not even such a state as "being" female, itself a highly complex category constructed in contested sexual scientific discourses and other social practices. Gender, race, or class consciousness is an achievement forced on us by the terrible historical experience of the contradictory social realities of patriarchy, colonialism, racism and capitalism. Who counts as "us" in my own rhetoric? Which identities are available to ground such a potent political myth called "us," and what could motivate enlistment in this collectivity?"56

A postmodern feminist theory must insist that a "natural matrix of unity" is neither desired nor coherent. .7

Haraway summarizes her own ideas as being built around two themes. The first is an argument against any universal or comprehensive theory, for these are doomed to

\footnotetext{
${ }^{53}$ Flax, "Postmodernism and Gender Relations," 41.

${ }^{54}$ Donna Haraway, "Manifesto for Cyborgs," 191.

55 Ibid., 194.

56 Ibid., 197.

57 Ibid., 199
} 
misrepresent most of reality. Second, her essay revolves around a central character of the "cyborg" which is to represent and emphasize the need to take responsibility for and acknowledge the affects of science on social life. This means there can be no creation of an anti-science metaphysics or a demonetization of technology that surfaces in the politics of a feminist standpoint. It calls for a "recreation of boundaries," where a partial connection with others is affirmed as a passage "out of the maze of dualisms" that have long defined our bodies and ourselves. .58

Where the feminist standpoint held aloft the notion of an "other" to oppose the traditions of subject-object relations, and actively celebrated the irrational and embodied aspects of the feminine that had been assigned them by sexist philosophy, a postmodern feminism champions not the theme of "other" but the theme of "difference."59 Rather than a reliance upon the singular difference available in gender, a proliferation of differences is adopted.

\section{Anti-Universalist Nature of Knowledge}

Where standpoint theory argued against a universal conception of knowledge in order to break knowledge into different "knowledges" for different groups, postmodernists break knowledge down a step further into different "knowings" between individuals. This further denies the homogeneity of knowledge, even within groups, and prefers to hold each individual responsible for their own conceptions of knowledge. Fraser and Nicholson argue that one of the prime tenants of postmodernism, one that ought to be shared with feminism, is the strong position it takes against any meta-narratives. ${ }^{60}$ Postmodernism would join with feminism to fight

\footnotetext{
${ }^{58}$ Ibid., 222-223.

${ }^{59}$ Di Stefano, "Dilemmas of Difference," 67.

${ }^{60}$ Fraser and Nicholson, "Social Criticism without Philosophy," 26-30.
} 
against the "very large social theories" of history, culture, or psychology which claim to identify causes and features of sexism that operate across contexts and across eras. 61 Any theory which makes these types of claims rests fundamentally upon some assumption about an essential nature of human beings and the conditions of social life that individuals operate within. For postmodern writers, these "essentialist" theories, of which standpoint theory is a prime example, are not sufficiently aware of issues of historical, cultural, and individual diversity which feminists must account for.

\section{Justification of Knowledge}

Feminists in favor of a postmodern turn to their project argue there is no force or reality outside of our social relations and activity that will relieve us of our partiality and differences. They further argue that the most beneficial path for feminism to follow is with those who seek to further the decentering of worldviews. Feminist theory, like other postmodernisms, can encourage toleration of ambiguity and multiplicity and work to expose the roots of the need to impose order and structure upon reality no matter how arbitrary and oppressive these needs may be. ${ }^{62}$ Rather than be tempted by a "will to truth" postmodern feminists develop a commitment to plurality and difference. Feminism should focus on deconstructing paradigms of social understanding which rely upon traditional philosophical epistemologies, and upon moral and political theory rooted in partial and historically situated characteristics that are shown as necessary, universal and ahistoric truths.

\footnotetext{
${ }^{61}$ Ibid., 27.

${ }^{62}$ Flax, "Postmodernism and Gender Relations," 56.
} 


\section{In Support of a Feminist Postmodernism}

The advantages of a coalition between these two movements stems from postmodernism's powerful focus on philosophic criticisms and feminism's primary concern for political-social issues. Feminism would strengthen postmodernism's weakness in supporting social activism, and postmodernism will help feminist theory avoid falling into "foundationalism and essentialism."63 Fraser and Nicholson argue that in order to be accommodating to the wide range of social possibilities and problems, a postmodern feminism would need to be pragmatic in its approach to identifying bias. ${ }^{64}$ It would tailor its methods and categories to fit the specific use that it is called for at the time. It would include multiple categories when possible in order to avoid the "metaphysical comfort" of a single feminist epistemology. This diverse and multifaceted theory would be most useful in its application to political practice. Feminist politics is seen as an increasing system of alliances, rather than a unified front around a single interest or identity. Feminist politics would be cognizant that there is no single solution to the diversity of contemporary oppressions confronting women, child care, social security, or housing. Rather than argue for a single grand scheme to represent feminism, there ought instead be an alliance between "many feminisms." 65

\footnotetext{
${ }^{63}$ Fraser and Nicholson, "Social Criticism without Philosophy," 20.

${ }^{64}$ Ibid., 34.

${ }^{65}$ Ibid., 34-35.
} 


\section{ENLIGHTENMENT REVISITED}

Recently, however, there has been another turn in feminist theory, arguing that the project of feminism must remain tied to some understanding of justice if the goal of emancipation is to be coherently attempted. These writers are currently working toward a suitable epistemology upon which to base this development in the feminist project. This "way of knowing" will be enlightened by the penetrating feminist critiques of mainstream epistemology, building upon the strengths and acknowledging the weaknesses of previous, if insufficient attempts at a feminist theory of knowledge. This new theory will have to work carefully through the claims it makes for the deeply contested notions of "woman" and "rationality," and will need to plan meticulously the role which the "re-introduced" notion of "justice" will play.

These theorists acknowledge improvements of expanded scientific inquiry initiated by feminist empiricism but do not find its assumptions consistent with feminist needs. Empiricism relies heavily upon traditional notions of rationality, which have been used in the past to exclude women as non-rational. If the notion of rationality is to be retained, a new understanding of the concept will need to be attempted by these theorists. A further characteristic of empirical science was its aim toward an objective knowledge. While this concept has been thoroughly criticized by many feminists, many theorists are beginning to reconsider its benefits, questioning its hostile rejection by standpoint theorists and the uselessness attributed to it by the postmodernists.

This group also acknowledges the importance of critiquing the androcentric subject of knowledge highlighted by standpoint theorists. It has also been important to reexamine the Enlightenment's ideal of a universal knower whose knowledge is unmediated by environment. Dualism remains rejected by these feminists, and a 
knowledge of human beings must be found that does not rely upon a separation of our physical existence from our ability to know. But standpoint theories rested upon two questionable assumptions. First, the notion of a privileged viewpoint from where the oppressed accurately perceive reality seems incoherent with the rejection of any universal knower. Second, standpoint epistemologies are unable to overcome the essentialism that accompanies to the notion of woman, however widely defined. The distinction of women in general as "different" has legitimated unequal treatment of women in the past and must be rejected "theoretically and practically" if women are to be considered in society as the "nondifferentiated" equals of men. 66

Postmodernism as well is no longer viewed as pro-feminism. A growing number of writers highlight the gulf that exists between the tenants of postmodernism and the values and goals of feminist theory. Postmodernism's rejection of assigned ways of being avoids essentialism, and denies any privileged vantage point for philosophical investigation, but upon examination becomes inappropriate for feminist theory in a number of ways. First, the timing of an allegiance between feminism and postmodernism seems strange, for why is it that "just at the moment in Western history when previously silenced populations have begun to speak for themselves and on behalf of their subjectivities, that the concept of the subject and the possibility of discovering/creating a liberating "truth" become suspect?" 67 Postmodernism is interpreted by these authors as serving the needs of a specific group; white, privileged men of the industrialized West, who have already had an Enlightenment for themselves and are now ready to subject that tradition to critique. "Mainstream" postmodernism

\footnotetext{
${ }^{66}$ Di Stefano, "Dilemmas of Difference," 67.

${ }^{67}$ Nancy Hartsock, "Rethinking Modernism: Minority vs. Majority Theories," Cultural Critique 7 (Fall 1987): 187-206; in Di Stefano, "Dilemmas of Difference," 75.
} 
does not seem any more aware of issues of gender than any of the pro-Enlightenment theories that it claims to reject. 68

A further, and more damaging weakness in an alliance between postmodernism and feminism is the difficulty of building any political movement around a postmodern identity. Feminism seeks actual political and social change from the claims made by the women's movement. To identify a constituency and to bond them into a motivated movement, requires some source of shared identity between the movement's members. Feminism in the past has found this bond in the shared identity of women within the movement as "women." The postmodern rejection of subject centered inquiry and theory, and its rejection of labels and identities, does not allow a strong, permanent, or motivating use of the notion "woman." This seems antithetical to the needs of feminist theory which revolves around this specific constituency. If specific subjects are unable to identify with a postmodernist flag, it will be difficult to attract and rally the dedicated followers necessary for an organized political movement such as feminism. Further, postmodernism's "robust" celebration of differences, rather than a celebration of shared identity could be politically unreliable, creating a weakness in the face of the modern state and uses of power. 69

Christine Di Stefano attributes the dilemma in the search for feminist epistemology to an inability in any of these three schools of thought to deal adequately with the notion of difference. In feminist research which remains in the empirical/positivist tradition the she dissolves into he as gender differences are collapsed into the (masculine) figures of the "everyman." This sanitized figure remains a central weakness for feminism in the political claims of liberalism or Marxism. In research from a feminist standpoint, the

\footnotetext{
${ }^{68}$ Di Stefano, "Dilemmas of Difference," 75-76. By "mainstream postmodernists" Di Stefano refers to Derrida, Lyotard, Rorty, and Foucault.

${ }^{69}$ Di Stefano, "Dilemmas of Difference," 76.
} 
idea of a differentiated female subject is preserved, but she is preserved at the rather high cost of denying her transformation or liberation from the conventions of femininity. Here, radical feminism begins to blur with "new-right anti-feminism," which also seeks to discover the correct and proper concept of female, and to celebrate and encourage this conception in social life. Finally, in a postmodern feminism, the she dissolves into a dizzying array of differences, none of which is privileged over the other, leaving no way to determine if the emancipation of women has been realized or not. ${ }^{70}$

Thus, finding all three major movements within feminist thought unacceptable, these more recent writers in feminist epistemology have begun a return to the Enlightenment, acknowledging that the feminist movement is fundamentally rooted in the ideals of justice and freedom. ${ }^{71}$ Many authors currently working in feminist theory continue to identify with the label "feminist," though no longer to indicate a liberating project for women alone, but rather to indicate a project of emancipation that is consistent with the goals and discoveries of feminist inquiry into human social life. ${ }^{72}$ The feminist movement began rooted in an effort to raise women from the oppression encountered in a male dominated society. Its goals, however, were never to include the liberation of women from their commitment to the social relations around them, nor to liberate humanity from our social existence.

Alcoff and Potter have illustrated the situation that feminists must now be concerned with as an awareness that, "Each lives at a different node in the web of oppressions."73 Oppression exists, but so do connections between individuals. Oppression cannot be

\footnotetext{
${ }^{70}$ Ibid., 77.

${ }^{71}$ Lennon and Whitford, Knowing the Difference, 1-14.

${ }^{72}$ Alcoff and Potter, Feminist Epistemologies, 4.

${ }^{73}$ Ibid., 4 .
} 
accounted for when considering individuals in isolation, nor by declaring the relations between individuals universally oppressive. Many of these relations are the factors of social life which define individuals as who they are, and who they work to remain. An acceptable feminist epistemology must be able to identify those relations which are oppressive, and differentiate them from those relations which are the ties that bind us to our very identities and ways of life.

\section{Community of Subjects}

To defend against the radical difference championed by the postmodernists, many feminists have returned to investigate the connections and commonalties between individuals. While postmodernism had left feminism in an advantageous position, able to proclaim the diversity of women and all individuals in general, it also became "complex and unnerving, inhabiting a constantly shifting ground of emerging and dissolving differences." 74 Partly in response to the dissolving of knowledge into individual components, and partly for their need to account for human interconnectedness, feminists have turned to a communal understanding of knowledge, so that communities and groups replace the individual as primary in accounting for knowledge.

In response to the fragmented individuals of empiricism, the emphasis on a partial humanity in standpoint theories, or the partial representation of humans in postmodernism, new approaches are being attempted which allow knowledge to account for complete human individuals and entire human communities. The primary goal of scientific knowledge, for these authors, should be to represent in a concrete whole, human lives as experienced by both men and women, the oppressed and the

\footnotetext{
${ }^{74}$ Di Stefano, "Dilemmas of Difference," 68.
} 
oppressors. ${ }^{75}$ The epistemology underlying this task is intended to capture what is human in men and women, rather than to identify the essential characteristics which separate them. ${ }^{76}$ Arriving at this knowledge will require a modified conception of rationality, allowing a new role for experience's interplay with reason. Women's experience cannot be privileged nor is it static; it is simply a characteristic of historical existence. Neither experience nor reason, subjectivity nor objectivity, is a prior or more fundamental component of knowledge.

This argument accounts for both physical and mental characteristics of human beings, as opposed to empiricism's separation of these aspects. It also opposes standpoint theory which introduces a new, female perspective upon subject and object relations which neglects the male perspective and loses the ability to account for all views. Postmodernism's fragmentation of science into a multiplicity of types and vantage points is also combined into a unified understanding of human social life. This knowledge should be able to articulate the inter-relatedness of the parts while respecting the specificity of differing experiences, providing a narrative of concrete situations, as experienced by all parties involved. ${ }^{77}$ The social conditions of any group of oppressed individuals must be seen in connection with the group from which the oppression comes. A feminist epistemology must account for the lives of women seen in conjunction with the lives of men, acknowledging men as both part of the problem and part of the solution to women's emancipation. An acceptable understanding of

${ }^{75}$ Oshadi Mangena, "Against Fragmentation: the Need for Holism," in Knowing the Difference: Feminist Perspectives in Epistemology, eds. Kathleen Lennon and Margret Whitford (New York: Routledge, 1994), 275-282.

76 Marina Lazreg, "Women's Experience and Feminist Epistemology: A Critical NeoRationalist Approach," in Knowing the Difference: Feminist Perspectives in Epistemology, eds. Kathleen Lennon and Margret Whitford (New York: Routledge, 1994), 59.

${ }^{77}$ Oshadi Mangena, "Against Fragmentation: The Need for Holism," 275-282. 
knowledge must include individuals as they wholly exist, and account for the entirety of their social interactions.

This group of feminist theorists also retains an argument against the commitment to "epistemological individualism," the assumption that, although other people exist, knowledge is produced by each individual alone, from one's own senses and experiences. ${ }^{78}$ The argument of a traditional methodological solipsist often assumes the possibility of private knowledge production, through an individual's own language. Assumptions about a private language have allowed feminists to turn the insights of Wittgenstein on these individual knowledge gatherers. ${ }^{79}$ Here we are reminded that individuals cannot privately produce language because private communication leaves no way to distinguish between true statements and those that seem true. Only the cooperation of two or more individuals can distinguish between how things are and how they seem. 80 These feminists follow Wittgenstein in arguing that the individual cannot be epistemically prior to the community, and that the community is composed of "epistemically interdependent individuals." 81 Knowledge is then primarily a social construct, and social influences upon knowledge, relations of oppression included, must be accounted for in a claim to knowledge.

Lynn Hankinson Nelson argues that postmodernism leaves any philosophical investigation with only two epistemological choices, where on the one hand we are committed to a Cartesian or essentialist self, or on the other hand, there can be no

\footnotetext{
${ }^{78}$ Elizabeth Potter, "Gender and Epistemic Negotiation," in Feminist Epistemologies, eds. Linda Alcoff and Elizabeth Potter (New York: Routledge, 1993), 163.

${ }^{79}$ Ibid., 163.

${ }^{80}$ Though, as Wittgenstein points out, this does not in any way guarantee an accurate representation of the way things exist. This only best supplies the individuals with a knowledge of "same" and "different," knowledge that is a necessary check against one's memory.

${ }^{81}$ Potter, "Gender and Epistemic Negotiation," 165.
} 
epistemology at all. Nelson argues, however, that this does not exhaust the realm of possibilities. She feels that this postmodern dichotomy rests on an assumed individualism. 82 Similarly, postmodernism presents us with the choice between "one truth" or "multiple truths," and thus claims that there are no truths at all which are prior to any others. She rejects both the isolated individuals of traditional epistemology, and also the embedded, but not necessarily social subjects of standpoint theories. In response to this, Nelson proposes not a "middle ground" between these alternatives, but a communal account of agency and evidence that abandons the Archimedean points which base both objectivism and relativism. ${ }^{83}$

She offers an account of epistemic agency which rests on three assumptions. First, agents of epistemology have no fixed historic content. Instead it is individuals, embodied and situated in a specific history who know, where their embodiment and context are also relevant to their knowing. Second, these agents are not isolated, but rather strongly related to other features of an epistemology, especially with regard to evidence for knowledge claims. This account considers evidence to be dynamic, relating to the new role of active knowers within a feminist epistemology. Finally, epistemology is understood as "radically interdependent with other knowledge. 84

For this change in epistemology to occur, the first item on an agenda of study must not be the individual knower, but rather an inquiry into how knowledge is generated within specific histories, social relations, and practices of communities. ${ }^{85}$ It is within these practices that ontologies are developed, criteria for evidence are established, and

${ }^{82}$ Lynn Hankinson Nelson, "Epistemological Communities," in Feminist Epistemologies, eds. Linda Alcoff and Elizabeth Potter (New York: Routledge, 1993), 128.

${ }^{83}$ Ibid., 129.

${ }^{84}$ Ibid., 123.

85 Ibid., 126. 
theories are made and rejected. The discovery of a piece of scientific evidence is only possible within a system of practices that exists within a community. Commitments there are made within particular communities to standards and methods that legitimize scientific knowledge. Even experience is fundamentally a social notion, interpreted through the guide provided by society. These communities are simply epistemologically prior to the individuals that live within them. With these bases for knowledge established, any notion of a solipsistic knower becomes inconceivable.

\section{Reconsidering Objectivity}

Some writers within this category of feminist thought have begun to discuss the need for feminist theory to return to notions rejected by standpoint and postmodern writers. Notions such as objectivity and rationality, it is argued, remain too useful in the construction of a social theory to be completely discarded. But these writers do not advocate a blind return to the notions as traditionally used, and remain enlightened by some of the more important claims of previous feminist thought. Important considerations they make in a return to these notions involve an account for human social existence and an insistence on the accountability of our knowledge production. ${ }^{86}$ This justification is important not only to the criteria of other scientists, but also to the community of feminists.

Writers from this group argue that a careful reconsideration of objectivity ought to be undertaken, to discover which aspects of it are needed for a feminist project, and which aspects are rightly discarded. Ismay Barwell writes that there is no necessary reason why, if part of a concept is rejected, that the entire concept must be forgotten. Objectivity is at work in two locations within science and philosophy, as a part of its

\footnotetext{
${ }^{86}$ Lennon and Whitford, Knowing the Difference, 7.
} 
methods, and as the goal to be achieved. Rejecting prior methodologies as not achieving their claim to objectivity is not necessarily followed by the need to reject objectivity as a goal for science. Objectivity remains a valuable characteristic of a theory because it indicates an intent to depict phenomena accurately and explain how and why events occur. This gives objectivity a relationship to "truth" which must be maintained as a regulatory principle in theories. ${ }^{87}$

The value of objectivity and truth for feminist theory lies in feminism's need for accurate descriptions and analyses concerning social organization which are being judged according to their justness. Not all of the many varieties of feminism, Barwell writes, see themselves as radical movements for social upheaval. Instead, feminist aims are towards the creation of social arrangements more just than those already in existence. Existing states of affairs need to be judged according to possible states of affairs. Any creation of a notion of justice will rely upon an accurate description of states of affairs, which is provided by objectivity. These possible, and more just social arrangements, need to be created according to some standard. This standard cannot be recreated each time they come to be considered by another individual.

But this is not to say that traditional concepts will escape without a thorough reexamination. Writers in this group note three aspects of objectivity that need to still be rejected. First, any claim to a 'God's-eye view' is eliminated, as practically and philosophically impossible. Second, the idea that objectivity needs a 'complete justification,' which might provide absolute certainty of scientific knowledge remains highly questionable. Finally, the notion that there could be any theory completely devoid of values brought about by the theory's self-understood goals is rejected.

${ }^{87}$ Ismay Barwell, "Towards a Defense of Objectivity," in Knowing the Difference: Feminist Perspectives in Epistemology, eds. Kathleen Lennon and Margret Whitford (New York: Routledge, 1994), 81-82. 
Epistemic values such as accuracy, simplicity, or comprehensivness are commonly constitutive of a theory. 88

The challenge remains, for these feminists, as to how to best achieve this ideal. Ismay Barwell defends objectivity with a reworked notion of Harding's strong objectivity, while still questioning the primacy Harding gives to the perspective of oppressed groups. She rejects the traditional dichotomy that knowledge is either guided by interests or by the facts, in favor of an idea that different groups possess greater or lesser amounts of the truth, and that the interaction of groups can lead to a greater number of individuals possessing the truth. She argues that there must be a role given to a notion of groups as possessing shifting authority in perspective, depending on the subject, and changing over time. Interacting groups, critical of each other's perspective, will result in the production of knowledge not specific to one or another of the groups. With the additional acknowledgment of shifting authority, Barwell hopes to exclude an over abundance consensus or a lopsidedness of power. ${ }^{89}$

Allessandra Tanesini agrees with a revisiting of the notions of "rationality" or "reason" which were rejected by feminists as irreparably sexist and androcentric. 90 This rejection relied upon an assumption about the unchanging nature of words, and about their use in epistemology. For Tanesini, however, epistemology is not a simple matter of describing norms or current practices of word usage. Instead, epistemology should be understood as a practice of advancing and defending proposals on how to ground our knowledge. Epistemology is a constant process, something which creates

\footnotetext{
${ }^{88}$ Ibid., 83.

89 Ibid., 90-92.

${ }^{90}$ Allessandra Tanesini, "Whose Language?" in Knowing the Difference: Feminist
} Perspectives in Epistemology, eds. Kathleen Lennon and Margret Whitford (New York: Routledge, 1994), 214. 
and recreates norms. ${ }^{91}$ What was once accepted as imperative does not dictate what must be the case today. Past use of the idea of rationality or knowledge can be redefined in terms of what is compatible with today's ideas of these concepts.

\section{Return to Justificatory Strategies}

Other feminist authors have used the notion of community to support the need for legitimizing knowledge claims. Because feminism is an oppositional movement, it will always challenge authority, unable to embrace the idea that any claim of truth or legitimacy relies upon some mysterious universalism..$^{92}$ For Lovibond, the idea of morality involves the idea of responsibility, and the ability to account for your actions to your community of equal fellow citizens. It will not be possible for this community to be an empirically existing one, but rather a notional one defined in terms of a general interest.

Fricker proposes a theory of "holism" to form a suitable epistemology for feminism. This ideal must allow a role for value-laden observation of experience as has been argued for by many feminists, but must also provide a notion of truth, to avoid the relativist inability to act upon these claims. The criteria that her empirical account of the facts must meet are normatively determined, and a historical product. Thus we see the strong role that norms should play in such a theory, as well as the ability of empirical criteria to change over time, resulting in a "dialectic" between facts and values. ${ }^{93}$ This dialectic eventually becomes a form of self-criticism that will be inherent in the ideal of

91 Ibid., 214.

${ }^{92}$ Sabina Lovibond, "The End of Morality?" in Knowing the Difference: Feminist Perspectives in Epistemology, eds. Kathleen Lennon and Margret Whitford (New York: Routledge, 1994), 65.

${ }^{93}$ Miranda Fricker, "Knowledge as Construct: Theorizing the Role of Gender in Knowledge," in Knowing the Difference: Feminist Perspectives in Epistemology, eds. Kathleen Lennon and Margret Whitford (New York: Routledge, 1994), 105. 
knowledge. Thus, Fricker's holism provides an epistemological base for both feminist deconstructions and reconstructions of Western thought. ${ }^{94}$

Other authors have addressed the need for a feminist epistemology to account for the role of norms in the interpretation of experiences..$^{95}$ There must be an ideal of "truth" or some criteria for establishing what is "real," transcending situated perspectives as a regulatory ideal. Any social or political account of knowledge must remain able to represent and account for the events experienced in the real world. This "realism" is necessary, especially for a political movement such as feminism, because an emancipatory epistemology must also seek real change in the events of that world. It is necessary for an acceptable theory to be able to account for actual events if such a movement is going to retain the ability to present experiential claims as reasons for or against certain political views. ${ }^{96}$

For many, feminism is a political project that requires the feminist claims of androcentrism and sexism in traditional epistemology and social science to be regarded as legitimate, and not only legitimate for feminists. For these writers, it thus becomes problematic to abandon totally the ideas of objectivity and the referential claims of knowledge. Contemporary feminist writing attempts to create a new form of rationalism on which a feminist epistemology can be founded. A "feminist knowledge" is being sought which will remain trustworthy to feminist inquiry. ${ }^{97}$ Many of these writers have returned to the idea of accountability of knowledge, or the justification of claims of knowing. This new form will need to incorporate the diversity of female

\footnotetext{
${ }^{94}$ Ibid., 107-108.

${ }^{95}$ Ibid., 95-109.

${ }^{96}$ Ibid., 95.

97 Lennon and Whitford, Knowing the Difference, 7.
} 
experiences, forcing it to be able to deal with issues of power and conflict over interests, and the ability of the self to change in the pursuit of knowledge. 98

\section{FORWARD WITH THE FEMINIST PROJECT}

This chapter has explored the developing project to ground feminist political and social theory in a coherent theory of knowledge. Feminism was followed, beginning in the claims and arguments of feminist empiricism, through its branching into feminist standpoint theory and an attempted alliance with postmodernist thought. Each of these developments was made on a valid critique of the inadequacy of competing theories, as each school of thought has also continued to critique other positions in defense of its own. With an understanding of the shortcomings of each of these theories, we have gained some understanding of where feminist theory might move in its next major development. Some of the clues to the development were explored in the overview of feminists who do not consider themselves in any of the available epistemological camps.

In addition to an understanding of what is rejected by each of these groups, we have also seen some of the baggage, in the form of requirements, that has been taken on board the feminist project along the way. In the survey of these many parcels, we have been able to handle many claims made by feminist theorists, seeing which notions have been tried and rejected, and which aspects have been tried and found fitting. Those items which have been cast away from all of these schools of thought must be noted, and thus avoided in the future. The items remaining on board will have to be incorporated into the final construction of the feminist project.

98 Ibid., 13. 
First, the Cartesian ideal of a dualistic split between mind and body in the investigation of human social interaction has been thoroughly rejected. All three of the later groups of feminist writers have demanded an understanding of human embodiment, and the consequences of context, to be accounted for in a theory of knowledge. Any idea that some unique, unattached, 'God's-eye view' of human life can be achieved by human beings, who cannot escape our physical existence, is rejected.

Second, the move that standpoint theory makes towards an essential description of women ought to be rejected. As many have since argued, these claims seem antithetical to the original intentions of the feminist movement, to allow women to define themselves as they see fit, and for them not to be forced to comply with an imposed way of life. Another characteristic of standpoint theory is the tendency to privilege the perspective of some group's hold on reality over the perspective of others. While this is a notion founded upon the strong traditions of Hegel, we still do not have sufficient reasons why we ought to acknowledge or accept any group's primacy over another.

Third, a feminist epistemology cannot be relativistic. This was seen as the most important reason for rejecting the alliance with postmodernism. What would become of the feminist movement if each individual is allowed their own understanding of correct social relations. On what basis would a feminist project judge one relation over another as just or unjust? And what basis would there be for rejecting an unjust situation? Feminism seems in need of some standard of judgment. What was found lacking in postmodernism, must be demanded of any acceptable theory, the ability to form a strong political movement on the basis of its claims. Women must be able to identify with each other as women, and must be able to identify concrete instances in their experiences to fight against, as well as be able to identify concrete improvement in social life that they can fight for. This was a central factor in the roots of the feminist 
movement, and will remain so until the creation of a truly just social order is created, and its maintenance guaranteed.

Therefore, as this paper continues to explore what may develop into a comprehensive feminist epistemology, we have been able to locate three characteristics that it must contain. First, this epistemology must acknowledge and account for the idea that knowledge is contextually derived and dependent. This will involve meeting feminist demands to account for both embodiment and embeddedness.

Second, this feminist epistemology ought to be capable of accounting for individuals as distinct individuals, yet as individuals with a history and context. This will demand that a theory provide a more complex understanding of individuals than is currently available in any of these three theories.

Third, an epistemology compatible with the emancipation of oppressed groups, women as well as others, must provide some means of justifying legitimate knowledge claims. It must be able to show how knowledge comes to be acceptable to a community and to individuals, and it also must be able to show why this knowledge deserves this status. In order to meet these demands, this epistemology must provide some understanding of the idea of justice. As of yet, no single feminist writer has devised such an understanding of knowledge.

We leave for now our consideration of feminist epistemology in order to explore a possible source of inspiration for this next stage in feminist thought. After an account of this approach to political and social life, and the conception of knowledge it is based upon, we will return in the fourth chapter of this thesis to compare this theory to the needs of a feminist epistemology explored in this chapter. 


\section{CHAPTER III}

\section{COMMUNICATIVE SOCIAL SCIENCE}

In a separate venue, some distance from the previous chapter's circles of feminist theory, another writer and another school of thought struggle with many of these same issues, attempting to build a politically potent philosophical understanding of human existence and human potential. The critical social science of Jürgen Habermas is one of the leading theories that seeks such an understanding of social life, considering both human social development and contemporary society, while building ideas for an improved social order in the future. This chapter will begin with an introduction and explanation of the steps Habermas has taken away from traditional social science's strict adherence to positivism and purposive rationality. Second, in order to grasp Habermas's conception of human social life, this chapter will explore the "lifeworld" in which his social and moral theory is grounded. Finally, this chapter will introduce the developments Habermas has made in his theories concerning moral and ethical life, and what these developments mean for human actors in their autonomy and communal commitments. It is from these three aspects of Habermas's work that this thesis will propose a path for resolving some of the internal dilemmas of feminist political and social theory.

Habermas's early writings began to articulate his understanding of human knowledge, and the consequences this understanding was to have for a science 
attempting to describe social life. ${ }^{1}$ In his "philosophical anthropology" he works out three distinctive characteristics of human understanding that form our basic "knowledge-constitutive interests." These interests are "knowledge-constitutive" because they determine what is to count as an object of knowledge, identify what we accept as relevant for a claim to knowledge, and provide different procedures for discovering and accepting these claims. ${ }^{2}$ The three distinct categories Habermas has separated our knowledge into are: the technical, the practical, and the emancipatory. In turn, each of these areas of interest corresponds to a type of science or discipline and an area of human social activity.

The first, technical interest, is incorporated by the empirical-analytic sciences, and is associated with the human activity of work. Habermas argues that human work is a primary level of action, representing ways in which individuals control and manipulate their natural environment in order to physically preserve themselves. Technical sciences are intent on a "cosmological" mission of describing the universe in law-like statements as it is seen to exist. A scientist of these disciplines can and should work from a disinterested perspective, excluding bias and beliefs from claims of knowledge. ${ }^{3}$ Habermas emphasizes that his theory does not attempt to denigrate the empiricalanalytic sciences or knowledge. Rather, he argues that it is incorrect to claim that this is the only type of knowledge, or that all other knowledge ought be judged by this realm of technical human interests.

\footnotetext{
${ }^{1}$ See Jurgen Habermas's Frankfurt inaugural address of June 1965, titled "Knowledge and Human Interest: A General Perspective," chap. in Knowledge and Human Interest, (Boston: Beacon Press, 1971; original German edition published by Suhrkamp Verlag, 1968), 301-317.

${ }^{2}$ Richard Berstein, The Restructuring of Social and Political Theory, (Philadelphia: University of Pennsylvania Press, 1976), 191-193. Habermas further argues that these categories are dependent on the most fundamental needs of the human species for cultural and biological reproduction. See Habermas, Knowledge and Human Interest, 196-197.

${ }^{3}$ Habermas, Knowledge and Human Interest, 302-311.
} 
Second, the historical-hermeneutic sciences incorporate the practical interests of human knowledge, and are associated with interactive human social existence. For Habermas, social interaction is a "nonreducable type of action requiring a distinctive set of categories for the description, explanation, and understanding of it." 4 Habermas argues that individuals shape and determine themselves through this aspect of human knowledge, not only through their work, but also through communicative interaction and language. Habermas emphasizes that these interactions are vital for understanding social and political life. In the historical-hermeneutic sciences the validity of knowledge claims are not dependent upon a technical control of nature, but instead rely on access to "the facts" provided by comprehending the meaning of activities, not by observing them. ${ }^{5}$ Hermeneutic knowledge is always mediated, through the initial preunderstanding of an interpreter to the circumstances investigated. Habermas fully develops the importance and intent of this human interest in his understanding of the human lifeworld, as will be explored in the second section of this chapter.

A critical science, however, unlike the empirical or the hermeneutic sciences, is not content with theoretical explanations. Critical science is concerned with going beyond this type of knowledge to exposing instances when these other sciences become dependent upon or influenced by ideologies. The methodological framework which determines the meaning for or the validity of critical propositions is established by the concept of "self-reflection." ${ }^{6}$ Here Habermas stands as part of a philosophical tradition arguing that "when reason or knowledge is properly understood, we realize that there is in it a primary interest or demand to become fully actualized."7 "Reason...means the

\footnotetext{
${ }^{4}$ Berstein, The Restructuring of Social and Political Theory, 195.

${ }^{5}$ Habermas, Knowledge and Human Interest, 309.

${ }^{6}$ Ibid., 310.

${ }^{7}$ Berstein, The Restructuring of Social and Political Theory, 198.
} 
will to reason."8 The human emancipatory interest seeks to utilize fully the human capacity of rationality, which Habermas defines more robustly than many have traditionally done. Additionally, Habermas believes that an "emancipatory interest cannot be realized by the solitary ego or Absolute Spirit, but only in and through the concrete social and political lives of men." The results of this belief will be shown below in the development of Habermas's discourse ethics.

This chapter will explore briefly each of these aspects of Habermas's thought. It will first touch on Habermas's belief in the need for a deeper understanding of social life than can be provided by empirical science. Discussion will then move to Habermas's suggestion for how to understand social life, through an account of the lifeworld, and the science needed for this understanding. Finally, Habermas's ideas on ethics and morality will be discussed in relation to this lifeworld, along with the consequences these ideas have for individual lives, and his understanding of a scientific investigation of this relationship. With the philosophical developments discussed in this chapter in mind, the following chapter of this thesis will explore the constructive use to which feminist theorists can put Habermas's understanding of social life in their own development of an understanding of human knowledge.

\section{THE SHIFT TO A PHILOSOPHY OF LANGUAGE}

One of the central claims to Habermas's work is the inadequacy of a science which depends exclusively upon empirical-analytic criteria for its claims to knowledge. $\mathrm{He}$ identifies areas where empirical-analytic methods are appropriate, concepts bounded by

\footnotetext{
${ }^{8}$ Habermas, Knowledge and Human Interest, 314.

${ }^{9}$ Berstein, The Restructuring of Social and Political Theory, 198.
} 
human technical interests, and shows how the empirical-analytic sciences atrophy when they attempt to step beyond these limits. To demonstrate this inadequacy, Habermas does not directly attack the claim that these sciences are able to provide us with an accurate understanding of the world, and instead questions the ability of empirical science to explain how knowledge is accumulated and transmitted by the scientific community of inquirers. Habermas shows here that the intelligibility of this community, "with its distinctive forms of intersubjectivity and communication, presupposes a level of action-symbolic interaction-and a set of categories needed to account for that action, which are richer and more inclusive than those explicitly countenanced by the technical cognitive interests." 10 Thus the intelligibility of these disciplines, that these scientists are able to communicate with one another, cannot be fully explained by technical interests, and requires a more comprehensive concept of socialization and rationality.

\section{Expanding Rationality}

In order to develop this "richer and more inclusive" understanding of human knowledge, Habermas begins with a careful examination of what information is available to the human capacity for empirical-analytic knowledge. In the empiricalanalytic sciences the logic of inquiry leads to true statements about reality, through the scientific method, which has proven the best of methods for arriving at valid beliefs, "beliefs that all future events will not render problematic but rather confirm."11 Valid beliefs are universal propositions about reality that can be transformed into technical recommendations. But this does not yet explain how scientific progress is possible. ${ }^{12}$

\footnotetext{
$10^{\text {Ibid., }} 196$.

${ }^{11}$ Habermas, Knowledge and Human Interest, 119.

12 Ibid., 120-121.
} 
The logic of experimentation on which scientific knowledge is produced does not explain how it is that scientists themselves came to the agreement that this knowledge has universal significance. Before scientists are able to agree on experimentation, there must have been agreement that has allowed their communication. For this, scientists, as well as all social actors, rely upon a rational agreement not limited by a technical interest, an agreement which must be included in our understanding of human knowledge.

Part of this knowledge can be explained in an expanded concept of rationality, which Habermas develops by making a fundamental distinction between traditional notions of instrumental rationality and communicative rationality. Instrumental, or strategic, rationality is typically defined as the rationality that governs the choice between means to given (often material) ends. For Habermas, only those who presuppose a set objective world to act within will limit their definition of rationality to the empirical tests of truth and efficiency. Contrary to this "realist" view of rationality, Habermas points to another way of testing the rationality of one's expression, a method which is based upon the awareness that those actors who behave rationally have presupposed an objective world to act within. This phenomenological view of rationality accounts for the fact that the world is interpreted by individuals, and that for a community of individuals living together, this presupposed world is largely a uniform set of interpretations.

Communicative rationality characterizes the activity of reflecting upon our interpretations and background assumptions about the world, bringing our basic norms to the fore, to be occasionally questioned and negotiated. ${ }^{13}$ Instrumental rationality takes these background assumptions for granted and concentrates on achievements in the world.

\footnotetext{
13 Jane Braaten, Habermas's Critical Theory of Society (Albany: State University of New York Press, 1991), 12.
} 
The abstract, background concept of the world is a necessary condition if communicatively acting subjects are to be able to reach an understanding among themselves about events in the world. It is through this communicative practice that these acting subjects assure themselves of their common life-relations, of an intersubjectively shared lifeworld. ${ }^{14}$

This lifeworld is bounded by the totality of interpretations presupposed, by all members, as background knowledge upon which all other interactions are founded. ${ }^{15}$ Habermas further explains this concept as "implicit knowledge that can't be represented in a finite number of propositions; it is a holistically structured knowledge...we cannot make it conscious and place it in doubt as we please." 16 In the phenomenological view, being rational is most closely linked to being meaningful. Here, individuals are considered to be 'rational' whenever they act on the basis of their lifeworld, i.e., when they follow a norm established in that lifeworld. These actions are defensible when challenged, and if an action is criticized the actor can explain the situation in light of established norms to legitimize the behavior. Further, this phenomenological approach to rationality allows a theory to account for the rationality of utterances concerning personal desires or intentions. Criticism of these statements can be defended by explaining the action as a consequence of one's personal experience or particular history. ${ }^{17}$ Thus, phenomenology allows our understanding of the term rational to be

\footnotetext{
${ }^{14}$ In the Theory of Communicative Action Habermas uses the word "lifeworld" in at least three different ways. This is the first, and most fundamental to his theory. This "lifeworld" is a foundational, intersubjective understanding of the world which seems closely related to a Wittgenstinian concept of a "form of life." For an explanation of his other uses of "lifeworld," refer to his Theory of Communicative Action, volumes 1 and 2.

${ }^{15}$ Habermas, Theory of Communicative Action, vol. 1, 12-13.

16 Ibid., 336.

${ }^{17}$ Ibid., 15.
} 
expanded to include not only (i) assertions about the objective world, but also (ii) normatively regulated actions, and (iii) expressive self-presentations which are meaningful and understandable in a context connected to criticizable validity claims. These three types of communicative action, each being open to criticism, and each able to be defended with reasons, point to a definition of rationality that is implicit in each of these areas. Thus for Habermas, "rationality" becomes more broadly defined as being open to criticism and defensible with reasons.

The rationality of all three of these types of actions are based in the end upon reasons for their validity. Validity claims are internally connected with reasons and grounds, found in the meaning of the speech act itself, and not connected to any additional sanctions. This validation involves giving reasons for the normative justification of this claim. If a hearer does not take the utterance of a speaker as immediately justified, the hearer is able to ask the speaker to validate her claims. Then, discussion ensues concerning the facts, norms, or beliefs that led to the utterance, until both parties come to an agreement on their validity. This process of coming to an understanding, and re-establishing a consensus about the interpretation of the world that was broken by doubting a statement's validity plays a fundamental role in continuing the lifeworld of the subjects. This process, of giving and responding to reasons for an utterance, Habermas refers to as "argument." Rationality is therefore firmly tied to the idea of validity, and depends upon this linguistic give and take of reasons to support its claim to the title 'rational.'

The lifeworld also refers to one of many "layers" of knowledge. This layer functions strictly in the background and is absolutely needed by any subject who acts communicatively. ${ }^{18}$ All cultural renditions of a lifeworld must be complex enough to

18 Ibid., 337. 
allow actors to relate to concepts in the objective, social, and subjective realms of human action if these actors are to be able to behave rationally. With every utterance, any speaker must be taking up reference to one of these three worlds and orienting her actions towards it. These are more closely understood as one of three "actor-world" relations:

(i) The objective world represents the totality of all entities about which true statements are possible. Action towards the objective world presupposes relations between an actor and a world of existing states of affairs. Action here gives the agent the ability to form beliefs about the existence of the world through her perception of it, and further develop intentions to bring about desired states of affairs by choosing promising means. ${ }^{19}$ In the objective world a decision is made among courses of possible action, toward an end, guided by maxims, and based on an interpretation of the situation. Consideration for this world is often the base of utility and game-theories in sociology, economics, social psychology.

(ii) The social world represents the totality of all legitimately regulated interpersonal relations. Action within this world is normatively regulated by "something recognized as obligatory in the social world supposedly shared by all the members of a collective." 20 All actors for whom the corresponding norm shares the same force belong to the same social world. Members can then expect one another, in corresponding situations, to orient their action to the values held by each of them. Because an actor is able to take up relations to this world, existing norms motivate to the degree to which all present value the norm, and to the degree to which different needs are interpreted through the socializing process. Normatively regulated action is

\footnotetext{
${ }^{19}$ Ibid., 87.

${ }^{20}$ Habermas, Theory of Communicative Action, vol. 2, 120.
} 
behavior of members of a social group who orient their action to common values, not about solitary actors who encounter other actors in their environment. In the social realm, actors comply with a norm, thus fulfilling a generalized expectation of behavior. This action is not a cognitively predicted behavior, but rather accounts for the normative sense that others are entitled to expect a behavior. Consideration for this world is often the base of theories in the study of sociology.

(iii) The subjective world represents the totality of the experiences of the speaker to which he has privileged access. ${ }^{21}$ Here an actor engages in dramaturgical action, presenting a view of himself toward his own subjective world. In this world, desires and feelings are primary motivations. Desires are oriented towards need satisfaction, while feelings "perceive" situations in the light of possible need satisfaction. ${ }^{22}$ Actors orienting their actions towards the subjective realm purposefully disclose their subjectivity, and are centrally concerned with a presentation of self. Consideration for this world is often the base of theories in the study of phenomenology.

Each of these areas of action relies to some degree upon a linguistic medium to carry actor-world relations. In the objective world, language is one of several media through which speakers attempt to influence others or the world. In the social world, language is presupposed as the medium which transmits values and consensus. For the subjective world, language is the medium of self-representation. Habermas's critique of empirical analytical science and its reliance upon purposive-rational activity has not rejected its foundations. Instead, he finds the realm of understanding available to empiricism inadequate for investigating the complexity of human social life, and argues for the creation of a science that is able to account for the full range of human activities.

\footnotetext{
${ }^{21}$ Habermas, Theory of Communicative Action, vol. 1, 100.

${ }^{22}$ Ibid., 91-92.
} 
This science will focus on the foundation of this complexity, human abilities to communicate linguistically with both a community and themselves. For Habermas,

"The phenomena in need of explication are no longer, in and of themselves, the knowledge and mastery of an objective nature, but the intersubjectivity of possible understanding and agreement-at both the interpersonal and intrapsychic levels. The focus of investigation thereby shifts from cognitiveinstrumental rationality to communicative rationality. And what is paradigmatic for the latter is not the relation of a solitary subject to something in the objective world that can be represented and manipulated, but the intersubjective relation that speaking and acting subjects take up when they come to an understanding with one another about something. In doing so, communicative actors move in the medium of a natural language, draw upon culturally transmitted interpretations, and relate simultaneously to something in the one objective world, something in their common social world, and something in each's own subjective world."23

\section{Leaving Descartes}

The three realms of action also play a role in Habermas's understanding of the evolution of human social life. For Habermas, a correct understanding of the development of society is as important as a full understanding of rationality. In developing his theory of communicative action, Habermas argues that contemporary society must be viewed as the product of a historical evolution, and traces the increasing complexity of human interaction from tribal organization, through traditional society, to the organization of modern society today. This transition in social organization is understood as having accompanied a shift in the norms that govern action, from those based only in traditions to norms that can be rationally justified.

One of the figures central to Habermas's concern for social evolution is Max Weber and his theories of social rationalization and secularization. The great influence that Weber has had on more recent philosophy and sociology is not lost on Habermas, and

\footnotetext{
${ }^{23}$ Ibid., 92.
} 
accordingly he makes a great effort to explain Weber's theories and expose their weaknesses. Most importantly, Habermas seeks to prove wrong the conclusions reached by Weber in his interpretation of Western civilization's historical evolution. ${ }^{24}$ Weber theorized that the development of human societies was represented in the diffusion of purposive-rational action into social spheres previously governed by religion or tradition, focusing particularly on the rationalization of the economy and the state. History has thus brought a general loss of meaning and freedom to human life through the de-mystification of traditions which once guided much of human interaction. Habermas argues that this theory is incomplete, as it does not account for, nor even consider, the concurrent rationalization of the lifeworld that has occurred, particularly the additional rationalization of the means to reaching a shared understanding about that lifeworld. ${ }^{25}$

Habermas intends to prove that the loss of meaning that Weber envisioned for human life is neither unavoidable nor a true account of social existence. In order to do this, Habermas attacks the conception of rationality central to Weber's thinking. For Weber, it was the strategic-purposive rationality, especially apparent in capitalism's rise in legitimacy to replace tradition and religious social ordering, that is responsible for the loss of meaning. It is this conceptualization of reason in purely subject-object terms that is the fatal flaw in Weber's prognosis. Weber, and all who like him consider human rationality in only instrumental terms are wrong. ${ }^{26}$ Habermas argues that because Weber could only conceive of rationality in terms of subject-object relations he was

${ }^{24}$ David Rasmussen, Reading Habermas (Cambridge: Basil Blackwell, 1990), 24.

${ }^{25}$ Habermas, Theory of Communicative Action, vol. 1, 339-340.

${ }^{26}$ Other classic theories which fall, arguably, with this argument include Hobbesian selfinterest, Hegelian recognition, and Marx's concept of labor. See Rasmussen, Reading Habermas, 25. 
unable to ground rationality in anything other than these relations. For Habermas, this exposes traditional rationality as merely an ideology. In order to ground rationality in something other than itself, and to be able to account for the full richness of human social life, this strict adherence to subject-object rationality must be rejected.

Habermas's theories can be read as an argument against not only this tradition of purposive-rational dominance, but against all post-Cartesian philosophy of the subject, or philosophy of consciousness, which was left with the concept of a completely isolated subject whose relationship to the world can only be understood instrumentally, and cannot be intersubjectively established. 27 One cannot fully conceive of oneself, or truly be self-consciousness, if there are only subject-object relations. One must use a more pragmatic approach to conceptualize the performative, and not only the referential, use of the expression "I" that allows a self-consciousness. Traditionally, only the referential aspects of the expression "I" were acknowledged, which neglected the performative "I's" aspects. It is this performative "I," the "I" as different than and distinct from others, that promises to save philosophy. ${ }^{28}$

\section{THE LIFEWORLD}

\section{Habermas's use of Action Theory}

An important foundation for much of Habermas's thinking is the use that he makes of action theory. The theory of communicative action is tightly linked to an action theory in order to show how our basic moral intuitions are grounded in something

\footnotetext{
${ }^{27}$ Rasmussen, Reading Habermas, 26.

${ }^{28}$ Habermas, Theory of Communicative Action, vol. 1, 397.
} 
deeper and more universal than our particular traditions. ${ }^{29}$ In this case, Habermas is linking our "basic moral intuitions" to a fundamental characteristic of human beings, our ability to communicate. Habermas uses the term "action" to refer to the symbolic expressions with which a human actor assumes a relation to an aspect of the intersubjective lifeworld. ${ }^{30}$ In this realm, knowledge is guided by a knowledgeconstitutive "practical" interest, an interest that has as its aim not the technical control and manipulation of the environment, but the understanding of conditions for communication and intersubjectivity. ${ }^{31}$ Members of the human species become individuals through and within social networks that provide them with a basic orientation towards the world. In this shared world, individual identities are formed and maintained. Thus, both the integrity of the individual and the welfare of the community, equality and solidarity, are accounted for in communicative action. All of these actions are fundamentally oriented to the human act of linguistic communication, upon which all of these events depend. To understand communicative action, an actor becomes involved in the presupposition of a linguistic medium which reflects the actor's relation to the world.

Habermas argues that there are two forms of action: the strategic and the communicative. Strategic action is oriented towards achieving success in the world. In strategic actions actor A seeks to influence the behavior of B through the use of threats,

${ }^{29}$ Thomas McCarthy, "Kantian Constructivism and Reconstructivism: Rawls and Habermas in Dialogue," Ethics 105 (October 1994): 47.

${ }^{30}$ Habermas, Theory of Communicative Action, vol. 1, 96.

${ }^{31}$ Habermas clarifies his definition of "action" by emphasizing that "action" does not specifically refer to bodily movements or physical operations which are performed as a part of an "action" and includes meaning only secondarily, through being embedded in another action. In other words, "A bodily movement is an element of an action but not an action." Consider, for example, the bodily motions involved in playing or teaching. See Theory of Communicative Action, vol. 1, 96-97. 
sanctions, or rewards in order to cause the interaction to proceed as A intends. On the other hand, action oriented towards reaching an understanding is called communicative, and is non-instrumental. In communicative action, speaker A seeks to rationally motivate hearer B by referring to the binding effect in the implicit guarantee by speaker A that she will, if necessary, make efforts to validate her claims made in communicating. ${ }^{32}$ This communicative action remains "rational" in the sense that a communicatively achieved agreement has a basis upon which all agree. It cannot be forced upon or forced by either party. ${ }^{33}$ Habermas's claim that these communicative forms of language are primary to strategic types is both fundamental to his theory, and controversial. ${ }^{34}$

In a communicative model of action, language is relevant via the pragmatic use actors make of it in their orientation to reaching understanding amongst themselves. Reaching an understanding functions as a mechanism for the coordination of actions. A basic coordination of actions is essential for actors who share the same social context, allowing actors to base their actions on the expected reactions of others. Without this coordination, no actor would be able to predict the responses of other actors to even the simplest of social actions. Action coordinating is achieved through coming to an intersubjective agreement about the validity of their utterances amongst themselves. The theory of communicative action presupposes language as the medium for reaching

32 Jürgen Habermas, Moral Consciousness and Communicative Action, trans. by Christian Lenhart and Shierry Weber Nicholson (Cambridge Mass.: MIT Press, 1990; original German edition printed by Suhrkamp Verlag, 1983), 58.

${ }^{33}$ Habermas, Theory of Communicative Action, vol. 1, 287.

${ }^{34}$ Habermas, Theory of Communicative Action, vol. 1, 397; and Rasmussen, Reading Habermas, 27-28. 
this kind of understanding, in the course of which actors, through relating to the world, reciprocally raise validity claims amongst each other that can be accepted or rejected. ${ }^{35}$

Every process in which action oriented towards reaching an understanding occurs takes place against the background of this pre-understanding founded within a cultural context, their lifeworld. When one of these background norms of action is brought to the fore by participants in order to contest it, the rest of this background remains firm. There is no way that actors can simultaneously argue over all parts of their communicative background. This is because in order to understand an utterance, the interpreter must have a background familiarity with the conditions surrounding its validity. One must know what conditions do or would make the validity claim connected to the assertion acceptable. The only context from which the interpreter could gain this knowledge is from having participated in the communication community around her. She can understand the meaning of a communicative act only because it is embedded in contexts of action oriented to reaching understanding. The interpreter has learned through socialization within that particular culture which conditions validate a symbolic expression and which do not.

This validity can be claimed in relation towards one of the three aspects of the lifeworld to which humans orient themselves. Again, these are the objective, the social, and the subjective aspects of the lifeworld. With each utterance, a speaker is making a claim that her statement is valid in relation to one of these realms. Each speaker, who has oriented her actions toward reaching an understanding with the other actors involved, with each utterance, claims validity in terms of one or more of the following:

(i) Truth. That the statement made is true relative to the existential world.

${ }^{35}$ Habermas, Theory of Communicative Action, vol. 1, 99. 
(ii) Rightness. That the speech act is right with respect to the normative context of interaction. (Or that the norm expressed is legitimate.)

(iii) Sincerity. That the manifest intention of the speaker is meant as it is expressed. ${ }^{36}$

To each of these claims made by the speaker, a communicatively competent hearer is able to accept or reject the claim, responding with a yes or no. As long as this process continues, and as long as claims to validity are accepted, the lifeworld remains unified and unproblematic. Eventually, however, a claim will not be redeemed as valid, and a process of establishing which actor is correct, the norm proposer, or the rejecter, will ensue. This process is one of serious discourse, and will be elaborated in the final section.

\section{Autonomy Through Socialization}

As one progresses into Habermas's theory it is important to understand the emphasis the theory of a communicative ethic places on the role of the universal and the contextual. Habermas often reiterates the importance of the individual's social context for developing any ideas of individuality or solidarity. He feels that many previous moral theories have overemphasized the universal, and are thus unable to account for the specific individuals that make up the real world. On the other hand, strictly concrete and contextualized theories are not able to offer any conception of morality, which depends on a non-specific point of view.

Habermas explains how methods typically used to identify the individual are flawed, and lead to the individual being suppressed by the universal. For example, many

${ }^{36}$ Ibid., 99. 
theories are able to identify individuals numerically. ${ }^{37}$ Here, the individual is considered as a private concept, and is defined as a deviation away from the universal features of the social context. On the other hand, some theories attempt to account for individuality qualitatively. Here, the differentiation of social roles is used as a means to increase individualization. In other words, the greater the number of social roles that are available for an individual to choose from, the more unique each person's combination of roles can be. In both of these cases however, the universal characterization overshadows any uniqueness. If each is uniquely individual, there is no comparison to allow differentiation. Qualitative methods also seem flawed as there is no reason to believe that having an increasing number of social roles to choose from increases autonomy. Habermas criticizes these theories that identify the individual "ironically as the nonidentical." 38

Habermas argues instead for a concept of individualization that allows us to understand autonomy, and the capacity to be one's self. It should allow us to distinguish between two phenomena: (i) social differentiation, and (ii) progressive individualization. We can arrive at this type of an understanding by revisiting Cartesian dualism. This subject-object model of consciousness is sufficient only for understanding the ego as knowing consciousness as an object, i.e. the conscience is conceived of as an "it." In contrast, Habermas uses a view of the "practical self" to demonstrate his understanding of individualization. He begins the explanation of this self with the writings of Mead. Mead retains the dualistic ideal of a self-reflecting upon itself as an object. In this rendering, however, the object is not found from the third-

37 Jürgen Habermas, Postmetaphysical Thinking: Philosophical Essays, trans. William Mark Hohengarten (Cambridge MA: The MIT Press, 1992; original German edition published by Suhrkamp Verlag, 1988), xii.

${ }^{38}$ Habermas, Postmetaphysical Thinking, 157. 
person perspective, but rather from a second-person perspective as a participant in a communicative context: where the other is an alter-ego. The self then conceives of itself as the "alter" of this alter-ego. Mead explains this as when an organism first takes up a relationship to itself, and is thus first constituted as a subject, in the moment when communicative relations are established between organisms. Subjectivity and intersubjectivity are thus coeval.

This new self-understanding is constituted of two parts:

(i) the theoretical "me," or I which is a person's consciousness of her "self"; and

(ii) the practical "me," (alter) which is the agency through which she monitors her behavior.

For Habermas's theory of individualization, it is the practical me that is of interest here. This "me" (alter) comes into existence as the subject establishes a practical relation to herself by adopting a normative attitude of an alter ego toward her own behavior (which is the "I"). In later development this me (alter) expands to encompass the generalized expectations of all members of society, thus becoming the attitude of the generalized other. Thus a self identity which is constituted solely in this "practical me" would be totally conventional in character (reflecting only the generalized norms of society). For Habermas, the "I" of presocial impulses does battle with the "me" of convention, constrained by social norms.

This points to a critical potential embedded in this understanding of the self's development. The suppression of the "I" indicates that the identity of the individual is not a true one, and remains to be emancipated from this internal suppression. The releasing of this "I" is a precondition for the emergence of a post-conventional self capable of moral reasoning. At the conventional (strictly norm-governed and not yet individualized) stage of reasoning the "I" is suppressed by the "me." In the development to a postconventional level of reasoning, the priority of the I and me will 
become reversed, the I will project a new intersubjective context, that of a wider, universal community. It is the self's relation to a universal community which will make the achievement of true self-knowledge possible. To realize one's true identity the self cannot remove itself from this community. Instead, in order to develop to the postconventional level of moral consciousness, it is necessary that the individual take up a critical attitude to the merely given norms of the particular community

Individualization then, is not equal to social differentiation, nor to an increasing number of social roles. Habermas does, however, see the increase in societal differentiation as necessary. This process leads to the disintegration of conventional reasoning via a breakdown of the conventional individual's ability to reconcile the new, large number of social roles. This breakdown becomes emancipatory, allowing the individual to escape from the traditional confines and norms of her community, though in the process losing herself (her meaning). It then becomes possible for the self to project the regenerated, universal community with which she can reason, thus finding a true self-identity and a moral ideal.

To show why this does not again triumph the universal over the individual, Habermas argues that a balance is struck between the "moral self-determination" and the "ethical self-realization." First, moral self-determination transcends the specific context to a universal normative consensus. But this does not imply the leveling of differences. It implies the abstraction of universalized norms, which become more compatible with concrete diversity, and more tolerant of different, tolerant, forms of life. Second, through ethical self-realization actors appeal to the projected universal community, not for agreement, but for recognition of her claim to authenticity. When making any claim, I also claim my individuality. Even rejection of these claims is confirmation of "me," of the self's claim to identity. Hence, communication between 
individuals does not clean away differences between individuals, it confirms, and is necessary for that difference.

\section{Communicative Action}

We have seen how human actions regulated by norms, expressive self-presentations and evaluative expressions, combine with speech acts to form a communicative community. This practice, which must be conceived of in its entirety, forms the lifeworld for acting human subjects, and provides the foundation for all of their actions and orientations to the world. Operating within their lifeworld, actors use this communicative community of criticizable validity claims to achieve, sustain, and renew their identities and individuality as well as a consensus about their interpretation of the world. An important premise of this theory is that language, as communicative discourse, is both emancipatory in the ways we have seen, and even more fundamentally, has a priority over other forms of linguistic usage in certain forms. Habermas has made this claim based upon the nature of discourse rather than from any particular reading of political theory. This claim rests upon the scientific/empirical assertion about the nature of language (i.e., its acting as a foundation for all social interaction), thus freeing the theory from any claim of epistemology. ${ }^{39}$ Habermas is not arguing that communicative forms of language ought to be primary, but arguing that they are primary. "Reason does not need to be regenerated, it is by nature regenerative in the sense that reason as communicative reason is embedded in language."40 This stems from language's original use as an instrument oriented to reaching understanding,

\footnotetext{
${ }^{39}$ Rasmussen, Reading Habermas, 18.

${ }^{40}$ Rasmussen, Reading Habermas, 28; See Habermas, Theory of Communicative Action, vol. 1, 288-292.
} 
rather than oriented to achieving success. Communicative actions are foundational, and can not be reduced further to teleological terms.

Embedded within the practice of coming to a consensus about the lifeworld, there is a fundamental practice that can be seen as "rational." This understanding of rationality is not strictly tied to tests of truth or efficacy about means to a desired end. Instead, a richer understanding of rationality extends to include actions that are meaningful, and can be supported by reasons. Thus, we must be clear about the role of reasons in communicative action. We say that in each speech act an actor makes a claim to validity in one of the three realms of action: objective, social, or subjective, and must be prepared to support that claim with reasons if called upon to do so. An individual "only understands reasons to the extent that one can understand why they are or are not sound." This knowledge comes to a hearer by applying his "own standards of judgment," or "standards that he has made his own." 41 These reasons are responded to with either a yes or a no, which indicates the hearer's acceptance or denial of the validity of the reason. Since all rational actions must be able to be criticized, all rational actions are supported with claims to validity.

The subjects of a communicative community are able to operate normally, in everyday communication, as long as the consensus of norms is continued. This is the case when speaker A makes an assertion $x$, to which a hearer $\mathrm{B}$ responds by rejecting the validity of $x$ with criticism $y$. In support of her assertion $x$, A then offers a reason $z$ in support of her assertion. To this reason, B applies his powers of judgment and responds with a "yes" or "no" to that reason. If the reason is accepted, consensus is reestablished and communication continues as usual. If however, B rejects the validity of reason $z$ in support of assertion $x$, then the communicative consensus has broken down

\footnotetext{
${ }^{41}$ Habermas, Theory of Communicative Action, vol. 1, 116.
} 
and must be repaired. For this repair an argument must ensue between $\mathrm{A}$ and $\mathrm{B}$, an argument free from force, and based only on the rational acceptance of reasons to rebuild consensus, ensuring the further, proper functioning of the lifeworld. For this reason, Habermas believes, "that the concept of communicative rationality, which refers to an unclarified systematic interconnection of universal validity claims, can be adequately explicated only in terms of a theory of argumentation." 42 Argumentation, then, must be further explored. This theory next turns from normal, everyday communicative action that occurs between individuals in a lifeworld, to seek an understanding of the discourse that emerges between individuals when a breakdown in this shared world occurs. This type of serious discourse is the argumentation that will repair breakdowns in the lifeworld. Habermas's understanding of the rules of these arguments will be explored in the next section, the theory of Discourse Ethics.

\section{THE UNIVERSAL}

Before beginning this section, a possible misunderstanding within Habermas's theory of discourse ethics should be clarified. In this section, an argument will continue to be built upon the idea of a community based upon an intersubjectively shared preunderstanding of the world, communicating with itself about the regulation of social actions. Linguistic communication between individuals leads to the grounding of universal principles. These universal principles are the only principles that Habermas intends to refer to as "morals." Guides to social action that are context and group specific, and not universally valid, are to be called "ethics." Habermas is not centrally concerned with grounding, explaining, or justifying these ethical principles. He is

\footnotetext{
${ }^{42}$ Ibid., 18.
} 
concerned with and focused upon the grounding and foundation of morals, morals which posses validity across contextual situations, and are understood as universal. Thus his theory would be better labeled "Discourse Morality," or a "Discourse Theory of Morality." The title "Discourse Ethics," however, has been affixed to his theory, and thus he, as well as all other authors, continue with the original wording. ${ }^{43}$ Thus, in what follows, the ethical is what relates to the contextual and the moral refers to the universal, except references to "discourse ethics," which is intended to be universal.

In his theory of discourse ethics, Habermas has set out to champion the project of modernity against anti-enlightenment critiques, taking direct aim at claims that "the Enlightenment's project of establishing a secularized morality free of metaphysical and religious assumptions has failed." 44 By rejecting these claims, he also attempts to unravel the paradox of modernity. Habermas hopes to understand, in less dire terms, the loss of meaning that has accompanied modernity's turn away from the tradition and religion that once ordered so much of human interaction. In order to support these arguments he developed two complementary theses, one of society based on the rationalization of institutions and interaction, and another of rationality grounded in linguistic communication. It is through these two theses that Habermas finds an understanding of rationality that allows insight into the moral.

Using the Kantian tradition as a point of departure, his theory of discourse ethics seeks to defend the primacy of justice over the good. Habermas argues that we must separate questions of ethics, which give us information about the pursuit of certain ends given our preferences, from questions of morality proper which provide us with insight

${ }^{43}$ McCarthy, "Kantian Constructivism and Reconstructivism," note 7; and Jürgen Habermas, Justification and Application, trans. Ciaran P. Cronin (Cambridge MA: The MIT Press, 1993; Original German edition published by Suhrkamp Verlag, 1990 and 1991), 2.

${ }^{44}$ Habermas, Moral Consciousness and Communicative Action, 43. 
about justice and a fair and impartial consideration of competing claims. He seeks to provide an understanding of morality that is universally valid, and not dependent on ethical concerns for the good life. Habermas, however, departs significantly from Kantian thought by arguing against the role of solitary reflection. With Habermas, both consciousness and thought are seen as structured by language, and as such are social aspects of humanity. The subject, in considering issues of morality, must be seen in the context of communication, where meaning and individual identity are communally determined.

If it has not already been made apparent, it should be made clear now that Habermas's theoretical construction of the moral does not attempt to avoid a serious consideration of modern pluralism. While the diversity of claims to validity in modern times may rule out the idea of philosophy providing a universal answer to the question, "How should I (we) live?" Habermas does not believe that this denies the possibility of a "narrower" sort of theory, specifically, a theory of justice. ${ }^{45}$ Discourse ethics seeks to understand the moral point of view from which questions of right are fairly and impartially judged. This point of view will be characterized by its impartiality amongst claims and acceptability to all concerned with these claims. This will at last arrive at the procedure that Habermas envisions for the community of moral subjects engaged in a dialogue of practical argumentation aimed at reaching a rational agreement between the actors involved in the cultural context in question.

In the exploration of discourse ethics, the consequences a linguistically founded theory of consciousness have for an understanding of human interaction will be seen. After Habermas's understanding of meaning and validity are seen to be based on linguistic agreement, the possibility of universal agreement on certain aspects of action

${ }^{45}$ McCarthy, "Kantian Constructivism and Reconstructivism," 46. 
will be grounded. This will allow an understanding of discourse ethics to show how human beings can be capable of agreeing upon principles to guide our actions in the world, a concept of morality which can be shared across lines of tradition and community.

Understanding the power that normative validity holds in a moral theory of communicative action, Habermas argues that meaning is given to actions by the communicative community, rather than by a solitary thinker. Even the concept of truth, so central to many philosophies of consciousness (as leading to a God-like knowledge of the cosmos), is displaced by what is acknowledged as valid by all in communication. Finally, rationality as well was found in terms of communication rather than a mode or style of solitary thought. The next section shows, in discussing meaning, truth, and rationality, a dependence upon 'what has been accepted by the communicative community,' or what has been accepted as 'valid' by the community. In the final sections we will see how Habermas describes and empowers the idea of validity, and how through this idea he is able to ground his universal moral principle.

\section{Meaning. Truth, and Rationality Through Consensus}

To begin the move towards discourse ethics, Habermas's ideas concerning meaning and truth must be grounded in the idea of a lifeworld, as the foundational background agreement between all subjects in a communicative community. In this community, we must understand how mutual understanding between speakers is possible. ${ }^{46}$ The answer for Habermas stems from an idea of communicative competence, which all capable of speech in a community possess concerning the shared knowledge of the norms of communicative rationality. The most basic of these shared norms is that the

\footnotetext{
${ }^{46}$ Braaten, Habermas's Critical Theory of Society, 19.
} 
use of language to reach an understanding between actors is the original mode of language use. 47 Because there is a fundamental motivation amongst the participants in communication to work for and accept a consensus, this is never a mere "agreement for the sake of agreement." It is a necessary aspect of communicative ability.

Habermas argues that linguistic meaning must be understood in communicative terms. Every utterance depends upon two characteristics of communication for its meaning. First, every utterance implies or states a propositional component $p$ that predicates something of an object. The second, and equally important aspect of an utterance is how this propositional content is put forth. The force of the utterance is given to it by its illocutionary component. This component may or may not be made explicit by a performative clause such as: "I assert...," "I command...." Even without such a stated claim, an utterance may make a promise, a promise to support the statement with reasons. 48 For Habermas, communicative actions are only those in which all participants pursue only illocutionary intentions, which establishes that the speaker is performing some action with her speech, and work to mediate acts of communication. In fact, however, this illocutionary component of the speech act is only one of the three distinct validity claims that each utterance makes. With her utterance, the speaker makes a truth claim relating to the objective world, she claims the rightness of her assertion regarding the social world of normatively regulated interactions, and claims the truthfulness of the statement relating to the subjective world of experiences to which only the speaker has access. The meaning of a statement is thus tied to conditions of its validity.

${ }^{47}$ Habermas, Theory of Communicative Action, vol. 1, 287-288.

${ }^{48}$ Habermas, Theory of Communicative Action, vol. 1, 288; and Theory of Communicative Action vol. 2, 89. 
Further, each of these claims is universal in two senses. First, each of these claims is itself a universal formal feature of linguistic communication. Rational communication is not possible without making one of these claims. Second, each also claims to be universally defensible for its claims to truth, rightness, and sincerity. In other words, a claim to validity points implicitly to a procedure of argument, of the giving and taking of reasons, that could be given in support of the validity claim. ${ }^{49}$ In discourse ethics the idea of the world is no longer understood through a monological consciousness, but rather through interacting subjects who make validity claims amongst themselves. Meaning must be viewed pragmatically in terms of the acceptability conditions of utterances raised to claim validity.

From this conception of meaning, Habermas understands the idea of truth in a language community as a social one. For example, the difference between knowledge and ignorance is not made in order to clarify statements from the perspective of a disembodied ideal observer. ${ }^{50}$ Instead, the difference must be understood from the view of the human community engaged in communication. It is a basic need of this group to achieve and maintain a solidarity based upon mutual and rational agreement about how the world is. An agreement about these ideas for an entity beyond this community would have no purpose for them, would be meaningless, and not sought. ${ }^{51}$ Thus, anyone fully capable of communicating in a community has at least an implicit understanding of what is meant by 'truth.' This is because every speaker is aware that they can be held accountable for presenting a statement as true, that they could be called upon to produce reasons why the utterance ought to be accepted. Truth must be

${ }^{49}$ Habermas, Postmetaphysical Thinking, ix-x.

${ }^{50}$ Braaten, Habermas's Critical Theory of Society, 22.

${ }^{51}$ See Habermas, Theory of Communicative Action, vol. 1, 279-286 on the purpose of validity claims. 
understood as one of many rationally criticizable validity claims. For all actors who communicate in this way, 'truth' is that which can be agreed upon as the rational consensus of all thus engaged.

This illustrates the emphasis that Habermas makes between his pragmatic theory of truth, and other, semantic theories of truth. Truth for Habermas must be tied to its communicative purposes, rather than some form of 'metalanguage' seeking an absolute knowledge. This understanding of truth arises through an understanding of the way "truth" is used in communication. The phrase, "x is true," is used to support the idea of justifiability of a statement in a discussion. It does not supposes some god-like ability to know the state of the cosmos. Thus the concept of truth stems purely from its purpose in maintaining a communicative competence between subjects. 52

If truth is understood as a type of validity claim, we must further clarify what it means to claim that an agreement is rational. Habermas argues that we generally evaluate validity claims not by directly comparing a statement with a state of affairs in the objective world, but by examining the reasons that a speaker can give to support what she has said. As above, to claim that one's statement is valid, is to claim that good reasons could potentially be given in support of it. These reasons are evaluated on their intersubjective acceptability. To be rational, it is important that these arguments be decided through the force of the better argument alone, and not influenced by any power relations between the participants. Habermas describes certain conditions that speakers must feel are met before they are confident that an agreement was reached based on reasons alone. These conditions form a basic structure of argumentative speech that

\footnotetext{
${ }^{52}$ Braaten, Habermas's Critical Theory of Society, 22-23.
} 
creates a general symmetry between participants. Habermas has referred to these conditions as an ideal speech situation..$^{53}$

Originally this ideal speech situation was used as a way to describe the conditions of an argument that would have to be met in order to be able to call the outcome of that argument rational. These conditions were meant to show how the agreement, could, in the end, be based only on reasons and the power of the better argument. The conditions of the ideal speech situation are summarized in three main points:

(i) That the argument is open to all competent communicators. (Potential Participants)

(ii) That everyone is free to question any assertion. (Equal Opportunity)

(iii) That all are free from any internal or external coercion. (Repression Free) Habermas emphasizes that this "ideal" speech situation should not be misunderstood as a condition that must be achieved in actual social life..$^{54}$ The criteria in the ideal speech situation should not be considered as constitutive rules of discourse in the sense in which chess rules are constitutive of a real chess game. While the rules of a chess game "determine the playing of the actual chess game, discourse rules are merely the form in which we present the implicitly adopted and intuitively known pragmatic presuppositions for a special type of speech...." 55 The ideal is to refer to its "regulative functions." It is also emphasized that the participants need only feel that the conditions of this ideal speech situation are met to a sufficient degree. When this is the case, then it is correct to say that the participants were rationally motivated to agree with a speaker, and communicative consensus will again maintain prominence. Habermas argues that

\footnotetext{
${ }^{53}$ See Habermas, Moral Consciousness and Communicative Action, 88; and Theory of Communicative Action, vol. 1:25.

${ }^{54}$ Habermas, Moral Consciousness and Communicative Action, 91-93.

${ }^{55}$ Ibid., 91.
} 
the ideal speech situation is an "inescapable presupposition" of argumentative speech, and should not be interpreted as a simple contextual convention. ${ }^{56}$

\section{The Principle of Universalization}

What concerns Habermas at the outset of grounding a principle of universalization is to show how agreement is at all possible among diverse individuals in a communicative context. Thus, before he seeks to explain how individual norms are to be evaluated by a group to determine their validity, he explains how agreement between diverse actors is even theoretically possible. His principle of universalization (U) will show that agreement is possible in moral argument "whenever matters of concern to all are open to regulation in the equal interest of everyone." 57

To begin, in Habermas's theory of normative acceptance, ethical norms do not claim to be true or false, but rather claim to be valid or invalid. Normative claims are understood as different from, but in some ways analogous to truth claims. Truth claims are descriptive statements which show concern for the external, existing state of affairs. While normative validity claims concern what are intersubjectively recognized as "legitimately ordered interpersonal relations. The truth of a proposition signifies the existence of states of affairs in much the same way as the rightness of actions signifies the observance of norms." 58 In statements about normative validity, we can see reflected a dependence of language upon the social world, one which is not true for instance between language and the objective world. While there is an "unequivocal relation" between existing states of the world and statements about it, the existence of a

\footnotetext{
56 Ibid., 89.

57 Ibid., 66.

58 Ibid., 59-60.
} 
social norm does not guarantee its validity. Therefore, we must distinguish between "the social fact that a norm is intersubjectively recognized and its worthiness to be recognized." 59

For a norm to be deserving of the status 'valid' we must be able to say that there are good reasons for it being so. Obviously then, with the assertion of a claim to validity, there is an implicit guarantee to support it with reasons. Indeed, it is the case that one "ought" to provide these reasons when questioned about how a moral judgment was arrived at. While this is true of normative judgments, the same is not true of statements about a worldly state of affairs. There is no concept of "ought-to-be-justified" tied to judgments about the world. Habermas feels that when questioned about how we make empirical judgments about the world, we present reasons based in epistemologies and the philosophy of science. When, on the other hand, we are asked what makes moral judgment possible, we immediately proceed to describe our ability to adjudicate normative claims, or our "logic of practical discourse." 60

For Habermas, this logic of practical discourse is based upon a fundamental assumption that is shared universally when actors engage in argumentation over normative claims to validity. This means that actors must implicitly accept the rules discussed in the ideal speech situation, as well as implicitly acknowledging the possibility of agreement between actors. Habermas expresses this necessary condition for discursive argumentation as:

(U) All affected can freely accept the consequences and the side effects that the general observance of a controversial norm can be expected to have for the satisfaction of the interests of each individual. 61

\footnotetext{
${ }^{59}$ Ibid., 61.

${ }^{60}$ Ibid., 62.

${ }^{61}$ Ibid., 93.
} 
Habermas explains this as a bridging principle which, as a presupposition of argumentation, makes agreement in practical discourses possible whenever matters of concern to everyone are open to regulation in the equal interest of everyone. The principle of universalization insists that all affected must freely agree that the consequences of a norm satisfy the interests of each individual. Being a moral principle, it is meant to reflect the "general intuition" that true or valid statements are not only valid for the single actor, but for all that may be affected. ${ }^{62}$

Before leaving discussion of the principle of universalization, it is important to clarify its role in communicative action. (U) is a moral principle, and the only moral principle in Habermas's theory. It is not a rule of logical argumentation, nor is it a substantive principle of participation, nor a basic norm. If $(U)$ were conceived of as a rule or a norm which is produced within a cultural tradition, it would itself require justification. This is not the case. (U) is necessary for the process of argumentation to occur and to be resolvable at all. If (U) were not in principle possible (i.e., if no agreement was even conceivable), no actors would enter the discourse. As a presupposition of argument, (U) shows us what it means to have achieved agreement in the moral argument. Every argument, occurring in any context, is based upon the pragmatic presupposition "from whose propositional content the principle of universalization can be derived." 63 The principle of universalization justifies the existence of moral argumentation at all.

\footnotetext{
${ }^{62}$ Habermas, Justification and Application, 52.

${ }^{63}$ Habermas, Moral Consciousness and Communicative Action, 82.
} 


\section{Discourse Ethics}

Leaving the justification for moral argumentation via the principle of universalization (U), we move to consideration of the actual discourse that actors go through in moral argumentation. While nearly all philosophies have expressed an idea of the importance of impartiality in moral judgments, those that rely upon teleological reasoning are not sufficient for determining validity. Teleological reasoning can only provide information about the consequences of situations: (i) where all persons followed the norm or, (ii) if all persons acting in an identical position followed the norm. These perspectives, however, are not able to account for all possible points of view. For example, (i) excludes the consequences of this norm from the viewpoint of different individuals; while (ii) denies the concrete differences among discrete individuals. Habermas, on the other hand, asserts that "true impartiality pertains only to that standpoint from which one can generalize precisely those norms that can count on universal assent because they perceptibly embody an interest common to all affected." 64 This is a reflection of the intuition that valid norms deserve recognition by all concerned. Thus in order to make moral judgments from a truly impartial point of view, each must consider the perspectives of all persons who will be affected by the norms.

Within discourse ethics, Habermas moves from a principle that justifies the practice of moral argumentation (U), to a principle used in application, in deciding which of the contested norms that have been brought to the discourse are in fact worthy of being called ethical norms. This principle of application is what Habermas has called discourse ethics (D), and provides the actual criteria that must be met by a proposed norm to be claimed valid. The idea of an ethics of discourse is reflected in the principle: 
(D) Only those norms can claim to be valid that meet (or could meet) with the approval of all affected in their capacity as participants in a practical discourse. 65

Discourse ethics states the basic idea of a moral theory, but is not a part of the logic of argumentation. This principle presupposes that we can justify the norm we have chosen to consider, but this assumption was justified by the discussion of the principle of universalization. ${ }^{66}$ Individuals, who were shown capable of $(\mathrm{U})$, must engage in an actual discourse to validate a norm. This discourse will be concluded when (D) has been achieved.

The principle of discourse ethics (D), is a guide to a procedure, that procedure of the "discursive redemption of normative claims to validity." 67 This practical discourse is not a method for the production of justified norms, but rather a procedure which will allow the testing of the validity of the norms that have been proposed to the community in discourse to debate over. This shows how this discourse is dependent upon the context of the community to bring contending norms before it to be decided upon. This discourse is also always connected to a concrete point in the lifeworld where there has been a breakdown in consensus. Thus, while the procedure is quite formal (in the Kantian sense) it depends upon and deals exclusively with, concrete norms.

It is within this procedure of discourse that needs of mere individuals will be discarded for needs of the community as a whole. When norms are questioned, the norm is defended with casuistic evidence about the consequences and side effects of

\footnotetext{
65 Ibid., 93.

${ }^{66}$ Ibid., 66.

${ }^{67}$ Ibid., 103.
} 
applying the norm for the fulfillment of accepted needs. 68 This limitation to accepted needs shows that needs are not taken at "face value" but are first interpreted through critical reflection in discourse. For Habermas, an individual's experiences and interests are not satisfactory bases for the validity of a claim. These personal claims are subjected to the criticism and reflection of the community, thus "transcended and made to be intersubjective." 69 In this way, personal experiences (and needs) are brought out of the private and into, and thus part of, the world that the communicative community shares. Interests which are anti-social are found to not be generalizable, because of being based on needs which deny more basic and general interests. ${ }^{70}$ This gives rise to what Habermas refers to as "discursive will formation."

Discursive will formation, which leads to the discovery of genuinely generalizable interests, happens within an interactive process that Habermas refers to as need interpretation. Habermas shows how individuals know that they have needs, and shows how others are convinced that others have these needs. The only needs and interests relevant to ethical norms are those which are universal or generalizable. An ethical norm could only be universally valid if it is based in these, common, universal interests. A norm cannot be universal if only some of the group's interests are represented. What Habermas refers to as generalizable interests belong to a very specific group of interests, interests that are discovered in the context of "general will." For Habermas, these interests are those that we can only find as social beings, and only through a "reflective dialogue." This is what some authors feel is one of the more

${ }^{68}$ Ibid., 65.

${ }^{69}$ Habermas, Moral Consciousness and Communicative Action, 67-68; Braaten, Habermas's Critical Theory of Society, 31-32.

${ }^{70}$ Braaten, Habermas's Critical Theory of Society, 32; Moral Consciousness and Communicative Action, 67. 
important and unique features of Habermas's Discourse Ethics, the way in which he feels that genuine and generalized interests are formed. ${ }^{71}$

It is the process of ideal role taking, and producing a general will that returns to support the "action-coordinating function that normative validity plays" in the lifeworld. Moral arguments are not solved by isolated individuals, but are only solved in cooperation with other actors. It is necessary that in these moral matters the common will of the community be expressed, and not the judgment of a single person. For this reason a "real" argument is needed in which participants are those real individuals concerned with the outcome of the debate. It is only this real argument, consensually solved, that can give participants in the communication community the knowledge that "they have collectively been convinced of something."72

The basic norms that will be represented in contextual law and morality are substantive principles to be justified within practical discourse and fall outside the realm of what moral theory alone can produce. Historical eras change, and each community's lifeworld will generate its own ethical ideals. It is these discourses which give rise to the ethical principles and make use of substantive normative rules of argumentation. ${ }^{73}$ It is these rules alone that a theory of moral argumentation is able to produce. Each specific context produces norms to bring into the arena of discourse where they will be judged valid or rejected.

Finally, Habermas is not arguing that all norms must be shown as universally valid. There are many areas of social interaction that do not depend on universal norms, and yet posses norms for that group. Examples of these are rules of etiquette or tactfulness, the expectations of family members, and the standards found within private, voluntary

72 Habermas, Moral Consciousness and Communicative Action. 67.

${ }^{73}$ Ibid., 86. 
associations. Habermas distinguishes these non-universal norms from the universal by the method with which they achieve validity. These non-ethical norms need only prove valid for a consensus of that group, and no further. ${ }^{74}$ It is important that these generalizable interests be discoverable, as otherwise all the norms validated will only seem valid in the context of that communication community. ${ }^{75}$ Those norms that are specific to a community should be seen as candidates for universal norms, but only for that context until they are put to a test of universalizability. These contextualized norms are where Habermas finds concerns for the "good life." Most of these will be required to stay there, in context, and unacceptable to universalization. ${ }^{76}$

\section{SCIENTIFIC, PRACTICAL, AND CRITICAL}

Habermas has followed the development of human societies from pre-modern groups that relied upon God or fate to settle debatable issues to contemporary civilizations with highly complex methods of dispute resolution. The secularization and rationalization of society that Habermas shows in this process, however, have left us with no way to establish normative rightness or propositional truth except through the medium of rational argumentation. Through this development, "normatively" secured agreements are replaced by agreements that have been communicatively achieved, which are the only agreements considered to be acceptable or legitimate. In other words, as the older sources of legitimacy (God) have lost their authority, social actors have had to increasingly rely upon their own resources. To do so, human beings

${ }^{74}$ Braaten, Habermas's Critical Theory of Society, 33; Habermas, Moral Consciousness and Communicative Action, 104.

${ }^{75}$ Habermas, Moral Consciousness and Communicative Action, 104.

${ }^{76}$ Braaten, Habermas's Critical Theory of Society, 35. 
have reached agreements based upon rational argumentation, and they have expanded these arguments into ever more spheres of experience, even those once considered beyond debate.

This intersubjective discourse is, for Habermas, emancipitory. This occurs not only because agreements are communicatively achieved, and thus "free" (because humans are forced to take ever more responsibility for their actions and utterances), there is also a logic of equality that Habermas finds, unavoidably, within the rational argumentation. Actors have had to assume that the conditions for an unlimited and unconstrained discourse have been achieved and that all participants are sufficiently free from internal and external constraints, and thus the agreement has been decided based only upon the force of the better argument. It is assumed that each has an equal opportunity to express their views, and each has assumed responsibility for their claims to validity. It is from this "idealized" relationship between actors in argumentation that we derive the notion of the universalization of normative validity claims, and the ideas of freedom and equality.

Habermas's exploration of the human capacity for technical knowledge of the objective world found this knowledge insufficient to explain fully the realm of human actions he identified. This capacity was supplemented with a practical knowledge of the social world shared by human beings, in order to describe our ability to mutually understand one another. In addition, in order to understand how human beings relate to their own inner, subjective worlds, Habermas argues that it is necessary to allow for a critical realm of knowledge as well. Only with these three separate, but complimentary, sets of knowledge does Habermas feel it is possible to fully represent the way humans act in the world, interact with other individuals, and also remain distinct in their own views of themselves. Having then seen the manner in which Habermas incorporates his idea of technical, practical, and critical knowledge into the objective, social, and subjective realms of action, the next chapter will integrate these ideas with the 
epistemological demands made from the empirical, standpoint, and postmodern schools of feminist thought. 


\section{CHAPTER IV:}

\section{TOWARD A \\ COMMUNICATIVELY STRUCTURED FEMINISM}

This thesis first examined the rifts that exist between differing schools of thought in feminist political and social theory concerning their conception of scientific knowledge, the role of social existence within science, and the ability of science to produce knowledge which is universally legitimate. This review has shown feminist concern for these ideas split into three distinct schools of thought; those empirically oriented, the standpoint feminists, and the postmodernists. Second, this thesis turned to examine the way that Jürgen Habermas has dealt with these same issues in his theory of communicative action and discourse ethics. From the outset of the examination of Habermas's theories, we were introduced to his belief that human knowledge is possible in three realms, the technical, the practical, and the critical. The present chapter now moves to demonstrate the ways in which a communicatively structured understanding of science, as found in Habermas's works, can resolve many of the differences that exist between the themes of feminist theories examined in chapter two of this thesis. The challenge here will be to demonstrate how the many claims for an acceptable theory of feminist epistemology, made by the three schools of feminist thought, can be shown to exist within Habermas's three interwoven realms of human action: the objective, the social, and the subjective. Aspects of each school of feminism will be shown to be compatible with a communicative ethic, and where some specific claims of a school 
may be unacceptable, it will be shown that the fundamental concerns of those theorists are compatible with a communicatively structured feminism.

In order to accomplish this, it must be shown that communicative action is able to account for the variety of demands made by feminist theory. First, in order to avoid losing the benefits of analytic science, a proper role should be established for the claims of empirical feminism. Their task of "objectively" explaining and describing the world as it exists around us remains both useful and necessary for feminist theory. How communicative action accounts for objectivity will need to be shown useful for describing the world. A feminist theory that seeks knowledge of the world, and a trustworthy description of changes to be proposed and accomplished will continue to rely on many aspects of empirical theory. Further, in a world of concrete individuals it is important to account for the lives of actual people and to identify concrete changes and improvements in their lives. Second, the claims made by the standpoint theorists, to account for the embodiedness and contextual embeddedness of human beings, must also be accounted for. Specifically, a science will need to account for the role that women play in their relations with others, not accounting for them as further atomistic individuals, which standpoint theory claims has been detrimental for women in the many male-oriented theories of the past. Again, communicative action will need to prove that it is capable of accounting for these demands. These claims, however, must be tempered by the needs of postmodern theory in order to determine the degree to which this new theory will allow an individual to exist as an individual, guaranteeing one not be assigned a particular way of being. This idea is fundamental to any feminist movement which seeks to separate the lives of women from the roles that have long been assigned to them in social life. But, as has been shown, feminists are also wary of too much individualism, and argue against falling into the abstractness that arguably accompanies a postmodern emphasis on the individual's distance from other beings. A 
balance must be found between these competing and seemingly mutually exclusive claims, a balance that communicative action will be able to provide.

To respond to these claims, it will be necessary to examine many of the bases of communicative action, including its handling of empirical science, the role of the lifeworld, and Habermas's understanding of an individual's autonomy. The role which communicative action allows for technical knowledge, empirical claims about the world, will be shown as incorporating the claims of empirical feminists, while providing a way of moving past the limits of empirical knowledge as demanded by standpoint and postmodern theorists. Social knowledge, accounted for in an understanding of the lifeworld, must be shown to meet the demands of embodiment and contextuality argued for by standpoint theory. It will also be seen to account for standpoint claims of politically oriented knowledge, focused upon participation, rather than a neutrality toward the status quo. Finally, it will be shown how communicative ethics also takes seriously the demands of postmodernism, considering an individual's unique identity, and one's ability to be free of a pre-determined way of being.

It is also appropriate to ask, with Sandra Harding, "Why do feminists need an epistemology at all?"1 Postmodernists have vehemently argued that there has already been too much "policing of thought" and that epistemology tends to rationalize the beliefs of the powerful and eventually legitimize exploitation. Why do feminists need to reproduce this cycle? For Harding, and many other feminists, the answer is three-fold. First, feminism needs a defense against and an alternative to objectivism, which insists on a value-free, disinterested defense of the status quo. Equally, feminism needs a defense against and alternative to relativism, which cannot provide a basis for judging between justice and injustice in social life. Finally, feminism relies upon an

\footnotetext{
${ }^{1}$ Sandra Harding, "Feminism, Science, and the Anti-Enlightenment Critiques," 87-90.
} 
epistemology to end male domination. A feminist epistemology could help expose and demystify understandings of male and female social relations, energizing both to work for the emancipation of women in all social contexts.

Further, inquiry into feminism's need for an epistemology may also seem to imply that the needs and values of feminism are theoretically prior to a more strictly philosophical account of epistemology. This is countered, however, by feminists who argue that it has usually been the case that philosophical inquiry is preceded by social or political agendas, pointing to evidence of the traditional agenda to exclude women from serious philosophical investigation. ${ }^{2}$ Miranda Fricker, in agreeing with this account of a gender-biased tradition, points out that as a part of Western philosophy, feminism is not unique in bringing a political agenda to epistemology, but is rather simply making this agenda explicit in its investigations. ${ }^{3}$ The implications which this will have are not yet fully apparent, but, she argues, it is clear that the project must be two-fold, both deconstructive and reconstructive, something must be built back, where the old has been torn down.

\section{EMPIRICAL KNOWLEDGE}

The goal of empirical feminism, to produce accurate, objective descriptions of the world based on the sensory experiences of individuals, is also the aim that Habermas attributes to the human capacity for technical knowledge. As has been explored, feminist empiricism accepts the tenets of philosophical realism, assuming the existence of the world independent of human "knowers." Empirical feminism argues that sexism

\footnotetext{
2See Genevieve Lloyd, The Man of Reason: 'Male' and 'Female' in Western Philosophy (London: Methuen, 1984).

${ }^{3}$ Fricker, "Knowledge as Construct," 95.
} 
and androcentrism are identifiable biases of individual actors which can be removed by a more strict application of the existing norms of empirical science. The absence of any bias in science is to be equated with the achievement of objective knowledge, which is understood as providing an unmediated truth about the world, "it frees substantive knowledge about reality from the distorting lenses of particular observers." 4 We have seen, however, that many feminists refuse to accept this understanding of science, claiming that it has led to the exclusion of women and a continuation of their oppression. The strong thesis of these anti-empiricism feminists, however, calling for a rejection of all that is identified with this type of science, also leaves feminist theory in a weak position, without a regulating ideal of truth or value and without a trustworthy description of the world. Thus, some feminist writers have sought to re-work a type of empiricism that will provide the desired functions while furthering the project of emancipating women from their subordinate position in society.

Habermas has written about empirical science as well, concerning its proper role and the need to supplement it with a more complex understanding of human capacities for knowledge. In the theory of communicative action, and more clearly in later writings, he argues for the necessity of empirical science, as well as its incompleteness. The need for an empirical knowledge is strong in Habermas's writing, for he remains as much a sociologist as a philosopher, and throughout his works, he has attempted to remain free from a purely transcendental foundation for his theory, which he considers too abstract to be fully convincing. ${ }^{5}$ Habermas's intent, in his theory of communicative ethics, is to build an empirical theory "with strong universalistic claims." He argues that this is possible because his theory is as much based in empirical claims about the role and

\footnotetext{
${ }^{4}$ Mary Hawkesworth, "Knowers, Knowing, Known," 329.

${ }^{5}$ Rasmussen, Reading Habermas, 94.
} 
nature of language in human social life as it is about the emancipatory potential that exists within this language use. He follows closely the works of science based on empirical methods of Durkheim, Mead, Weber, and Piaget, as each incorporates a philosophical idea into the context of his empirical research. To achieve a full understanding of the lifeworld that human beings exist within requires knowledge of the "whole spectrum" of human knowledge, not only the "fruits of science and technology." 6 Thus, in comparing the demands of feminist empiricism to the role of empiricism that Habermas argues for, it will be shown that a rejection of empirical science is not appropriate and instead, an acknowledgment is needed that a greater range of knowledge is possible and can be pursued in philosophical and social inquiry.

\section{'Realist' Knowledge}

In developing her idea of an acceptable feminist epistemology, Fricker argues for the importance of a feminism to be able to account for a "mind-independent reality placing normative constraints upon what we may correctly believe about the world."7 She asks, "What would it mean...to be committed to the eradication of poverty, or of violence against women, without a realist commitment to the empirical proposition that...whole communities are periodically wiped out by famine, or that many women suffer domestic violence and other forms of attack by men?"8 Any realist account must be backed by empirical claims, in order for them to be listed as reasons for political beliefs or action. Feminism must be allied with an epistemology that allows us to appeal to states of affairs as rational constraints upon political thought. In her account of

\footnotetext{
${ }^{6}$ Habermas, Moral Consciousness and Communicative Action, 18.

${ }^{7}$ Fricker, "Knowledge as Construct," 98-99.

${ }^{8}$ Ibid., 99.
} 
feminism, a realist view of knowledge is necessary for empirical beliefs to count as normative constraints upon our beliefs and actions.

Habermas accounts for the traditional understanding of subject-object relations in two ways. First, in his conception of rationality, he provides a "realist" account such that a rational actor engages in activities that are "goal-directed, feedback-controlled interventions in the world of existing states of affairs." 9 Further, communicative action accounts for empirical claims in its conception of action. For Habermas there are two fundamental types of action, that oriented toward success, and action oriented toward reaching an understanding. While, as explained above, he holds that action oriented toward understanding is prior to action for success, action towards success is still necessary and is further separated into social and nonsocial components. Nonsocial action oriented toward success Habermas refers to as "instrumental action," social action oriented toward success is "strategic action." Action oriented to success is "instrumental when we consider it under the aspect of following technical rules of action and assess the efficiency of an intervention into a complex of circumstances and events." Action oriented to success is "strategic when we consider it under the aspect of following rules of rational choice and assess the efficacy of influencing the decisions of a rational opponent."10 Thus, when feminist theorists such as Fricker demand that we be able to be philosophically committed to the correcting of unequal physical circumstances or that we take action against the unacceptable treatment of one individual by another, communicative action allows us certainty in these convictions. This realist knowledge is also able to act as a reason for action, as Habermas argues instrumental action is valid because of technical rules, and strategic action is taken because of the

\footnotetext{
${ }^{9}$ Habermas, Theory of Communicative Action, vol. 1, 11-12.

${ }^{10}$ Ibid., 284-286.
} 
rules of rational choice. Fricker further argues that this knowledge should place some limits upon our normative beliefs. Habermas, by accepting experiential knowledge as legitimate, also commits communicative action to these limits and avoids a commitment to social values that do not reflect an agreed upon interpretation of the way the world exists.

These actions are a part of the theory of communicative action, and actual aspects of human life. They are not, however, a complete understanding of social existence, as this form of action does not explain how mutual intelligibility or coordination of actions is possible to actors engaged in action oriented toward success. For this, a more fundamental understanding of human interaction is needed and action oriented toward success must be augmented by the addition of action oriented to understanding. That communicative action is prior to strategic action remains a fundamental claim for Habermas, and forces us to step beyond the claims of empirical science made by both feminism and this part of communicative action, and into the claims made concerning the fundamentally social nature of a suitable epistemology.

\section{$\underline{\text { Role for Objectivity }}$}

Within the feminist debate over the nature of technical knowledge there is a need to determine whether or not the notion of objectivity ought to play a role in knowledge claims. One criticism of objectivity arises from the empiricists who accept the goals of objectivity, but argue that in practice objectivity has not yet lived up to its own standards. Other arguments, notably from the standpoint theorists, hold that objectivity is neither achievable or desirable, as it is irredeemably androcentric and tied to a version of knowledge not compatible with feminist needs. Finally, postmodernists argue against objectivity as a feature of epistemological foundations, which it is argued, are either repressive or do not exist. Within these diverse critiques lie two more 
fundamental considerations relevant for feminist theory. First, is the debate over whether or not objectivity is possible to achieve in a knowledge claim. Second, is whether or not, if objectivity is possible, it is desirable for feminists. ${ }^{11}$

Before considering these two possibilities, it is necessary to clarify what "objectivity" is understood to mean, and why it has been understood as a valuable and beneficial characteristic of knowledge. Ismay Barwell explains this as follows:

When objectivity was a characteristic of a theory, the theory was supposed to provide accurate explanations of how and why things happened as they did. Accuracy or truth were valuable either because they 'could be relied upon' or because they had intrinsic value. It is this connection which is crucial. The ultimate value of objectivity lies in this connection with truth and truth must be preserved as a regulatory principle in at least some theoretical enterprises. ${ }^{12}$

Feminism remains a movement for social change and requires descriptions and analyses of human social life that allow judgments about justice and injustice. These judgments will require a trust in the description of how things are. This has not, however, committed the idea of objectivity to any type of "view from nowhere," or to a "complete justification" of knowledge claims.

For Barwell, the value that remains in the goal of theoretical objectivity resides in the notion that the goals of objectivity are non-arbitrary; they apply to every actor considering the notion based on an agreed upon understanding of the constitutive goals of the idea of "objectivity." Thus, it will be necessary to build a sufficient compatibility among the principles of objectivity which are used by differing groups. This ideal would necessarily be self-regulating according to standards which were not in danger of being arbitrarily co-opted by either individuals or groups. What these standards might

\footnotetext{
${ }^{11}$ This division is made in Barwell, "Towards a Defense of Objectivity," 80.

${ }^{12}$ Ibid., 81-82.
} 
be remains unexplored in Barwell's analysis, but there is another feminist who explores further the role of objectivity in feminist theory.

One of the strongest proponents of the need for continued objectivity in feminist epistemology is Sandra Harding, who, writing from a feminist standpoint, argues that women are better able than men to achieve a true objectivity. This notion, which she considers "transformed" from the old notion of objectivity, has the potential to be improved into a "strong objectivity." Examining the characteristics of this objectivity, and the benefits she argues are derived from it, will show whether or not the objectivity available in communicative ethics might also meet with Harding's concerns.

Harding's objectivity is not achievable by one group or an individual, and is only available to a society with the inclusion of marginalized groups into the process of legitimizing knowledge. This is important because culture-wide beliefs often serve as legitimate evidence in scientific inquiry, and only the inclusion of those groups rejected by the majority culture will allow an unbiased conclusion to the debate. The objectivity that is characteristic of traditional empiricism is too weak, as it fails to set about to identify all of the historical-social "desires, interests, and values that have shaped" scientific agendas, allowing these beliefs to shape science. Traditional objectivity was also limited in that it excluded certain groups that held beliefs which were considered "different from the accepted notions of science. Harding also feels that not all values need to be excluded as "bad." For example "democracy-advancing values" have systematically generated less partial and distorted beliefs than others." 13 Traditional objectivism weakens its attempts to maximize objectivity because it turns away from critically identifying all of those broad, "historical social desires, interests, and values" that have shaped past history. These weak, traditional notions of objectivity created an

\footnotetext{
${ }^{13}$ Harding, "Rethinking Standpoint Epistemology," 71.
} 
idea of "objectivity" based on a mystic notion, allowing it to be perverted by dominant groups. Those values that encourage the participation of more groups, especially those that have previously been left out of the production of knowledge are good, and ought to be included in the investigation of human affairs.

To achieve these new standards of objectivity in social understanding, Harding provides us with the process of "reflexivity," which gives strong objectivity the ability to avoid the mysticism of objectivism, and encourages the participation of marginalized groups. Harding's notion of "strong objectivity," however, should not be confused with traditional notions of this idea, as it differs from that notion in many ways. Objectivity in traditional science refers to some characteristic of a knowledge claim, characteristics that it should or should not possess. Harding's "strong objectivity" seems more to refer to a process for creating a type of knowledge that is acceptable to the many different groups that are affected by that knowledge, this acceptability seems determined by validity. Harding does not reject a political agenda for her notion, nor strive to make it value-free. Instead of these claims, Harding's objectivity is specifically "democracy enhancing" and aimed at rooting out gender injustices, and would somehow work to provide a voice for the opinions of those outside of powerful circles. Her purpose is to ensure that might does not make right in knowledge production. This more open process requires an understanding of what others think of us and our beliefs and actions, not just what we think of ourselves and our ideals. Strong objectivity "is useful in providing a way to think about the gap that should exist between how any individual or group wants the world to be and how in fact it is." 14

Returning to Habermas, these very same concerns are found in his understanding of discourse ethics. He provides a method of legitimizing beliefs and knowledge open to

\footnotetext{
${ }^{14}$ Ibid., 72.
} 
all concerned with the outcome. While he argues that the ability of science to describe the world as it is still fundamentally remains, claims about how knowledge should affect diverse individuals remain for these individuals to negotiate, and should not be decided only by a few. Where Harding only alluded to some method of arriving at this consensus in validity, Habermas provides us with his complex notion of reaching an understanding amongst actors in discourse ethics. Further, his process of diversifying knowledge claims, Harding's "reflexivity," he refers to as "decentering" one's understanding of the world, achieving the same goal of greater participation in the knowledge forming process.

For Habermas this discussion of scientific objectivity is included in his understanding of the process that actors in a communicative situation must undergo in order to reach a mutual understanding about something in the world. In this process, actors not only use speech acts to represent a state of affairs in the world, they are also creating or renewing interpersonal relationships, based on the legitimately ordered interactions of the social world. Further, what Harding vaguely referred to as how an individual "wants the world to be," Habermas argues for as the subjective world, accounted for in those speech acts in the expression of the lived experiences of individuals, to which they alone have access. Whether or not these individuals in communication have reached an agreement is indicated by the acceptance or rejection that each participant gives to the validity claims made with every utterance in the debate. When one actor rejects a validity claim, she is claiming that "the utterance is not in accordance with either the world of existing states of affairs, our world of legitimately ordered interpersonal relations, or each participant's own world of subjective lived experience." 15 Thus Harding's concern for both individual and group differences from a

15 Habermas, Moral Consciousness and Communicative Action, 137. Italics in original. 
dominant norm are not excluded from consideration in Habermas's process of reaching agreement, but remain a part of the negotiation. When all of these voices are included in knowledge production, knowledge from all three of these worlds, Harding's "strong objectivity" can be achieved.

We have seen then, that Harding does not so much rely upon the nature of objectivity as possessing a special quality which provides a better source of understanding feminist knowledge, but instead finds the most benefit in the process that must be undertaken to achieve "strong objectivity." It seems that instead of emphasizing the importance of objectivity itself, a theory could arrive at an equally "objective" knowledge by emphasizing the role which individuals or groups play in the acquisition of knowledge judged reliable and valid by the whole. As we have seen, this is precisely where Habermas seeks to emphasize the importance of objectivity, in a process that provides, not a mystically endowed bit of knowledge, but rather a unit of knowledge that is accepted by all in debate over the value of that knowledge as legitimate.

Further, the concerns of Barwell, about the agreement between groups who may hold differing conceptions of objectivity, and about the need for some self-regulatory standards upon which objectivity must lie, can be found in Habermas's ideal speech situation. As was explored above, this set of circumstances must apply to a degree that each individual feels has been sufficient to consider an agreement rational. All who desire to participate must be allowed to, they must be free from any internal or external constraints, and they must be free to debate any aspect of the argument. These standards are self-regulatory and are needed for any rational agreement which is to convince participants of its validity.

Leaving this chapter's consideration of Habermas's use of empirical knowledge we see that communicative action has accomplished a number of the tasks outlined at the beginning of this section. It has been shown to fulfill the need for access to knowledge 
of how the world actually exists. Feminist theory does not exist in isolation from a real world of events and situations, which must be responded to by these theorists. In order to respond to these facts, feminists need an accurate and trustworthy knowledge responsible to the norms of empirical science and placing constraints upon how this knowledge is interpreted. Through its acceptance of such a science, and a notion of a communicatively achieved objectivity, communicative action accomplishes just this.

\section{SOCIAL KNOWLEDGE}

We have seen, communicative action contains an important role for empirical knowledge, and is able to account for the demands a feminist science would make for objective, "realist" knowledge of the world. Within this first step in comparing feminism and communicative action, however, already lies the need to expand the empirical explanation of knowledge beyond a simply positivistic account of the world. Habermas has accepted this task, and presents an expanded notion of rationality, beyond what the realist vision allows, by proposing a theory of human action more varied than action simply oriented towards success in the world. A more fundamental understanding is necessary; one based upon language, the human ability to communicate, and our need to exist amongst each other and with ourselves. As will now be demonstrated, these concerns closely resemble those that initially turned feminists away from the limits of atomistic empiricism, toward a more informed notion of human social life, dependent upon those around us for our identities, and united in some form of solidarity. This will be demonstrated in the compatibility of feminist and communicative conceptions of context, truth, and solidarity. 


\section{Contextuality}

Allison Jaggar has written that a feminist theory cannot be based on the abstract individualism of Cartesian thought which assumes that essential human characteristics arise prior to any social context. Jaggar, arguing for a feminist standpoint, feels that meaning is given to inner experience and behavior only by the emotions, beliefs, and attitudes supplied by our social context. As argued above, the idea of a "pre-social human being without any determinate kind of nature is conceptually incoherent."16 Habermas agrees, and his use of action theory, and socialization through the lifeworld, insure the necessity of a social context. Indeed, not only is his theory founded upon the communicative nature of social activities, it discusses clearly the role of raising and socializing young members of society as part of communicative action. As explored in its own chapter above, the theory of communicative action denies neither our physical or social existence. Differences in biology are not removed by the theory, there is no neutrality that removes these aspects of existence. Based upon these claims, a standpoint such as Jaggar's will be able to identify with the embedded subjects of communicative action.

Iris Marion Young points to another advantage Habermas's theory would provide for feminism. Her writing has called for a new public/private distinction in social and political theory which is also compatible with Habermas's theory. Following the feminist slogan "the personal is political" Young wants to redefine the private not as what has been excluded from the public, but rather to define private as what an individual excludes others from. This would be characterized as "withdrawing" rather

${ }^{16}$ Allison Jaggar, Feminist Politics and Human Nature, 42. 
than being kept out. ${ }^{17}$ Modern politics, she argues, is characterized by an over emphasis on reason, which excludes any passion from the public sphere. She argues for two new principles which would deny a social division of the spheres differentiating institutions and human activities. In order to allow open discussion over new topics such as, the sexual division of labor or sexual violence, no social institution or practice ought to be excluded from public discussion or debate a priori. She also argues that no aspect of a person's life or their actions ought to be excluded from the public and forced into the private. This would allow differences of age, sex, or race to become part of public discourses. These demands would lead to the liberation of public expression to include discussion of both ends and means, reasons and passions, all of which feminists seek to incorporate into social life. The principles of discourse ethics, again, are that no one be excluded, that any claims may be made and criticized, and that no coercion may enter the discussion. These principles should surely satisfy the demands of Young for a new, more open and inclusive, understanding of public and private in public dialogue.

\section{Consensus Theory of Meaning and Truth}

For many feminists a fundamental reason for rejecting previous philosophies has been the lack of female voices in their construction of regulatory ideals, and feminist bases for accepting new ideals have been to see that women's voices are included in their creation. On an even more basic level, the norms of an epistemology must be justifiable to women as well as men. Ideas central to philosophy such as knowledge,

${ }^{17}$ Iris Marion Young, "Impartiality and the Civic Public: Some Implications of Feminist Critiques of Moral and Political Theory, in Feminism as a Critique: On the Politics of Gender, eds. Seyla Benhabib and Drucilla Cornell (Minneapolis: University of Minnesota Press, 1987), 74. 
justification, or reason need not be abandoned, but remain to be struggled over, redefined and reworked until acceptable to the notions of modern social actors.

Arguing that an ideal of truth is needed, transcending situated perspectives as a regulatory ideal, Miranda Fricker writes that an acceptable feminist epistemology must provide a strong role for political and social values. ${ }^{18}$ Further, this feminism must be constrained by two provisions. One, it must provide an account of norms as providing the basis for beliefs, and second, it must distinguish between first and second-order perspectives in order to provide some capacity of self-criticism. The first provision is intended to direct our attention to the idea that there are some things that we ought to believe in order to constrain us from believing "anything at all." These beliefs must be presented to the subject with normative force, in order to be enforced and accepted. The second rule is a continuation of this, and must epistemologically account for how it is indeed possible for human beings to critique their actions.

In building an acceptable idea of knowledge she proposes a theory which is accountable to experience, but not fully determined by it. With the incorporation of political and social values into epistemology, she will also provide a role for political argumentation in order to regulate the unavoidable influence of these political interests into a dialectic of facts and values. This acknowledges that political values, as well as empirical "facts" influence our beliefs. Thus, there is no need for a sharp categorical distinction between facts and values. All beliefs in the system of beliefs become interdependent, justification for one depends on its coherence with the rest of the system, and the first rule she proposed is accounted for. If a realist account of empirical belief is depicted as normatively constrained by the world, then norms have provided empirical beliefs. ${ }^{19}$

\footnotetext{
${ }^{18}$ Fricker, "Knowledge as Construct," 95-109.

${ }^{19}$ Ibid., 106-107.
} 
In communicative ethics, Habermas certainly accounts for both of these epistemological demands, an understanding of the relationship between norms, beliefs, and empirical information, as well as a very detailed understanding of an individual's ability to critique her social world. His "consensus theory of truth and knowledge" allows an active role for normative beliefs to inform what is held as an empirical truth, as well as what is to conform with social demands for legitimacy. Recall from above the weight that Habermas places on validity of claims in the determination of truth, "the concept of truth combines the objectivity of experience with a claim to the intersubjective validity of a corresponding descriptive statement,..."20 Thus the idea of truth is only possible in a community that is tied to the same interpretations of statements. If speakers and listeners are able to identify when a statement is true, or accepted as valid by the community, then they also have access to the meaning of the statement. The meaning of utterances cannot be understood without also knowing the conditions of the statement's validity. ${ }^{21}$ Truth depends on the "idealized agreement" that occurs when an individual is able to relate the notion to an ideal communication community, one sharing a collective identity and the goal of reaching agreement on discussion about the organization of their lifeworld. How Habermas moves from the relation of facts and intersubjective validity of statements to criticizable validity claims, as well as Fricker's need for "first and second order perspectives" for a critical examination of our beliefs will be accounted for more specifically in the section concerning critical knowledge below.

${ }^{20}$ Habermas, Theory of Communicative Action, vol. $2,72$.

${ }^{21}$ Habermas, Theory of Communicative Action, vol. 1, 276-277. 


\section{Solidarity}

In building a coherent epistemology for feminist theory, the agents of knowledge must be carefully theorized to provide a role for both the identities that individuals can claim as part of a group and the identity they claim as unique to themselves. These demands are apparent in many aspects of feminist theory, and one of the most important arguments they have made in support of the notion of solidarity is the need for a theory to appropriately account for an individual's position in a community. This is especially true of feminist standpoint theories, who depend on the notion that differing positions within a social structure are able to provide different perspectives from which to view that society, one of these perspectives often being more privileged than the others. For standpoint feminists, it is generally the position of women in society, subjugated into that position as a social group, that holds a privileged position over the perspective of men. Nelson's understanding of epistemological agents describes them as not being "isolated or isolatable." Feminists from many camps have argued that an atomistic knower is impossible, based on reasons of human biology, 22 others have argued against claims that human knowledge is personal property, and insist instead on "interpersonal relations" as being the actual source of human knowledge. ${ }^{23}$ As Jaggar has written, the very discovery of a women's standpoint depends on the "collective process of political and scientific struggle." 24

\footnotetext{
${ }^{22}$ Helen Longino, often categorized as a feminist empiricist, has argued for plural accounts of knowledge in Science as Social Knowledge: Values and Objectivity in Scientific Inquiry, (Princeton: Princeton University Press, 1990). Alison Jaggar uses biological arguments for pluralistic understanding of knowledge in her Feminist Politics and Human Nature.

${ }^{23}$ Nelson, "Epistemological Communities," 121-160.

24 Jaggar, Feminist Politics, 371.
} 
To Habermas, the mere existence of an individual, and any of her capabilities, also depends upon a social setting for both socialization and the capacity to know herself as an individual. "In communicative action, the suppositions of self-determination and self-realization retain a rigorously intersubjective sense: whoever judges and acts morally must be capable of anticipating the agreement of an unlimited communication community, and whoever realizes himself in a responsibly accepted life history must be capable of anticipating recognition from this unlimited community." 25 This unlimited community, as we have seen, is the result of moving through an identification of the actual community around the individual and substituting the notion of this unlimited community in place of the actual one. The actual community is necessary for the individual to make any decisions about the good life, and the expanded notion of the community is required to make any decisions about morality. In both instances, the role of community, and the individual's place in it, remain centrally important to the individual's ability to make life choices. The individual remains indebted to the community for her individuality.

Lynn Hankinson Nelson has recently written that:

By current lights it is persons, embodied and situated in specific social and historical contexts, who know, with both their embodiment and "situations" relevant to their knowing. According to feminist epistemologies, such situations need to be specified using the analytic category gender, a category whose "content" and meaning are dynamic and multileveled and one whose relationship to other categories and social relations (e.g., class, culture, and race) as well as to knowledge, remains both contested and central to feminist theory. ${ }^{26}$

This notion of "situation" or "location," she continues, is becoming more complex in feminist theory, and functions as a "bridging" principle for diverse feminist

\footnotetext{
${ }^{25}$ Habermas, Postmetaphysical Thinking, 192.

${ }^{26}$ Nelson, "Epistemological Communities," 121.
} 
epistemologies, whether empirical, standpoint theorists, or postmodernists. ${ }^{27}$ The "contest" referred to above, over the relations of analytic categories, is further described as one undertaken by the agents of knowledge themselves, as opposed to the "passive" recipient or collector of knowledge characteristic of Cartesian knowledge. "These agents also differ from their predecessors in foundationalist epistemologies in that they shape, as well as undergo and absorb, experience; they construct meaning and knowledge-even, some say, negotiate and decide these." 28

Turning again to Harding's standpoint theory for women, we see also that her "strong objectivity" relies on an important position for groups. Her argument is dependent upon the existence of groups who will form the same sense of identity amongst themselves, and in opposition to other groups. It is the various ideas of these differing groups that must be accounted for in the production of knowledge. While it has usually been the case that a dominant group in society-white, wealthy, males-has determined what was to count as acceptable and legitimate knowledge, it is now understood that true and impartial knowledge cannot be achieved without the input of non-dominant and marginalized groups in society. Harding leaves us, however, at the point of identifying the importance of the process that allows groups to negotiate amongst themselves for a knowledge claim. She does not describe what this process is to look like, or articulate the rules under which it will proceed. But it is certain, that within strong objectivity, Harding's primary epistemological agent is not the individual, but the group or community, that must struggle to have its own unique voice heard.

For Habermas, the role of community in knowledge production is no less important. Habermas's understanding of the lifeworld, as explored above in detail, argues

\footnotetext{
${ }^{27}$ Ibid., 152, note 1.

${ }^{28}$ Ibid., 121.
} 
specifically that the knowledge of an individual is dependent upon the cultural traditions handed to her by the community in which she is socialized. Habermas has responded to these needs by accounting for both "individuality and solidarity" within his theory.

Justice and solidarity are two sides of the same coin because practical discourse is, on the one hand, a procedure that affords everyone the opportunity to influence the outcome with his "yes" or "no" responses and thereby takes account of an individualistic understanding of equality; on the other hand, practical discourse leaves intact the social bond that induces participants in argumentation to become aware of their membership in an unlimited communication community. ${ }^{29}$

\section{CRITICAL KNOWLEDGE}

These two realms of knowledge, that of empirical knowledge of the objective world around us and the practical knowledge which guides and coordinates our actions in the social world, do not however, fulfill the demands made upon a social science by either Habermas or writers in the feminist camp. To do so will require paying attention to the claims and demands made by feminists more closely allied with postmodern thought, and the related thinking of Habermas on individuals' ability to know themselves, and to exist as unique entities within the larger group where that identity is acknowledged. This final area of knowledge will be explored in this section, which incorporates Habermas's ideas of critical knowledge and its role in emancipatory human interests with the fears of postmodern feminists about essential descriptions of human nature and the totalitarianism brought with many foundational social and political theories. This third section will undertake an examination of these ideas, showing that Habermas meets the demands of postmodern feminists, while at the same time not abandoning the technical and practical bases of knowledge already established. This section will also

${ }^{29}$ Habermas, Justification and Application, 154. 
address some of the critical reviews communicative action has received from feminist theory.

\section{Gender Bias}

Nancy Fraser begins her examination of the theory of communicative action with the question: "in what respects does Habermas's critical theory clarify and/or mystify the bases of male dominance and female subordination in modern societies?"30 She begins by reviewing a distinction within communicative action between the lifeworld and the political/economic system it supports, which she points out, provides a powerful view of the public-private split of concern to many feminists. To explore this dichotomy she uses four concepts to represent the four categories created by a public-private and system-lifeworld matrix: family, (official) economy, state, and the public sphere. ${ }^{31}$ At the systems level, there is a distinction between the public state and the private official economy. At the lifeworld level there is the distinction between the family and the public (social) sphere. The private sphere links the economy and the family while the public sphere connects the state and the public sphere of social "will formation."

Fraser argues that there exists a gender bias in Habermas's theory by pointing out that these distinctions, in male-dominated, capitalist societies, rely upon traditional sexroles. To illustrate this, she first takes the case of the wage laborer. There is a strong sense, she argues, in which the worker is seen to be male. It is the male that leaves home to enter the private, economic-system in order to "bring home" the means of support to the family. Thus, only men create this link between these two private (economy and family) spheres. There is also a feminine subtext to the link of private

${ }^{30}$ Nancy Fraser, "What's Critical About Critical Theory?" 114.

${ }^{31}$ Ibid., 114-117. 
roles, via a woman's role as the consumer of goods. In capitalists families, it is generally the female who is the consumer, while the male is at work, thus the link in the private worlds between economy and family, via the consumer, is distinctly female. Finally, for Fraser, it is a significant deficiency in the theory that Habermas makes no mention of child rearing in the link between the economy and the family. There is no mention of the unpaid labor that is fundamental to the rearing of children, and is also generally a female role.

Habermas also seems to rely upon a gendered subtext to link the public spheres. For this, Fraser points to the role and concept of the citizen. In traditional capitalism, the role of the citizen is also seen to be a typically male role. This citizen has the ability to vote and the ability to engage in political debate and opinion formation. While Habermas does not mention gender roles in this context, Fraser notes that these activities are historically male. There is a more fundamental part of citizenship that Fraser points to which further points to the gendering of citizen, the role of soldiering. The role of soldiering is to protect the state and the family (women and children) who cannot protect themselves. Therefore the link between the protection of the state, and the role in public debate are characterized by traditionally masculine roles. Habermas remains dangerously androgynous on both the links between the systems and lifeworld spheres. $^{32}$

In conclusion, Fraser does not entirely reject Habermas's theory. She generally attributes it's weaknesses to "blind spots" of androgyny. She concludes with three changes that would need to be made in a "feminist critical theory." First, she points out that a feminist framework could not separate the male-dominated family and the stateregulated economy into the two primary, separate categories of domination. Second, a

\footnotetext{
${ }^{32}$ Ibid., 127-128.
} 
feminist theory cannot assume that influences move in only one direction in social life, norms, even as they weaken, continue to influence both institutions and social life. Finally, it must focus more exclusively upon the "evil" of domination and subordination, rather than upon simply the faults in welfare-capitalism. ${ }^{33}$

These criticisms of a private and public distinction within Habermas's theory of social rationalization do not, however, significantly weaken Habermas's claims about the three-fold nature of knowledge. The lifeworld/system distinction within communicative action that Fraser critiques is used by Habermas as a method to describe the process of cultural rationalization, to illustrate the inadequacy of instrumental rationality, and identify crisis points within the lifeworld, not to ascribe an essentialism to men and women. That these roles are unalterable is an assumption of Fraser. Focusing her critique upon two aspects of Habermas's thought ignores the more fundamental distinctions Habermas relies upon in the nature of knowledge. While Fraser is able to critique communicative action by attributing to it responsibility for the way the world appears today, this is not a fault of communicative action which Habermas argues is used only to describe, not prescribe. Further, Fraser misses entirely the subjective aspects of communicative action in which Habermas acknowledges the importance of an individual's ability and desire to reject standard values or aspects of the community. Finally, while the lifeworld/systems dichotomy does exist within communicative action, this does not form nearly so fundamental an aspect of the theory as the three realms of human action, which are not foundationally tied to a particular gender.

33Ibid., 138. 


\section{Considering Communicative Rationality}

Iris Marion Young critiques the rationality inherent in critical theory. ${ }^{34}$ She argues that an emancipatory ethics must break away from modern political ideas, developing a conception of normative reason which is not based upon an opposition between reason and desire, for this contrast has been used by traditional theories to exclude the experiences of women from discourse. Her attack on Habermas is that, while his theory offers a good departure towards such an ethic of reason and desire, he still relies too heavily upon the ideas of impartiality and universality.

Impartiality begins with the idea of an observer standing apart from a situation and judging without having any role in or connection to the situation. This requires the impartial observer to assume a normative rationality based on a situation that does not exist. Rationalizing in this way simplifies and removes otherness from the specific situations and specific individuals and assumes a kind of authoritarianism which need not take into consideration any point of view other than its own. An integral part of a feminist theory would need to remove this universal authoritarianism of reason. ${ }^{35}$ Habermas, she acknowledges, has been able to move away from the authoritarianism of impartiality. His rationality is based on the give and take of reasons in argument, of being reasonable and to being willing to talk and listen. Thus, truth and rightness are reached through discussion, not through intuition or with tests of consistency which removes reason from its great height. Also encouraging to feminist ethics is that communicative action considers statements about art and opinion as equally valid as factual statements. 36

\footnotetext{
${ }^{34}$ Iris Marion Young, "Impartiality and the Civic Public," 57-76.

35 Ibid., 61-63.

36Tbid., 68.
} 
Habermas, however, still retains some commitments to impartiality and to an opposition between reason and desire. Habermas writes that all participants enter discourse reasoning from the perspective of their experiences and need not leave behind their motives and feelings. As long as all participants can speak freely, motives and feelings will not have strictly private significance, and thus will not bias the outcome of a discourse mixed with other needs and feelings. But, Young feels, in Habermas's commitment to consensus as a basis for this discourse, desires become neutralized. Young feels this is a transcendental argument in that it imposes an abstract restraint upon the motives of real participants in the discussion. ${ }^{37}$

To Young, Habermas must assume that utterances have a single meaning, and are understood in the same way by all participants. This further limits the knowledge that a participant can bring to the discussion and relies upon several "unities." First, a unity of speakers, who must be assumed to know and faithfully represent their desires. Second, a unity between subjects that share the same meaning of words. Finally, a unity in the relation between the word spoken and the object in the world that it represents. ${ }^{38}$ Young also feels that Habermas ignores or devalues the "expressive and bodily aspects of communication."39 Reason based on the goal of reaching consensus, and limiting its functionality to argumentation, unnecessarily limits the richness of language. This ignores the other aspects of communication, jokes or metaphors, as well as other goals, the sharing of care and love.

In reading Habermas, however, these attacks seem misconstrued. The "consensus" which Young fears seems not to be an "abstract restriction upon the motives of

\footnotetext{
${ }^{37}$ Ibid., 69.

38 Ibid., 69.

39 Ibid., 70.
} 
individuals" but rather a necessary condition for meaningful communication. Actors may not want to achieve a mutual understanding, but this is at the cost of intelligibility, and no "communication" follows. Second, Young misses the role of misunderstanding in communicative action. Habermas acknowledges that misunderstandings occur, and that every utterance must be checked against background understandings. If the actors' backgrounds do not sufficiently overlap they must engage in "repair work" to reach sufficient common understanding. Every act of communication potentially will be misinterpreted and need to be repaired. ${ }^{40}$ Finally, Young has written that Habermas ignores the expressive bodily aspects of communication. Referring to Habermas, however, we see that he directly accounts for bodily movement in his definition of actions which are incorporated into his understanding of communication. ${ }^{41}$ As for the "richness of language" that Young feels Habermas ignores, it is difficult to see how aspects of communication like the "sharing of care and love" are excluded by discourse ethics which refer specifically to social and subjective worlds, about relations with others and feelings towards them, respectively.

Marie Flemming argues that communicative action remains irreparably incompatible with feminist demands because of its basis in an misogynist conception of reason. ${ }^{42}$ Flemming attacks Habermas as being either "unaware of feminist critiques of modernity or, even worse, unconcerned about them." 43 She bases these claims first, on the absence of sex-gender questions in Habermas's works, and second, upon the argument that "his adoption of a naturalistic stance toward logic ensures that his account

\footnotetext{
${ }^{40}$ Habermas, Theory of Communicative Action, vol. 2, 124-126.

${ }^{41}$ Habermas, Theory of Communicative Action, vol. 1, 96-97.

${ }^{42}$ Marie Flemming, "Women's Place in Communicative Reason," 25-262.

${ }^{43}$ Ibid., 258.
} 
will reproduce dualistic categories that are repressive for women." 44 Habermas's communicative reason, she claims, continues to rely upon the philosophy of the subject and legislates women as 'Other' and irrational.

These criticisms themselves, however, seem incompatible. First, without mentioning women or gender in his theories, it is complicated to see how this legislates a repressive treatment of women. Her argument is based upon a reading of Albrecht Wellmer's argument that Kantian monologism is based in a community, and thus based in dialogue. From this, Flemming determines that "autonomous reason is already an implicitly communicative reason...and cannot be justifiably viewed as fundamentally different and competing traditions." 45 Rejecting Habermas's communicative rationality because it is no different than the rationality of Kant's atomistic legislating individual, however, seems to disregard the important separations from Kant that Habermas undertakes in the role of a situated, historical, individual engaging in discourse with other actors to establish mutual understanding.

Her attack that Habermas is "unaware" or "unconcerned" with feminist critiques of modernity also seems inaccurate. While this paper argues that the major thrusts of feminism revolve around critiquing the application of empirical reason, the neglect of contextuality, and the need to represent individual identities, Flemming's rejection of Habermas, is based upon his response to Nietzsche's postmodern questioning of the "value of values themselves." 46 She argues that communicative action reproduces the dualism that is inherent in the traditional values of Enlightenment philosophy, "good/bad, true/false, mind/body, rational/irrational, man/woman," leaving women

\footnotetext{
${ }^{44}$ Ibid., 259.

45 Ibid., 256-257.

46 Ibid., $255-256$.
} 
identified with all that is to be devalued. None of these dichotomies, however, are overly central to communicative ethics, which is more fundamentally based on the tripartite distinctions between realms of action, knowledge, and rationality. There is no fundamental "true or false" in communicative action; instead, Habermas argues for an emphasis on "truth, rightness, and sincerity" as foundational values. Habermas also has replaced a traditional "mind/body" distinction with a richer understanding of the difference $s$ between the objective, social, and subjective realms of human action. The remaining dualism central to Habermas's thought is the yes or no response that is given by any communicatively competent individual, male or female, to an utterance made by another individual. This does not seem to assign women an "irrational" role, nor does this simply ignore postmodern attacks on modernity's values.

Seyla Benhabib writes to defend a role for a type of "universalism," which must be included in a feminist theory if they are to separate themselves from the imposed roles of situated communities. Her idea of universalism is different in several ways from the strong, deontic universalism found in many empirical theories. A "feminist universalism" would need to be interactive rather than legislative, cognizant of gender difference rather than gender blind, and sensitive to context differences rather than situation indifferent. This universalism is arguably found in Habermas's communicative action. ${ }^{47}$

As has been explored above in this essay, there is a firm place for contextual relations in communicative action. Through discourse ethics, Habermas commits actors only to the norms and values that have arisen in their specific communicative context, and fully accepts that different norms and values will arise in different situations. We can also see in Habermas the shift toward an interactive rationality. This

\footnotetext{
${ }^{47}$ Seyla Benhabib, Situating the Self: Gender. Community And Postmodernism In Contemporary Ethics (New York: Routledge, 1992), 4-5.
} 
can be found in his definition of truth, which is no longer substantive, derived from an objective reality to be grasped, nor does it rely upon a particular state of the human mind. In returning to Habermas's understanding of the three worlds we inhabit, the objective, social, and subjective, none of these has a monopoly on truth. Instead, Habermas argues for truth based on consensus which becomes linked to validity, and thus relies also upon sincerity and the appropriateness of the claim, as well as its objective appearance. 48

Another theme of Benhabib's work is the necessity of a moral theory to account for a "concrete other" in moral reasoning that works in addition to the "generalized other" of more traditional liberal moral theorizing. A generalized other excludes differences in moral reasoning and focuses upon only those aspects common to all participants. In the past this aspect of theories has often worked to exclude women as "different," bringing claims to moral reasoning that were not the same as men's. A "concrete other" in moral reasoning allows individuals to remain distinct and different in whatever way they choose, and thus, as they actually are. Discourse ethics, as provided by Habermas, is able to account for this need for a generalized and concrete other. In discourse ethics, a moral perspective is to be part of an actual dialog, not a theoretical process, and without placing limits on the information that a participant can bring to a discourse. Benhabib's support of discourse ethics allows us to see an escape from androgynous universalism that feminists argue against, without falling into standpoint theory's inescapable embeddedness. Discourse ethics also provides a successful method of reasoning as we actually are, engendered and concrete beings.

${ }^{48}$ Habermas, Theory of Communicative Action, vol. 1, 70-72. 


\section{Non-Foundational}

There are many feminists who argue against the foundational and meta-theoretical aspects of traditional notions of knowledge and science. Feminists argue against the foundational nature of a theory of knowledge because of what they interpret as its tendency to be used to universalize certain aspects of experience, while at the same time excluding others. Habermas has also taken steps to show that communicative action can be understood as being free of foundational claims or ultimate justifications, which he feels is a weak position for a philosophy to attempt to defend. Transcendental analysis he argues, is a non-empirical argument for achievements for which there is no alternative, "arguing to prove the "nonsubstitutability of certain mental operations that we always already perform in accordance with rules." 49 For Habermas, the correct role of philosophy is to mediate between the realms of knowledge that human beings are capable of orientation towards. ${ }^{50}$ Communicative action is built upon an empirical claim concerning the nature of language, its development, its functions, and its use in social life. As Rasmussen reads Habermas, "the theory of communicative action attempts to become,...a quasi-scientific theory and not a venture in foundational epistemology." 51

One such anti-foundational feminist, Jane Flax, argues for a close alliance with the postmodern trend of contributing "to the growing uncertainty within Western intellectual circles about the appropriate grounding and methods for explaining and interpreting human experience." 52 While she makes this claim in order to step away

\footnotetext{
${ }^{49}$ Habermas, Moral Consciousness and Communicative Action, 2.

${ }^{50}$ Ibid., 14-16.

${ }^{51}$ Rasmussen, Reading Habermas, 23.

52Flax, "Postmodernism and Gender Relations," 41.
} 
from a overly strong feminist standpoint, she also points out the necessity for feminism to take part in the work of casting doubt upon Enlightenment ideals of a coherent self or an objective foundation for knowledge.

Writing on the same theme, Fraser and Nicholson work to connect the goals of feminist and postmodern attempts to "develop social criticisms which do not rely on traditional philosophical underpinnings." 53 Specifically, they are hoping to show that philosophy can no longer play the role that it once did as a ground to social criticism and politics, because, they argue, contemporary social life has reached a point were "grand narratives of legitimation" are no longer believable. Modern foundationalist epistemologies and moral and political theories have been criticized by both feminists and postmodernists as being contingent, partial, and historically situated, while being presented as universal and ahistorical. ${ }^{54}$ Fraser and Nicholson here are criticizing both traditional forms of philosophizing and the standpoint feminists use of "very large social theories" which claim to "identify causes and constitutive features of sexism that operate cross-culturally." 55 The chief place of error in these theories is that they are "not sufficiently attentive to historical and cultural diversity, and they falsely universalize features of the theorist's own era, society, culture, class, sexual orientation, and ethnic, or racial group." 56 While they feel it is not the "size" of these theories that condemns them, it will be important for a feminist theory to "replace unitary notions of woman and feminine gender identity with plural and complexly constructed conceptions of

${ }^{53}$ Fraser and Nicholson, "Social Criticism Without Philosophy," 21.

${ }^{54}$ Ibid., 26.

55 Ibid., 27.

56 Ibid., 27. 
social identity..."57 They continue, without offering details, that "In general, postmodern feminist theory would be pragmatic and fallibilistic. It would tailor its methods to the specific task at hand, using multiple categories when appropriate and forswearing the metaphysical comfort of a single feminist method or feminist epistemology." 58

"Multi-leveled," "pragmatic," and "forswearing a single method" all resemble the structure of communicative action and discourse ethics. More importantly at this time, however, is the argument that Habermas also makes that his theory avoids any foundationalism. Habermas has written that he hopes to find a more modest role for philosophy than that of "usher and judge" of the sciences. As Habermas sees it, the proper role of philosophy is not to differentiate and appropriately limit the various realms of modern life. This is a task that philosophy cannot accomplish. Instead, Habermas feels that the differentiation of these realms is a given in today's world. Philosophy is left (without claims to a totality) with the role of mediator between these realms, adjudicating between the various spheres. ${ }^{59}$ Habermas does not want to allow philosophy the power to clarify the foundations of science once and for all, which would define the limits of what can and cannot be experienced. This would be equal to showing the sciences their proper place. 60 For individuals to mutually understand one another in Habermas's lifeworld will require a cultural tradition that "ranges across the whole spectrum, not just the fruits of science and technology." Philosophy will be able to play a role in the communication and intelligibility between the "cognitiveinstrumental, moral-practical, and aesthetic-expressive dimensions" of human

\footnotetext{
${ }^{57}$ Ibid., 34-35.

58 Ibid., 35.

${ }^{59}$ Rasmussen, Reading Habermas, 21-22.

${ }^{60}$ Habermas, Moral Consciousness and Communicative Action, 2.
} 
knowledge which have arisen. The issue now is "to overcome the isolation of science, morals, and art and their respective expert cultures." 61

Perhaps this role of philosophy as mediator between realms of knowledge that Habermas envisions is the same role that Haraway seeks in her postmodern "manifesto for cyborgs" faithful to "feminism, socialism, and materialism."62 Her central image of a cyborg is to represent the need for understanding of the relationship between "machine and organism," between "social reality" and "fiction." Her essay dwelt on the breakdown of boundaries, and the need to take responsibility in their changing. She writes of the confused boundary between human and animal, often reduced by biology and evolutionary theory to an ideological struggle. ${ }^{63}$ Second, she considers the differences that remain between the physical and the non-physical world, the lines between imagination and spirituality and technology and materialism. Habermas's thesis of the confusion of these boundaries, and the need for a mediation between them is an idea not alien to postmodernists at all.

${ }^{61}$ Habermas, Moral Consciousness and Communicative Action, 19.

${ }^{62}$ Haraway, "Manifesto for Cyborgs," 190.

${ }^{63}$ Ibid., 193. 


\section{CHAPTER V}

\section{CONCLUSION:}

\section{COMMUNICATIVE ACTION AS FEMINIST EPISTEMOLOGY}

Feminist political and social theory today still faces a dilemma, as the epistemological discord within feminist theory has not yet been resolved. Being composed of at least three distinct and often mutually exclusive schools of thought, it has been difficult for feminism to maintain a consistent attack upon the social and political structures it seeks to change. Feminist empiricism, standpoint feminism, and the postmodern feminists each stand upon their own entrenched philosophical grounds, making their distinct demands for an acceptable feminist epistemology, and attacking other positions as weak or misguided. None of these schools, however, is immune to a critique of its own position, and the inconsistencies of each or all of them suggest the need to move beyond the separate and specific demands of each towards a more comprehensive, coherent, and powerful understanding of "feminist ways of knowing." While a growing number of feminist theorists acknowledge the need for this new direction for feminist thought, there is as yet no single theory able to account for all of feminism's epistemological requirements.

This thesis has suggested, and demonstrated, that a possible source of enlightenment for this next step in feminist thought is provided by Jürgen Habermas. His theory of communicative action and discourse ethics seeks not only to defend some of the Enlightenment against the attacks of postmodernism, but also to enrich and clarify our understanding of human social life. In order to accomplish these tasks, Habermas has 
grounded his claims concerning what is known and knowable about human life upon a detailed understanding of human knowledge. It is this complex notion of human knowledge, and its differentiation into the objective, the social, and the subjective realms of human action, that is able to account for the diverse epistemological demands of feminist political and social theory.

It has been shown that the three realms of Habermas's knowledge account for the underlying claims of the differing groups of feminist theory, and provide a basis for reconciling the differences between them. Habermas's objective realm of knowledge corresponds to the concerns of empirically oriented feminists. Need for an accurate description of the events and conditions of the real world, as well as a trust in the human potential for grasping these objects and events accurately, is provided by communicative action and necessary for any feminist epistemology. Standpoint feminism's concern for interpersonal relations, accounting for the context of an individual's or group's existence, is reflected by the type of knowledge that Habermas considers practical in nature. Habermas's conception of our capacity for social knowledge, which guides our actions with other human beings, is shown to be dependent upon both social existence and human abilities to communicate with each other. Finally, Habermas acknowledges the human potential for critical knowledge to explain the individual's ability to differentiate herself from the group, a task which a postmodern concern within feminism demands in order to avoid essentializing any aspect of women.

The shared concern for accurate knowledge of the physical world and the human need for both solidarity and autonomy has been shown to be present in both feminist theory and communicative action. Within the theory of communicative action Habermas has implied what would necessarily be the type of political organization needed in order to realize the social order he visualizes. Some feminist scholars have also pursued their theories in order to uncover what an acceptable "feminist politics" 
might resemble. The politics of empirical, standpoint, and postmodernist feminism find compatibility with the politics that a communicative ethic advocates.

The politics envisioned by a feminist standpoint can be drawn out from the example of Harding's strong objectivity. For Harding, "strong objectivity requires that scientists and their communities be integrated into democracy-advancing projects..." 1 She argues for a scientific project and political order that is specifically biased towards the inclusion of more and more groups of actors. This is not only argued to be a benefit in the objective world of sciences, and in the political realm of social order, it benefits actors subjectively as well as, by creating less distorted beliefs about the social system. Harding's goal of conducting political inquiry with a bias toward greater democratic procedures is intended to further increase the degree of democracy at work in these procedures.

A discourse ethic would placate the demands placed on politics by Harding in that its constitutive rules require the participation of all that might be affected by an established norm, those powerful in a society as well as those marginalized by it. Further, a social conception based on communicative action assures us that not only do groups have the ability to add to the debate over their good life, the participation of the marginalized will be required for the outcome to be rational. Harding's writing also is concerned with the ability of the scientist in a society to determine what will be reflected in the norms of that community. Habermas, while certainly convinced of the threat that an elite group could gain control over the establishing of legitimate cultural norms, has specifically established his procedures so that such an occurrence would be unlikely to occur, or if it did, certainly it would be judged and exposed as non-consensual, and non-rational. There is no room in the participatory scheme of Habermas for a single "true" voice to

\footnotetext{
${ }^{1}$ Harding, "Rethinking Standpoint Epistemologies," 69.
} 
determine what is legitimate, for unlike other theories in defense of rationality, the terms, subject matter, and conditions of the debate are not to be determined in advance, but left solely up to the argument of the participants.

Fraser and Nicholson have written that the most important advantage of a postmodern feminism would be its usefulness for the political practices of contemporary feminism..$^{2}$ For them, feminism has become a matter of "alliances rather than of unity around a universally shared interest or identity." Feminist politics needs to recognize the diversity of women's experiences and reflect the notion that no single solution will solve all of the challenges facing women. Politics must reflect that while there are commonalties, none are universal, and that commonalties are strewn throughout with differences, even conflict. The solidarity of women needs to be accounted for in a manner "broader, richer, more complex, and multilayered." Iris Young, inspired by feminist postmodernism, argues for a "politics of difference" described as a "political vision of inexhaustible heterogeneity." This politics realizes the oppressiveness of assumptions about the unity of women, and respects the importance of acknowledging the specific differences between women. Alcoff and Potter write that the terms and project of feminism today must address virtually all forms of domination found in social contexts, not simply gender-based domination. This is because women exist in all of the classes and ranks and categories of human beings. ${ }^{3}$

Habermas's hope with a discourse ethics is to allow the greatest diversity and participation possible in his ethics. At least one description of the politics necessary for a communicative politics labeled it a "radical democracy." 4 It follows from

\footnotetext{
${ }^{2}$ Fraser and Nicholson, "Social Criticism Without Philosophy," 34-35.

${ }^{3}$ Alcoff and Potter, Feminist Epistemologies, 4.

${ }^{4}$ Rasmussen, Reading Habermas, note 10.
} 
Habermas's theory that the principles of radical democracy are built into the very structure of language. This stems from the nature of rationality that is built into language, and the notion that rationality, once it is apparent, seeks its full range of action and is thus laden with an emancipatory potential.

For Thomas McCarthy, Habermasian politics would be characterized by "unrestricted deliberation in the democratic public sphere." 5 For in communicative action the basis of political sovereignty arises from the popular use of reason in a variety of public arenas, voluntary associations, social movements, or the mass media. This use of reason by the public is transferred into administrative power by legal institutions. Habermas works deliberately to decenter political power into multiple and differing arenas for "detecting, defining, and discussing society's problems and the culturally and politically mobilized publics who use them, serve as the basis for democratic selfgovernment and thus for political autonomy." 6 Further, because the public use of reason is reflexive, as the use of reason demands to be fully realized, these public debates are necessarily open and reflexive. This is why Habermas has limited his explanation of the process to the procedure that is to be followed in public discourse, and leaves all of the substantive questions and answers of social life to be determined by the debating public.

In conclusion, Habermas's communicative action provides an acceptable unifying epistemology for the needs of a feminist political and social theory working to emancipate human lives from social oppression. This stems from communicative action's ability to account for the complex notions of autonomy and solidarity in a way that draws upon the strengths of both, without becoming tied to the powerful claims of

\footnotetext{
${ }^{5}$ McCarthy, "Kantian Constructivism and Reconstructivism," 63.

${ }^{6}$ Ibid., 49.
} 
either. While this simplification of the issues seems to detract from the complexity of the problem, Habermas himself has narrowed the question to a single statement, most clearly characterized by his long study of a phrase by William James, a maxim that in Habermas's words, "asserts the reciprocal dependence of socialization and individualization, the interrelation between personal autonomy and social solidarity, that is part of the implicit knowledge of all communicatively acting subjects":?

The community stagnates without the impulse of the individual, the impulse dies away without the sympathy of the community. ${ }^{8}$

${ }^{7}$ Habermas, Justification and Application, 114.

${ }^{8}$ William James, quoted by Habermas, Justification and Application, 113. 


\section{SELECTED BIBLIOGRAPHY}

Alcoff, Linda and Elizabeth Potter, eds. Feminist Epistemologies. New York: Routledge, 1993.

Barwell, Ismay. "Towards a Defense of Objectivity." In Knowing the Difference: Feminist Perspectives in Epistemology, eds. Kathleen Lennon and Margret Whitford, 79-94. New York: Routledge, 1994.

Benhabib, Seyla. Situating the Self: Gender. Community and Postmodernism in Contemporary Ethics. New York: Routledge, 1992.

Berstein, Richard. The Restructuring of Social and Political Theory. Philadelphia: University of Pennsylvania Press, 1976.

Bordo, Susan. "Feminism, Postmodernism, and Gender-Skepticism." In Feminism/Postmodernism, ed. Linda J. Nicholson, 133-156. New York: Routledge, 1990.

Braaten, Jane. Habermas's Critical Theory of Society. Albany: State University of New York Press, 1991.

Chodorow, Nancy. The Reproduction of Mothering. Berkeley: University of California Press, 1978.

Code, Lorraine. "Taking Subjectivity into Account." In Feminist Epistemologies, eds. Linda Alcoff and Elizabeth Potter, 15-48. New York: Routledge, 1993.

Di Stefano, Christine. "Dilemmas of Difference: Feminism, Modernity, and Postmodernism." In Feminism/Postmodernism, ed. Linda Nicholson, 63-82. New York: Routledge, 1990.

Flax, Jane. "Postmodernism and Gender Relations in Feminist Theory." In Feminism/Postmodernism, ed. Linda Nicholson, 39-62. New York: Routledge, 1990.

Flemming, Marie. "Women's Place in Communicative Reason." In Women and Reason, eds. Elizabeth Harvey and Kathleen Okruhulik, 245-262. Ann Arbor: University of Michigan Press, 1992. 
Fraser, Nancy. "Struggle over Needs: Outlines of a Socialist-Feminist Critical Theory of Late Capitalist Political Culture." Chap. in Unruly Practices: Power. Discourse and Gender in Contemporary Social Theory, 161-185. Minneapolis: University of Minnesota Press, 1989.

. "What's Critical about Critical Theory? The Case of Habermas and

Gender." Chap. in Unruly Practices: Power. Discourse, and Gender in

Contemporary Social Theory, 113-143. Minneapolis: University of Minnesota Press, 1989.

Fraser, Nancy and Linda Nicholson. "Social Criticism Without Philosophy: An Encounter Between Feminism and Postmodernism." In Feminism/Postmodernism, ed. Linda J. Nicholson, 19-38. New York: Routledge, 1990.

Friedman, Marilyn. "Feminism and Modern Friendship: Dislocating the Community." In Feminism and Political Theory, ed. Cass R. Sunstein, 143-158. Chicago: University of Chicago Press, 1990.

Fricker, Miranda. "Knowledge as Construct: Theorizing the Role of Gender in Knowledge." In Knowing the Difference: Feminist Perspectives in Epistemology, eds. Kathleen Lennon and Margret Whitford, 95-109. New York: Routledge, 1994.

Gilligan, Carol. In a Different Voice: Psychological Theory and Women's Development. Cambridge: Harvard University Press, 1982.

Habermas, Jürgen. Justification and Application: Remarks on Discourse Ethics. Translated by Ciaran P. Cronin. Cambridge, MA: The MIT Press, 1993. Original German edition published by Suhrkamp Verlag, 1990 and 1991.

Knowledge and Human Interest. Translated by Jeremy J. Shapiro. Boston: Beacon Press, 1971. Original German edition published by Suhrkamp Verlag, 1968.

Moral Consciousness and Communicative Action. Translated by Christian Lenhart and Shierry Weber Nicholson. Cambridge, MA: The MIT Press, 1990. Original German edition published by Suhrkamp Verlag, 1983.

- Postmetaphysical Thinking: Philosophical Essays. Translated by William Mark Hohengarten. Cambridge, MA: The MIT Press, 1992. Original German edition published by Suhrkamp Verlag, 1988.

. The Theory of Communicative Action, volume 1, Reason and the Rationalization of Society. Translated by Thomas McCarthy. Boston: Beacon Press, 1984. Original German edition published by Suhrkamp Verlag, 1981. 
The Theory of Communicative Action, volume 2. Lifeworld and System: A Critique of Functionalist Reason. Translated by Thomas McCarthy. Boston: Beacon Press, 1987. Original German edition published by Suhrkamp Verlag, 1981.

Haraway, Donna. "A Manifesto for Cyborgs: Science, Technology, and Socialist Feminism in the 1980s." In Feminism/Postmodernism, ed. Linda Nicholson, 190234. New York: Routledge, 1990.

Harding, Sandra. "Feminism, Science, and the Anti-Enlightenment Critiques." In Feminism/Postmodernism, ed. Linda Nicholson, 87-88. New York: Routledge, 1990.

. "The Instability of the Analytical Categories of Feminist Theory." In Feminist Theory in Practice and Process, eds. Micheline R. Malson, Jean F. O'Barr, Sarah Westphal-Whil, and Mary Wyer, 15-34. Chicago: University of Chicago Press, 1986.

. "Rethinking Standpoint Epistemology: What Is 'Strong Objectivity."' In Feminist Epistemologies, eds. Linda Alcoff and Elizabeth Potter. New York: Routledge, 1993, 49-82.

Whose Science? Whose Knowledge? Thinking From Women's

Lives. Ithica: Cornell University Press, 1991.

Hartsock, Nancy. "Foucault on Power: A Theory for Women?" In Feminism/Postmodernism, ed. Linda Nicholson, 168-172. New York: Routledge, 1990.

. Money, Sex, and Power: Toward a Feminist Historical Materialism. New York: Longman, 1986.

. "Rethinking Modernism: Minority vs. Majority Theories." Cultural Critique 7 (Fall 1987): 187-206.

Hawkesworth, Mary. "Knowers, Knowing, Known: Feminist Theory and Claims of Truth." In Feminist Theory in Practice and Process, eds. Micheline R. Malson, Jean F. O'Barr, Sarah Westphal-Whil, and Mary Wyer, 327-351. Chicago: University of Chicago Press, 1986.

Jaggar, Allison. Feminist Politics and Human Nature. Sussex: Rowman and Allanheld, 1983.

. "Love and Knowledge: Emotion in Feminist Epistemology." In Women and Reason, eds. Elizabeth D. Harvey and Kathleen Okruhlik, 115-142. Ann Arbor: University of Michigan Press, 1992. 
Jay, Nancy. "Gender and Dichotomy." Feminist Studies 7 (1981): 38-56.

Kantor, Rosabeth Moss. "Women and the Structure of Organizations: Explorations in Theory and Behavior." In Another Voice: Feminist Perspectives on Social Life and Social Science, eds. Marcia Millman and Rosabeth Moss Kantor, 34-74. Garden City: Anchor Books, 1975.

Kuhn, Thomas S. The Structure of Scientific Revolutions. Chicago: University of Chicago Press, 1970.

Lazreg, Marina. "Women's Experience and Feminist Epistemology." In Knowing the Difference: Feminist Perspectives in Epistemology, 45-62. New York: Routledge, 1994.

Lennon, Kathleen and Margret Whitford, eds. Knowing the Difference: Feminist Perspectives in Epistemology. New York: Routledge, 1994.

Lloyd, Genevieve. The Man of Reason: 'Male' and "Female' in Western Philosophy. London: Methuen, 1984.

Lofland, Lyn H. "The "Thereness" of Women: A Selective Review of Urban Sociology." In Another Voice: Feminist Perspectives on Social Life and Social Science, eds. Marcia Millman and Rosabeth Moss Kantor, 144-170. Garden City: Anchor Books, 1975.

Longino, Helen. Science as Social Knowledge: Values and Objectivity in Scientific Inquiry. Princeton: Princeton University Press, 1990.

. "Subjects, Power, and Knowledge: Description and Prescription in Feminist Philosophies of Science." In Feminist Epistemologies, eds. Linda Alcoff and Elizabeth Potter, 101-120. New York: Routledge, 1993.

Lovibond, Sabina. "The End of Morality?" In Knowing the Difference: Feminist Perspectives in Epistemology, eds. Kathleen Lennon and Margret Whitford, 63-78. New York: Routledge, 1994.

Malson, Micheline R., Jean F. O'Barr, Sarah Westphal-Whil, and Mary Wyer, eds. Feminist Theory in Practice and Process. Chicago: University of Chicago Press, 1986.

Mangena, Oshadi. "Against Fragmentation: the Need for Holism." In Knowing the Difference: Feminist Perspectives in Epistemology, eds. Kathleen Lennon and Margret Whitford, 275-282. New York: Routledge, 1994. 
Messing, Karen. "The Scientific Mystique: Can a White Lab Coat Guarantee Purity in the Search for Knowledge about the Nature of Women?" In Women's Nature: Rationalizations of Inequality, eds. Marian Lowe and Ruth Hubbard, 75-85. New York: Pergamon Press, 1983.

McCarthy, Thomas , "Kantian Constructivism and Reconstructivism: Rawls and Habermas in Dialogue." Ethics 105 (October 1994): 47.

Millman, Marcia and Rosabeth Moss Kantor. Another Voice: Feminist Perspectives on Social Life and Social Science. Garden City: Anchor Books, 1975.

Nelson, Lynn Hankinson. "Epistemological Communities." In Feminist Epistemologies, eds. Linda Alcoff and Elizabeth Potter, 121-160. New York: Routledge, 1993.

Nicholson, Linda, ed. Feminism/Postmodernism. New York: Routledge, 1990.

Potter, Elizabeth. "Gender and Epistemic Negotiation." In Feminist Epistemologies, eds. Linda Alcoff and Elizabeth Potter, 161-186. New York: Routledge, 1993.

Rasmussen, David. Reading Habermas. Cambridge: Basil Blackwell, 1990.

Tanesini, Alessandra. "Whose Language?" In Knowing the Difference: Feminist Perspectives in Epistemology, eds. Kathleen Lennon and Margret Whitford, 203216. New York: Routledge, 1994.

Tuchman, Gaye. "Women and the Creation of Culture." In Another Voice: Feminist Perspectives on Social Life and Social Science, eds. Marcia Millman and Rosabeth Moss Kantor, 171-202. Garden City: Anchor Books, 1975.

Young, Iris Marion. "Impartiality and the Civic Public: Some Implications of Feminist Critiques of Moral and Political Theory." In Feminism as a Critique, eds. Seyla Benhabib and Drucilla Cornell, 57-76. Minneapolis: University of Minnesota Press, 1987. 